\title{
A leap of faith: *Scale, critical realism and *emergence in the geography of religion
}

\author{
Michael P. Ferber \\ West Virginia University
}

Follow this and additional works at: https://researchrepository.wvu.edu/etd

\section{Recommended Citation}

Ferber, Michael P., "A leap of faith: *Scale, critical realism and *emergence in the geography of religion" (2010). Graduate Theses, Dissertations, and Problem Reports. 3246.

https://researchrepository.wvu.edu/etd/3246

This Dissertation is protected by copyright and/or related rights. It has been brought to you by the The Research Repository @ WVU with permission from the rights-holder(s). You are free to use this Dissertation in any way that is permitted by the copyright and related rights legislation that applies to your use. For other uses you must obtain permission from the rights-holder(s) directly, unless additional rights are indicated by a Creative Commons license in the record and/ or on the work itself. This Dissertation has been accepted for inclusion in WVU Graduate Theses, Dissertations, and Problem Reports collection by an authorized administrator of The Research Repository @ WVU.

For more information, please contact researchrepository@mail.wvu.edu. 
A Leap of Faith:

Scale, Critical Realism and Emergence in the Geography of Religion.

Michael P. Ferber

Dissertation submitted to the College of Arts and Sciences

at West Virginia University

in partial fulfillment of the requirements

for the degree of

Doctor of Philosophy

in

Geography

Trevor Harris, Ph.D., Chair

Gregory Elmes, Ph.D.

Ken Martis, Ph.D.

Carolyn Prorok, Ph.D.

Timothy Warner, Ph.D.

Department of Geography

Morgantown, West Virginia

2010

Keywords: Scale, Critical Realism, Geography of Religion, Emergence, West Virginia Copyright 2010 Michael P. Ferber 


\begin{abstract}
A Leap of Faith:

Scale, Critical Realism and Emergence in the Geography of Religion.
\end{abstract}

Michael P. Ferber

This dissertation explores the role of scale in human geography through a study involving a critical realist investigation of the geography of religious adherence. Using the contributions of a critical realist framework of stratification, emergence, and pluralistic methodologies, religious adherence is studied at the scales of the individual adherent, the church, and within local associations of churches. Analysis was performed through a study of two denominational congregations and an independent congregation in Harrison County, West Virginia and used a combination of surveys and in-depth interviews with religious adherents, pastors and local denominational leaders. The conceptual framework of this dissertation stands in contrast to traditional studies of the geography of religious adherence which rely on the quantification of denominationally collected attendance statistics aggregated to the scale of county boundaries and displayed as choropleth maps. Importantly, the traditional approach lacks the capacity to jump scale and is only valuable for making general assumptions at regional or national scales. Furthermore, these studies are embedded with the scaled problems associated with ecological fallacy and the Modifiable Areal Unit Problem.

This study demonstrates that the geography of religious adherence in Harrison County is emergent and irreducible. Emergent congregational and denominational powers and properties are facilitated through scaled structures and hierarchies, with mechanisms rooted in, but not reducible to, the scale of the adherent. Because questions pertaining to adherents, churches and church hierarchies are unique to the powers and mechanisms functioning at each stratum, methodological pluralism is required to understand a robust geography of religion. In contrast to traditional GOR studies, a critical realist approach has the capacity to reveal the scaled linkages and complex processes that operate between adherents, congregations and denominations. By incorporating ecclesiastical emergence into GOR, religionists gain a valuable tool to examine the substantial ways in which religion impacts social, economic and environmental life. This study also makes contributions to the broader debate about scale in human geography by suggesting that a framework of emergence provides a valuable contribution and addition to acknowledging and understanding the complex dimensions of scale. 


\section{Dedication}

To my wife Christina, who has been a constant source of encouragement and strength.

Thank you for your patience and sacrifice. 


\section{Acknowledgments}

I am in debt to many people after two years of course work, a year of comprehensive exam preparation and six years of work on this dissertation. First, I would like to wholeheartedly thank my committee. Dr. Trevor Harris, my chair, first instructed me as an undergraduate in a human geography course in 1992. I came back to WVU specifically to study under his tutelage as a PhD student, a decision which has proved to be fruitful academically and relationally. Dr. Briane Turley was very supportive in the early years of my $\mathrm{PhD}$ work and I greatly appreciate his wisdom, insight and encouraging nature. I wish him the best in his new role as an Anglican Priest. Dr. Carolyn Prorok has served as an extraordinary external committee member, and I have appreciated our many conversations regarding the geography of religion over the last few years. Dr. Ken Martis has also walked with me for over a decade - as an undergraduate in courses such as U.S. and Canadian Geography and now as a member of my committee. Dr. Greg Elmes has helped to shape this document in many ways through theoretical insights and questions. Finally, Dr. Tim Warner was a wonderful addition to the committee and has helped to polish this document into its final form. To each of you I am greatly indebted.

I owe many thanks to other colleagues and mentors at WVU who have helped make this journey more enjoyable. Dr. Robert Hanham introduced me to the philosophy of critical realism. Dr Ann Oberhauser refined my methodological skills and was an encouragement on many occasions. Randy Crowe was a valuable colleague throughout my $\mathrm{PhD}$ experience as both a supervisor in the computer lab and a constant source of technical assistance. Jesse Rouse, Sue Bergeron, Frank LaFone and Dan Bonnenberger have been faithful colleagues and friends through these nine years of coursework and labor. I also greatly appreciate those who came to my dissertation defense, especially Kevin Frick, Barb Maclennon, Eric Lewis, Christine Titus, Kevin Kuhn, and Jennifer Kopko.

Throughout the course of writing and research many scholars assisted by reading portions of this document and by providing helpful insights. Jim Proctor helped me refine my understanding of critical realism, which resulted in my 2007 article in the Annals of the Association of American Geographers. Roy Bhaskar and Margaret Archer both spent invaluable time with me at the 2007 Conference on Critical Realism in Philadelphia, PA. John Bauer provided a copy of his dissertation and helped me better grasp the literature in the geography of religious adherence. Sallie Marston also spent helpful time with me at the 2006 AAG and helped shape chapter two of this dissertation through the many references she provided.

I owe a tremendous debt of gratitude to the pastors and congregational leaders from churches in this study. I also thank my parents, Phil and Nancy Ferber, who have helped me in countless ways as I pursued this degree. Finally, and most of all, many thanks to my family - Christina, Leah and Brendan. They have endured a decade with a 
husband and father who has been preoccupied with $\mathrm{PhD}$ work while also working in full time professional capacities and teaching classes at night. I could not have finished this degree without their constant support, encouragement and sacrifice. 


\section{Table of Contents}

Chapter 1 Introduction: A leap of faith 1

$\begin{array}{lll}\text { Chapter } 2 & \text { The problem of scale } & 11\end{array}$

Chapter $3 \quad$ An 'emerging' solution 35

Chapter 4 Scale and emergent indicators in GOR 50

Chapter 5 Emergent indicators across scales: a case study in GOR 67

Chapter 6 Scaled religious adherence in Harrison County, West Virginia 79

$\begin{array}{lll}\text { Chapter } 7 & \text { An emergent geography of religion } & 105\end{array}$

$\begin{array}{lll}\text { Chapter } 8 \text { Conclusion } & 126\end{array}$

Bibliography 136

$\begin{array}{lll}\text { Appendix A Research Questions } & 145\end{array}$

$\begin{array}{lll}\text { Appendix B Human Subjects } & 151\end{array}$

Curriculum Vita 155 


\section{List of Tables}

3.1 Critical Realism Domains 39

5.1 Harrison County Adherents 68

\begin{tabular}{ll}
5.2 & Study Participants \\
\hline
\end{tabular}

6.1 Catholic Adherents View of Influences on Daily Life 80

6.2 Catholic Adherents Sense of Belonging 80

6.3 Catholic Adherents Reason for Attending 84

6.4 Catholic Adherents Frequency of Attendance 84

6.5 Methodist Adherents View of Influences on Daily Life 88

6.6 Methodist Adherents Sense of Belonging 88

6.7 Methodist Adherents Small Group Attendance 90

6.8 Methodist Adherents Small Group Frequency 90

6.9 Independent Adherents Reason for Attending 96

6.10 Independent Adherents View of Influences on Daily Life 97

6.11 Independent Adherents Small Group Attendance 98

$\begin{array}{lll}8.1 & \text { Three Types of Fidelity } & 129\end{array}$

$\begin{array}{lll}8.2 & \text { Fidelity to God } & 131\end{array}$

$\begin{array}{lll}8.3 & \text { Fidelity to Congregation } & 132\end{array}$

$\begin{array}{lll}8.4 & \text { Fidelity to Denomination } & 132\end{array}$ 


\section{List of Figures}

$2.1 \quad$ Scale Conceptualizations 12

2.2 Standing Rock Nation of Corson County, South Dakota 22

3.1 Downwards Conflation 39

3.2 Upwards Conflation 40

3.3 Central Conflation 40

3.4 Transformational Model of Social Activity 41

3.5 Morphogenetic Approach 41

3.6 Powers 45

$\begin{array}{lll}3.7 & \text { Tendencies } & 46\end{array}$

$\begin{array}{lll}5.1 & \text { Locations of Churches Studied } & 74\end{array}$

6.1 Residential Locations of Catholic Members 83

6.2 Residential Locations of Methodist Members 92

$\begin{array}{lll}6.3 & \text { Residential Locations of Independent Members } & 101\end{array}$

$\begin{array}{lll}7.1 & \text { The only existing map of churches in the Wesleyan } \\ \text { District of the West Virginia United Methodist Conference. } & 120\end{array}$

7.2 Office of the Wesleyan District of the West Virginia United Methodist Conference. 122 


\section{Chapter 1 Introduction: A leap of faith}

The goal of this study is to explore the issue of scale in the study of geography of religion (GOR). This quest has led to positioning scale within a critical realist framework of stratification and emergence in order to address the problems of scale and multiple scale-based studies. I first began questioning this issue in 2003 while writing a critique of atlases of religion in America with Trevor Harris (Ferber and Harris, 2003) and performing a literature review of GOR in general. It occurred to me that the literature focused on two recurring, yet disparate, scales of analysis: local studies centered on a single sacred space or individual agent, and adherent focused studies that aggregated individuals to county level units as a basis for studying national level trends.

The intricacies of scale in GOR are particularly complicated because of the variety of methodological approaches used. The localized approach in GOR is most commonly applied in studies rooted in humanism and, according to Henkel (2005), postmodernism. Much of the recent emphasis on human agency is rooted in Chidester and Linenthal (1995), who called for a re-appropriation of emphasis from the poetics to the politics of religion. Chidester and Linenthal argued that the politics of religious construction and contestation have always been a subtext behind poetic studies. Hence, in the last decade there has been a substantial increase in GOR studies concerning themes such as identity and contestation. Other scholars, such as Julian Holloway (2000), have adopted postmodern approaches, such as Actor-Network theory, which are entirely focused on the agents themselves.

Another group of researchers in GOR have pursued what has been described as ecclesiastical studies, utilizing available aggregated data (Park, 1994). The work of this 
research group is epitomized by the numerous religious atlases published in the last decade (Carroll, 2000; Gaustad and Barlow, 2001; Newman et. al, 2000) that seek to document and capture the complex ebb and flow of religious patterns in the United States over the course of centuries.

In these various strands of GOR it is clear that the methodology employed has been driven by the many approaches utilized to study religious phenomena. Of these, empiricist and positivist approaches are the traditional nuts and bolts of American GOR. Even in the last decade, empirical studies dominate the published works (Stoddard and Prorok, 2004). The major strength of this approach is demonstrated in works centered on religious demographics and diffusion. The comprehensive atlases published recently (Carroll, 2000; Gaustad and Barlow, 2001; Newman et. al, 2000) reflect this approach. Wilbur Zelinsky $(2001,757)$ in a review of Gaustad and Barlow's New Historical Atlas of Religion in America described the atlas as "A stupendous achievement, an occasion for unrestrained jubilation among all of us who nurture a serious interest in the geography or history of religion in this nation.” In addition, Sopher’s (1974) classic Historical Atlas of Religions of the World and Brown et al.’s (1994) Historical Atlas of Mormonism along with a number of journal articles (Andrews, 1990; Bascom, 1998; Land et al., 1991; Stump, 1998) accentuate the strong predilection for available county-based aggregations of religious adherence. In the midst of celebration, however, numerous weaknesses concerning gaps in data collection (Ferber and Harris, 2003), ecological fallacy (Martin, 1999), and the Modifiable Areal Unit Problem (MAUP) (Johnston, 1999; Martin, 1999; Raper, 1999) have been enumerated with this approach. 
While aggregated data has been extensively used for studying GOR at regional and national scales, other researchers have pursued studies at the scale of the local such as a particular sacred site, a small community, or an individual's outlook toward a sacred place (Casey, 1987; Chidester and Linenthal, 1995; Eliade, 1968; Gibson, 1966; Lane, 2001). Humanism and phenomenology represent popular approaches to exploring religious experiences on a scale usually commensurate with the individual or community. Marxist approaches in GOR accentuate the social and political conflicts that surround religious sites and boundaries, and so treat the individual / aggregate dichotomy in a very different manner altogether. Lane (2001) describes these three approaches as ontological, phenomenological, and cultural and he links these respectively to the tradition of Mircea Eliade (1968), with ecological thinkers such as James Gibson (1966) and Edward Casey (1987), and with Chidester and Linenthal (1995). These non-aggregated, experiential techniques reveal very different relations and processes than the findings obtained from aggregated religious data modeling and mapping as described previously. Not least recent post-structural geographers of religion have adopted hermeneutical approaches, culminating in the trend toward Actor-Network Theory, which explores the world as a multiplicity of different connected nodes in which the connections are more important than the nodes (Johnston et al., 2000). Julian Holloway (2000), for instance, uses Actor Network Theory to analyze the institutional geographies of the New Age movement in the United Kingdom.

For most geographers of religion, research using these positivistic, humanistic, or post-structural approaches is supported by philosophical and methodological assumptions, which quite logically lead to research at specific scales of analysis. Hence, 
the approach used in GOR has tended to drive both the method used and the scale of analysis.

Regardless of the issues involving method, scale is a challenging concept even for geographers. The Dictionary of Human Geography (Johnston et al., 2000) differentiates between cartographic and methodological conceptualizations of scale, and geographical scale, which refers to the dimensions of specific landscapes such as a watershed, regions, or the globe. Shephard and McMaster (2004) describe similar definitions of scale, but use the term operational instead of geographical to describe the logical scale at which a geographic process takes place. This division echoes recent debates over the ontological status of scale, particularly whether scale is a real entity that is present in the landscape (Herod and Wright, 2002) or whether scale is socially produced (Smith, 1990). As Sayer $(1992,67)$ states, "the world is not our own invention, even though the concept 'world' undoubtedly is,” and so, in a similar manner, geographical scale is socially produced whether or not the world would exist without humans to speculate about its scalar dimensions.

Ecological fallacy should also be seen as a potential and significant factor in the scaled approaches to studies in GOR. Ecological fallacy occurs when variables observed at one level of aggregation are applied to explanation at either a finer or broader scale (Martin, 1999), and when the characteristics of a population are attributed to individuals within that population or the characteristics of an individual are applied to an aggregated population (Johnston et al., 2000). Another major dilemma is the MAUP, a particular form of ecological fallacy (Johnston et al., 2000) that reflects the complexities involved with the numerous ways in which spatial data can be aggregated and the impact that the 
spatial unit can have on the outcomes of geographic studies (Martin, 1999). Ecological fallacy and the MAUP pose the interesting question as to which scale or boundary geography has ontological primacy over other scales and boundary formations (Raper, 1999). The dichotomy of scales of analysis in GOR is the result of the philosophical and methodological approaches geographers of religion use in their research. An important issue involved in ecological fallacy and in changing scales of analysis is reductionism; that the nature of complex phenomena can be reduced to simpler phenomena. Hence, to understand ecological fallacy and reductionism, one would need to understand less the mechanics of interscalar analysis and more the philosophical nature of reality itself.

In the light of the multiplicity of approaches and methods in GOR, it is appropriate and timely for geographers of religion to recognize and acknowledge the role and impact of scale in their studies. Outside of the GOR sub-discipline, scholars in geography in general are undertaking studies at multiple scales. Rita Colwell (2004, 706), in the centennial forum of the 2004 Association of American Geographers annual meeting stated, "Understanding of the whole demands observing at multiple scales, from the nano to the global. Complexity principles emerge at each level, from the cell, the organism, the community, the ecosystem.” Yi-Fu Tuan $(2004,729)$ reiterated this theme at the same conference by celebrating that "Cultural geography in the last thirty years or so has penetrated interior space and learned to cope with personal relationships.” Again in the same week, David Skole $(2004,740)$ summed up the challenge in environmental geography as being "to explore what it means to scale down from the global to the ground level in order to comprehend the social drivers that change the environment and the ecological processes that arise in process.” 
It is proposed in this dissertation that because critical realism (CR) implicitly acknowledges alternative assumptions about reductionism, levels of reality, and methodology, a critical realist approach could help illuminate the scalar divisions in GOR. A guiding principle in CR is that "the nature of the object of study determines what research methods are suitable and also what kind of knowledge it is at all possible to have of different phenomena in the world” (Danermark et al., 1997). This “critical methodological pluralism” opens the door wide for numerous potential quantitative and qualitative methods to be utilized, to ensure that issues of positionality in scale will not be lost. Therefore, reflecting on these complexities through a critical realist lens could be very helpful.

Critical Realism was established through the writings of Roy Bhaskar (1975, 1979), who drew on the ideas of his teacher Rom Harre (1972, 1979). Other significant critical realist authors include Margaret Archer (1988, 1995), Andrew Collier (1994), Danermark, Ekstrom, Jakobsen, and Karlsson (Danermark et al., 1997) and Andrew Sayer (1992, 2000). A critical realist view of reality suggests that the world is stratified hierarchically (Bhaskar, 1979) with "physical mechanisms in one stratum, chemical mechanisms in another, biological in a third, and 'at the top' are the psychological and social strata” (Danermark et al., 1997, 60). Despite this hierarchy, critical realists are strongly opposed to any form of disciplinary imperialism in which any one view of the world might take precedence over any other view. As one conceptually moves up these strata each subsequent stratum is "formed by powers and mechanisms of the underlying strata” (Danermark et al., 1997, 60). The various objects in these strata have "emergent powers, that is powers or liabilities which cannot be reduced to those of their 
constituents” (Sayer, 1992, 119). Emergence occurs “when the properties of underlying strata have been combined,” and “qualitatively new objects have come into existence, each with its own specific structures, forces, powers and mechanisms” (Danermark et al., 1997, 60). Stratification of reality in CR means that we can conceptually move downwards through strata to isolate causal mechanisms. Additionally, "new nonreducible properties and mechanisms... are added at each specific stratum” (Danermark et al., 1997, 61). For example, in terms of Christian religious adherence in the United States, specific powers and mechanisms operate at the scale of the individual adherent, the church, and formal networks of churches such as associations, parishes or denominations.

In addition to providing a potentially valuable epistemic approach for discussing scalar issues in GOR, CR also allows for a plethora of methodological tools to be brought to bear. Critical realists "reject cookbook prescriptions of method, which allow one to imagine they can do research by simply applying them without having a scholarly knowledge of the object of study in question” (Sayer, 2000). Hence, critical methodological pluralism enables numerous methods to be utilized at varying scales of analysis.

An analysis of stratification and emergence in GOR could provide a helpful lens to better understand the broader debate about scale within geography and from which geographers of religion have borrowed so heavily. By exploring the implications of changing scales of analysis in the study of GOR through stratification and emergence, this study seeks to contribute to these important debates within both GOR and broader spatial disciplines. 


\section{Research Goal, Objectives and Questions}

The overarching goal of this study is to explore the issue of scale in the study of GOR and the implications of a scaled geography of religion. This will be accomplished through five objectives and related sub questions:

1) Review the major trends and issues regarding scale in general and specifically in GOR.

a. What is scale?

b. What are the primary scales of analysis in GOR literature?

c. What are the major debates regarding scale in human geography?

2) Conceptually examine $\mathrm{CR}$ as a means of exploring scalar issues in human geography.

a. What is CR and how does it differ from other approaches?

b. How does CR address issues of scale?

c. What advantages or disadvantages does a CR approach offer?

3) Undertake a case study in West Virginia investigating Christian religious adherence at multiple scales.

a. What are the scalar relations and processes at the scale of the individual believer?

b. What are the scalar relations and processes at the scale of the church?

c. What are the scalar relations and processes at the scale of an individual county? 
d. What are the scalar relations and processes at the scale of the region and nation?

4) Investigate the complexities of scales of analysis in GOR

a. What mechanisms and processes operate at different scales of analysis in the case study?

b. What methodologies are appropriate or inappropriate to be used at different scales of analysis?

5) Evaluate the problem of scale in GOR and explore how this study contributes to the scale debate in human geography.

a. What are the implications of multiple scales of analysis and of changing scales in GOR?

b. How does this study contribute to debates on scale in human geography?

Following this introductory chapter, chapter two of this study consists of a literature review exploring how scales of analysis in GOR can be informed by debates regarding scale in other sub-disciplines of geography. Chapter three continues the literature review by exploring critical realist ontology and methodology, including stratification, emergence and the structure agency debate. Chapter four explores the problem of scale in the geography of religious adherence. Chapter five delves deeper into these issues by introducing a case study in GOR involving multiple scales of analysis. Chapter six reflects on this case study by exploring how the mechanisms and processes operating at different scales of analysis in different congregational and denominational settings focus upon different scales. Chapter seven comprises a 
discussion of an emergent GOR that weaves together the major themes of this research. Chapter eight is a conclusion with suggestions for future research.

\section{Methods and Tasks:}

In this dissertation, religious adherence is explored using pluralistic methodologies employed at various scales of analysis. Religious adherence is a fundamental component of GOR in the United States and has been variously studied using differing approaches, scales, and methodologies (Bauer, 2006). This study investigates GOR at the scale of the individual adherent, the church, and local associations of churches, in order to better understand the scaled nature of the geography of religious adherence. The analysis is performed through a combination of in-depth interviews with religious adherents, pastors and local denominational leaders. Two different denominational congregations and an independent congregation are used in the case study because the structures of the network of churches are fundamentally different. The Roman Catholic and United Methodist denominations are organized through a structured hierarchy that links adherents to national and international bodies. A third independent congregation studied in this dissertation represents the largest of all congregations in Harrison County, West Virginia. Significantly for the goal of this study, this church has not been included in any of the GOR national atlases due to its independent status, nor has any data about attendance been included in the national archives such as the American Religious Data Archive. 


\section{Chapter 2 The Problem of Scale}

\section{Conceptualizing Scale}

Scale is without question an important phenomenon throughout the field of geography and yet scale remains an elusive social construction fostering debate in nearly every sub-discipline of physical and human geography. It is a particularly central point of contention in debates throughout economic geography, political geography, ecology, GIS, and remote sensing (Brenner, 2001; Marston, 2000; Sayre, 2005) and generates intense debate on methodological and epistemological issues (Brenner, 2001).

Researchers in geography have defined scale in multiple ways that include cartographic, methodological, and geographical scale (Johnston et al., 2000; Shepherd and McMaster, 2002; Lam and Quattrochi, 1992). In addition to definitions, geographers utilize different scalar metaphors to frame the discussion of switching from one scale to another. The use of such a 'large metaphor' (Johnston et al., 2000) to structure the paradigm of scale carries with it significant baggage. Herod and Wright (2002) describe four different scale metaphors: the ladder, the circle, the Matryoshka doll, and the network. In the ladder metaphor representing a range of scales, the local is at the bottom and the global at the top. In the circle metaphor, the global is around, rather than above or below, the regional and the local. In the Matryoshka doll metaphor, each scale is within or without the others, but still not above or beneath. Finally, in the network metaphor, specific places are simultaneously local and global with scale looking more like tunnels made by earthworms as Euclidean space is “undermined”. 
Figure 2.1 Scale Conceptualizations

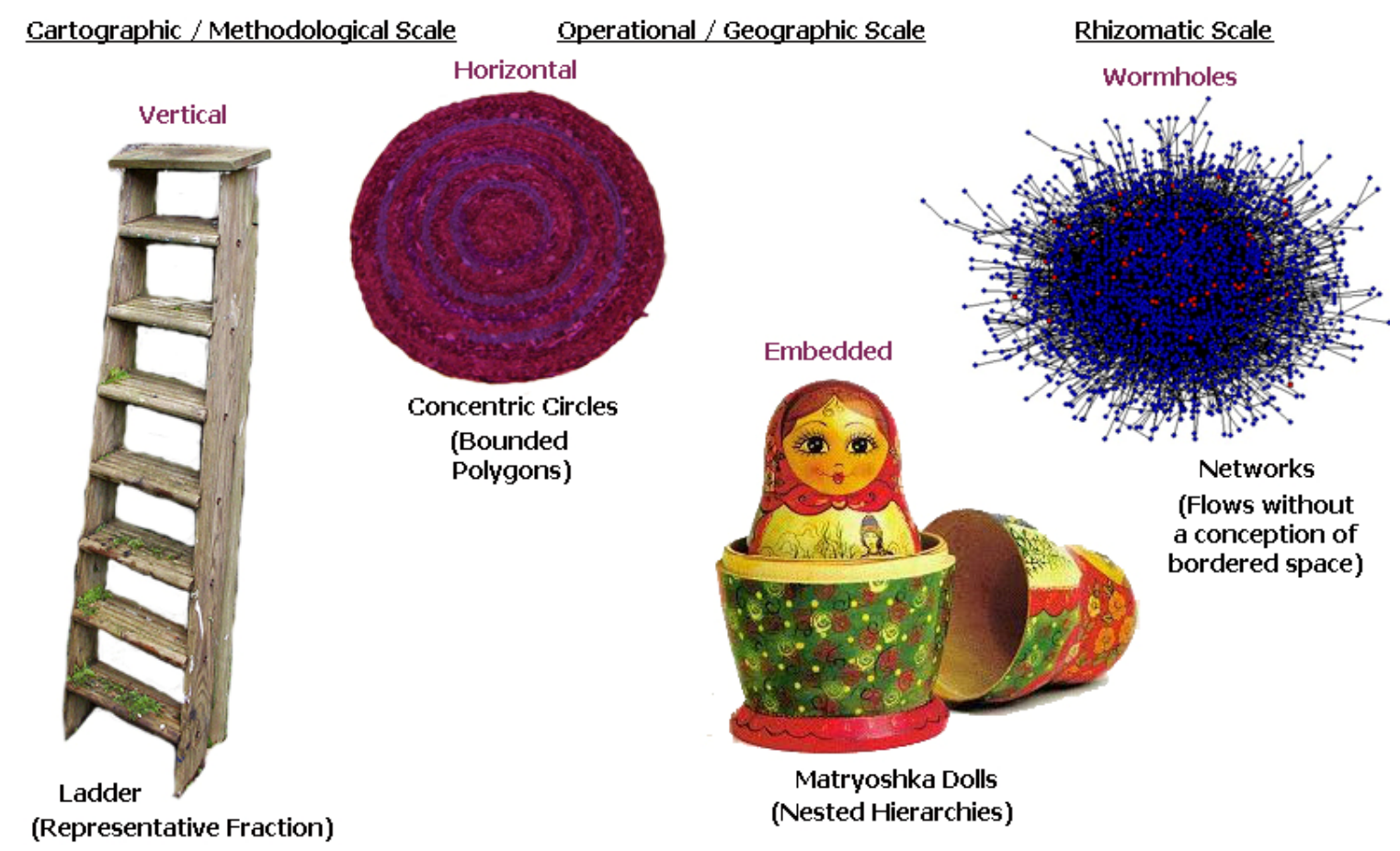

\section{Scalar Debates}

A classic problem associated with jumping scale concerns ecological fallacy. In 1950 Robinson first identified the issue of ecological fallacy when he was able to demonstrate that the association between the percentage of black population and the percentage of illiterate populations were not transferable to differing scales of analysis. Alker (1969) expanded upon Robinson’s basic analysis and included a number of different forms that ecological fallacy could take. These include:

Individualistic fallacy, which assumes that the whole is no more than the sum of its parts.

Cross level fallacy assumes that a relationship observed in one aggregation of a population applies to all others.

Universal fallacy assumes that the pattern observed in a selection of individuals holds the same for its population.

Selective fallacy in which data from carefully selected chosen cases are used to prove a point. 
Cross-sectional fallacy is the assumption that what is observed at one point in time applies to other times. (Johnston, 2001, 191)

A widely recognized variant of the ecological fallacy is the MAUP. Haggett (1965)

pioneered discussions regarding the MAUP when he suggested that different statistical results could be obtained by changing the boundaries of the areal units to which data was aggregated. Openshaw expanded Haggett's analysis in significant ways by identifying three types of problems regarding MAUP (Openshaw, 1983, 8):

1) a scale problem in which there are questions about the number of zonal units needed for a study and the significant variation in results that can arise as data are progressively aggregated into fewer and spatially larger units of analysis.

2) an aggregation problem that raises questions about how data are to be aggregated and the variation in results that may arise due to the use of possible alternative aggregation schemes at equal or similar scales.

3 ) the impact of ecological fallacy in instances where spatially aggregated data are used to infer similar characteristics of the aggregated unit on those individuals who populated the aggregated zones.

When these various problems are combined, Openshaw suggested that considerable problems occur when seeking to infer individual relationships from an aggregated study.

According to Harris (2006), issues of ecological fallacy and scale underpin both the observed patterns and our interpretations of hidden processes of geography. Central to the idea of jumping scale is a concern for the processes occurring at the various scales under study. Harris rhetorically asks questions of ecological fallacy in botanical terms that could easily be translated into GOR. "Can the operation of a forest ecosystem be determined if the problem were studied at the scale of a leaf? Equally, can one understand the physiology of a leaf if the problem were examined at the scale of the forest?” (Harris, 2006, 47). Thus, issues of ecological fallacy go far beyond a simple statistical concern about aggregated and non-aggregated data. Ecological fallacy strikes 
at the very heart of the inferences that are drawn from studies of processes and the patterns that vary across scales of analysis.

Ecological fallacy and the MAUP are significant concerns in the scale debate yet other scalar issues have also recently come to the forefront. Over the course of the last twenty years, geographers have debated what has come to be described as the scale question (Sayre, 2005). Neil Smith began this debate about scale theory through his writings in the 1980s and 1990s that were largely based on the concepts of Lefebvre (1974) and the production of space. More recently, a series of articles in Progress in Human Geography, about what is now known as the Marston / Brenner debate (Purcell, 2003), have illuminated the complexity and multifaceted nature of the scale problem. Marston’s initial paper (2000) assembled a decade worth of work in an effort to understand how scale is socially produced. Marston moves from a discussion of Howitt's (1998) metaphorical use of musical scale, to Agnew’s (1997) work on political parties in Italy, Herod's (1998) investigation of the International Metalworkers’ Federation, Adams’ (1996) three examples of oppositional movements, Brown’s (1995) investigation of AIDS politics, Leitner's (1997) examination of tension among nationstates in the European Union, Miller’s $(1994,1997)$ investigations of state defense investments, and Brenner’s (1997) extended analysis on the social production of scale. Following this review is a detailed analysis of those theorists who have contributed to the dialogue, including Brenner (1997b), Smith (1990, 1992, 1997), Cox (1995, 1996, 1998), and Taylor (1982,1984,1987). Marston (2000, 233) concludes that, “contemporary writing about scale in human geography has failed to comprehend the real complexity behind the social construction of scale and therefore only tells part of a much more 
complex story.” She then includes examples taken from her own work focused on the scale of the household to address the limitations of theorizing about scale construction in order to motivate others to consider new research directions.

Brenner $(2001,592)$ agrees on many of Marston’s points, but critiques her for her “analytical blunting of the concept of geographical scale,” a problem common in the "noticeable slippage in the literature between notions of geographical scale and other core geographical concepts, such as place, locality, territory and space,” that caused scale to collapse into “an over generalized chaotic conception” (2001,593). Brenner’s primary problem with Marston's approach involves the use of the household as a geographical scale. Brenner argues that the household operates in Marston’s analysis as “a sociospatial arena, territory, locale, or place rather than as a geographical scale in the technical sense of the term” (2001, 598). Hence, geographical scale becomes blunted and used to describe nearly any shift within social practices or processes.

In the same issue of Progress in Human Geography, Marston recruits the aid of Neil Smith and together, while agreeing that there has been an 'analytical blunting of this sharply defined concept” (Marston and Smith, 2001, 615), they refute Brenner on two fronts. First, they disagree with the idiosyncratic genealogy of scale theories that Brenner asserted, arguing that his premise was based on the same slippage between scale and space that he rejected, since his "reading depends on the insinuation of many statements about space as statements about scale” (616). Second, Marston and Smith question why the scale of the household is dismissed as a singular rather than plural construction, and express disappointment about the perceived patronizing dismissal of gender and social reproduction at the scale of the household. They subsequently posit a potentially more 
volatile question themselves: “One can imagine the response if the original article had dismissed states as 'relatively stable background structures” (618).

In a subsequent Progress in Human Geography article Mark Purcell (2003, 319) described these interactions as a “disconnected nondebate,” claiming that while both Marston and Brenner are essentially correct in their main arguments and in their critique of the other's limitations, they were unable to hear each other's critique. Purcell used the debate to assert that throughout human geography, islands of practice have caused scholars to remain embedded in particular research and writing routines that limit engagement beyond immediate interests. Purcell argues that Brenner was not suggesting that a household cannot be a scale, but that specifically Marston's paper offers a singular analysis of the household, and not an analysis of the household's scalar nature. At the same time Brenner essentially ignored Marston’s original suggestion to methodologically expand scale research. Purcell argues that Marston’s island of practice focuses on the household to the exclusion of other scales. Meanwhile, Brenner’s approach is topical, focusing as it does on capitalist production and the state. Hence, Purcell calls for a methodological agenda on the part of all critical human geographers that would broaden the scope of their analysis to create a more synthetic critical geography. The importance of process in the ecological fallacy debate is now well recognized (Harris, 2006; Purcell, 2003).

In 2005 Nathan Sayre also raised the issue of process by focusing on scalar issues that had arisen within ecology and especially when he considered that scale was the “fundamental conceptual problem in ecology, if not in all of science (277).” After a brief description of the Marston-Brenner debate, Sayre suggested that Purcell's argument did 
little to bring resolution to the debate. Sayre goes on to detail issues in both temporal and spatial scale in human ecology and discussed the differences that exist between closed systems, which do not exist in reality, and natural systems that are determined by multiple processes operating simultaneously at numerous spatial scales. Of primary importance to his argument is that different processes are discerned at different scales, and that the ability to understand these processes thereby changes with scale of study. Unfortunately, all too frequently researchers are rarely cognizant of this important relationship.

Ecologist T.F. Allen also addressed this issue of process in 1998 in his chapter in Ecological scale: Theory and applications entitled, “The landscape 'level’ is dead: persuading the family to take it off the respirator.” By way of example Allen uses a powerful metaphor by comparing the properties of an elephant with those of a pond skater, taking note that fundamental relationships exist between the size of organisms and the surface tension of water. Allen questions the appropriateness of observing levels of organization without taking into consideration the processes and relationships that are present. He jests, "It would have been very convenient for Hannibal if his elephants could have skated like insects across the Mediterranean to Rome. However, there was nothing he could do to achieve pond-skating pachyderms, even if he had conceived such an idea.” Even if Hannibal had genetically transformed a pond skater to the size of an elephant, the processes that enable the pond skater to remain afloat would have been altered by the insect's new weight. Jumping scale implies redefining the relationships and processes that are intrinsic to the phenomena under study. 
Sayre also discriminates between an ontological moment of scale, in which it appears as intrinsic to some external reality, and an epistemological moment of scale, in which one's choice of scale helps determine what is seen. The epistemological moment emphasizes how one observes something rather than what is observed. The ontological moment conceptualizes scale in terms of relations which are considered to be objective realities. In this sense, the elephant-sized pond skater sinks because of its altered relations to the surface tension of water.

According to Sayre (2005), ecologists define scale in the epistemological moment when scale is composed of two parts, grain and extent. Grain and extent closely parallel the use of the terms resolution and extent in geography. Grain is the finest level of resolution available with a given dataset, while extent is the size of the study area or the duration of the study. In the ontological moment, ecologists make a distinction between scale and level in that scale is used to refer to processes and relations, whereas levels is an abstract device imposed on data by the observer. Sayre (2005) concludes his discussion by taking the conceptualization of scale developed in ecology and applying it to the Marston-Brenner debate, arguing that had these distinctions been observed there might not have been any disagreement at all. Sayre also critiques the definition of scale cited at the beginning of this chapter from the Dictionary of Human Geography where scale is defined as a "level of representation" (Johnston et al., 2000, 724), arguing that throughout human geography level and scale are essentially used interchangeably. Sayre suggests that in Marston's original paper, the case study is about scale as it links processes across levels of social organization, but that the case study does not demonstrate why scale matters for the particular processes under examination. In Sayre's 
opinion, it would have been preferable to perform an analysis of processes associated with one level (the household) that would then elucidate processes at other levels such as at the municipal, state, or national government levels.

Possibly most helpful in linking the ecological and human geography literatures on scale is Sayre's (2005) analysis of Brenner's 'analytical blunting' between the singular and plural senses of scale. In this, Sayre argued again that the distinction was essentially similar to the ecological distinction between scale and level. Sayre reframed these ideas arguing that, "If one conflates scale and level, then any analysis of any level - household, community, region, etc... - can be deemed an analysis of (a) scale, without necessarily treating the processes that determine that level of social organization, and that mediate its relations to other levels” (Sayre, 2005, 285).

Other human geographers seem to be on the same track in regard to the importance of scale as process. Stemming from, but going beyond, the Marston-Brenner debate, Paasi (2004) also argued for a move from hierarchical scale to an understanding of scale as process. He asserted that too little attention had been paid to the relations of region, place and scale. In similar manner, Mansfield (2005) pushes for an understanding of scale as 'dimensions of practice', arguing that "spatial scales should not be taken for granted as ontologically given, discrete objects, but should be questioned and examined as relational processes” (Mansfield, 2005, 460) Hence, she suggests that the issue of scale should be thought of in relational terms of multiple scales simultaneously and she uses the concept of dimension to demonstrate how multiple scales are intertwined and work together as relational processes. In her study, the national is not a level, but a dimension of social practice. In this manner relationships and processes are key to 
understanding the complexity of changing scales of analysis. This reigns true for traditional debates such as ecological fallacy and the MAUP, as well as for more recent debates in ecology, political geography, and economic geography.

\section{Hierarchical Scale in GOR}

Geographers of religion would benefit significantly from this continuing dialogue on scale. However, it might be appropriate to first introduce them to the debate, since up to this point there has been little interaction, if any, regarding what scale is or means to religionists. This is not to suggest that all geographers of religion are ignorant about the conversations that have taken place in the other sub-fields of human geography. If this were the case, there would be no geography of religion case studies on, for instance, Actor Network Theory (Holloway, 2000). Rather, it appears as though geographers of religion have been content to allow these discussions to transpire in other communities and to then participate in the outcomes of these discussions.

While there is little debate on the meaning and implications of scale on GOR, there are nonetheless scaled studies within the GOR. The vast majority of these studies are based in what can be called a hierarchical scaled approach. Many of these GOR studies involve the use of aggregated adherents at scales beyond the individual; however a growing number of such studies are focused within the context of specific adherents or small groups of adherents. In Geography of Religion - Rediscovering a Sub-discipline, Henkel (2005) identifies two general directions in geography of religion during the past twenty years. These comprise empirical socio-religious research studies, and postmodern studies, which belong more to the tradition of humanistic geography. 
The classic visual rendering in American GOR is the choroplethic map of religious adherents aggregated to the county scale. Henkel (2005) describes other atlases by Knippenberg (1992) and Henkel (2001) that, in a similar manner, give a historicalspatial interpretation of the religious landscape of the Netherlands and Germany. As noted, while the epistemological and ontological aspects of scale have been continuously debated in political and economic geography, geographers of religion have been remiss to thoroughly investigate issues of cartographic representation and scale in the mapping of religion. Given the current emphasis on mapping in GOR, this is a critical omission. What criticism has arisen has been waged against empirical approaches such as those used in the three recently published atlases of religion in America (Carroll, 2000; Gaustad et al., 2001; Newman and Halvorson, 2000). In aggregating data to a county level, significant discoveries have been masked in each of these works. While the atlases are in the more classical traditions of Zelinsky, his own critique of these works (2001, 758) states, “Our authors have opted for the worst possible mode of presentation. Instead of relatively straightforward, unequivocal point symbols, such as dots or graduated circles, rectangles, cubes, or spheres, they elected to use four or five different tints of specified numerical value, each covering the entire surface of a given county,” making interpretation problematic. Possibly the most significant methodological shortcoming of these atlases is the inability to compare different denominations, and sometimes even a single denomination over time, due to disparate categorical definitions used in the static maps. This is particularly apparent in Newman and Halvorson (2000), who make no attempt to help the reader make comparisons between the various denominations and sects in the volume. The categorical choices also provide temporal challenges as scholars 
must deal not only with changing county boundaries over time, but also with nonstandard categorizations. This problem is still not corrected in Gaustad (2001), leaving Zelinsky so frustrated that when he tried to compare maps of the Episcopal church over time he stated, "Meaningful comparisons between the two figures are beyond the capabilities of mere mortals” (Zelinsky, 2001, 759).

Yet another criticism of these atlases that is indirectly related to the issues of scale involves the lack of normalization of the data. For instance, the most popular map in Gaustad (2001) is the denominational predominance map of 1990. The only county in the nation in which the Episcopal Church is the dominant denomination is identified as Corson County, South Dakota. When denomination is normalized by population, it is clear that the vast majority of adherents in this county are Episcopal.

Figure 2.2 Standing Rock Nation of Corson County, South Dakota

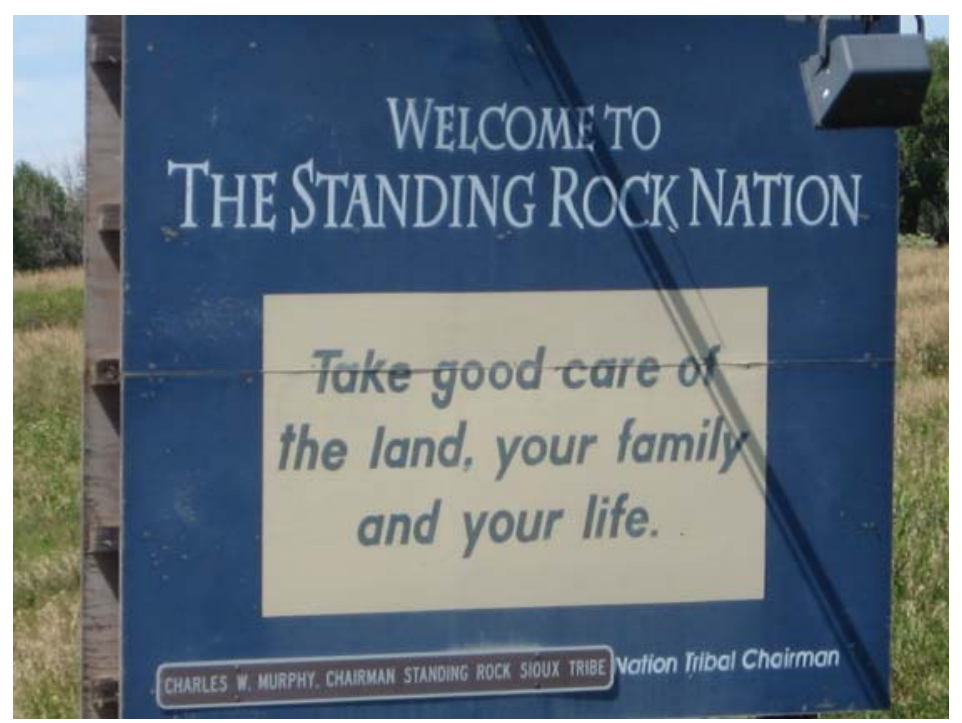

However, this is deceiving since the population of Corson County, which is entirely encompassed by the Standing Rock Native American Reservation, is very small, and traditional Sioux religions are not included in the data sets, even as an "other" category. The same data yields a very different nationwide picture of the Episcopalian 
denomination when it is normalized by the absolute number of adherents. Hence, to adequately understand the immense depth of this dataset it is necessary to take a dynamic, interactive approach that is not available in these static paper atlases which are concerned more with the 'shape' rather than the 'shaping' of the earth (Mitchell, 2000, 29). The danger here is that by focusing only on the present shape of an aggregated reality, a superorganic culture is created that somehow mysteriously exists superior to, and independent of, individual acting humans. Zelinsky has been criticized for arguing for a distinct national culture and even ethnicity in America during the same era as Vietnam, the Black Panther movement, feminism, and the American Indian movement (Mitchell, 2000). Hence, as with broader cultural studies, there is without question a significant need for investigations at the scale of the individual. Yet, little attention has been applied in GOR to understanding the processes occurring at the scale of nationhood outside of the aggregated analyses that are riddled with issues of ecological fallacy and the MAUP.

In a second broad-brush approach to GOR, Henkel (2005) has sought to incorporate humanistic with postmodern approaches - a technique that many human geographers would quickly resist. Henkel epitomizes this approach through the work of Kong (1990), who recognized a plurality of cultures in any one society with an often dominant and a subordinate culture with conflicting interests. Kong (1990; 2001) does a superb job of reviewing the numerous approaches to the study the geography of religion within new cultural geography. In this chapter I will not repeat this review with the exception of commenting on the thoughts of Chidester and Linenthal (1995). 
In 1995, Chidester and Linenthal edited the volume American Sacred Space in which they provided a medium to rethink the study of the sacred in America by exploring the meaning and power of sacred space. By differentiating between the substantial sacred (involving its essential character) and the situational sacred (at the nexus of human practices and social projects) these authors reframed GOR in terms of poetics and politics and argued that the politics of religious construction and contestation have always been a subtext of GOR, citing the hint of politics in Van der Leeuw’s (1963) Religion in Essence and Manifestation. By identifying sacred space as ritual space, significant space, and contested space, Chidester and Linenthal prioritized the roles of individual religious actors who personally affect changes to positions and properties. Hence, in the current stream of GOR literature, the bottom rung of the scale ladder - the individual (or in feminist terms the body) - reigns supreme. Nevertheless, there is not yet a coherent understanding of how religious processes function and change with scale.

\section{Re-defining scale: non-hierarchical ontologies}

Scholars in the last few years have made tremendous advances in their ability to conceptualize relational scale and especially so through Bruno Latour’s Actor-Network Theory (ANT). Jonathan Murdoch (1997) argued over a decade ago that space is bound into networks, and that any assessment of space simultaneously implies an assessment of network relations. Latour (1996, 370) states that modern societies have "a fibrous, thread-like, wiry, stringy, ropy, capillary character that is never captured by the notions of levels, layers, territories, spheres, categories, structures, systems.” Paasi (2004) interprets Latour as aiming at emancipation from the tyranny of distance and proximity 
by means of networks. Citing Latour, Murdoch posits that spatial analysis is network analysis, and that network analysis means following networks all the way along their length.

In contrast to Murdoch’s explanation of network analysis as being one of simply following the length of a network, other theorists have drawn upon metaphors from advanced physics and biology in order to reconceptualize spatial analysis as network analysis. Eric Sheppard (2002) advances the idea of positionality as a way of capturing the path-dependent ways in which places depend on their interdependencies with other places, proposing the metaphor of wormholes (from physics) as a way of representing the non-Euclidean spatiality of the global economy. According to Sheppard, "positionality can be ascribed to agents at scales ranging from the body to the world region,” meaning that “an individual’s positionality varies through space / time” (2002, 322).

Mapping positionality, however, is problematic, and so Sheppard only risks speaking of it in principle. He argues it is possible to map positionality by depicting relationships between different agents, in different places, and at different scales. He confesses that mapping positionality “onto the earth’s surface is far more complex... because there may be little relationship between proximity in Euclidean geographic space and positionality” (Sheppard, 2002, 323). Using the wormhole metaphor Sheppard asserts that the positionality of two places could be measured by the intensity of their interconnectedness. Hence, “wormholes leapfrog across space, creating topological connections that reduce the separation between distant places and reshape their positionality” (Sheppard, 2002, 324) 
Hess (2004), in his reconceptualization of embeddedness, draws upon the Deleuzzian (Deleuze and Guattari,1987) metaphor of a rhizome - a subterranean stem that grows into a network and in places sprouts bulbs and tubers - as a way of avoiding static understandings of agency and social structure. Drawing again on ANT, Hess considers a rhizome to be the perfect metaphor for a network and he uses the rhizome to address issues of scale in the three dimensions of embeddedness: societal embeddedness (where an actor comes from), network embeddedness (the network of actors a person or organization is involved with), and territorial embeddedness (the extent to which an actor is anchored in particular territories or places). In the metaphorical use of the rhizome, societal embeddedness is the rhizome's genetic code, network embeddedness is related to connectivity, and territorial embeddedness is represented in the Euclidean bulbs and tubers.

\section{Non-hierarchical scale in GOR}

Two recent studies in GOR may be described as "non-hierarchical.” These studies include Julian Holloway's (2000) use of ANT as described immediately above, and Thomas Tweed's (2006) theory of religion that is inherently geographical. Actor Network Theory rejects all scales beyond the individual, while Tweed's theory of religious crossing and dwelling transcends scale, from the essentially phenomenological perspective of the individual.

Holloway (2000) takes on the superorganic notion of a religious institution by addressing individual actors within the New Age movement. He concentrates on how New Age actors make, create, and delimit institutional geographies. Holloway(2000) 
describes his own goal by stating, "I wish to take institutions and the geographies that create and are created by them, as processes, as achievements, as effects, and thus always becoming institutions, rather than already institutions.”

In order to understand Holloway's goal, it is helpful to again engage in the language of ANT and Latour, who describes the nomenclature of the theory itself as "a name that is so awkward, so confusing, so meaningless that it deserves to be kept” (Latour, 2005, 9). Latour passionately despises aggregation, as highlighted in the following comical application of aggregation to dating:

So you think you are in love with your future partner. You read a statistical study of marriage patterns where his age, his height, his revenue, his degrees, the distance between his town and yours fit, within a very small margin, in the mean range of what thousands of other young girls are in love with at almost exactly the same period. So, who is in love then? Others for sure, a strange alien agency that does not look like you, which has no eyes, no mouth, no ears but which acts all the same (Latour, 2005, 44).

Latour $(2005,184)$ argues that "social scientists use scale as one of the many variables they need to set up before doing the study, whereas scale is what actors achieve by scaling, spacing, and contextualizing each other through the transportation in some specific vehicles of some specific traces.” Latour's $(2005,176)$ understanding of scale, the terms micro and macro yields the following cognitive picture:

Macro no longer describes a wider or a larger site in which the micro would be embedded like some Russian Matryoshka doll, but another equally local, equally micro place, which is connected to many others through some medium transporting specific types of traces. No place can be said to be bigger than any other place, but some can be said to benefit from far safer connections with many more places than others. This move has the beneficial effect to keep the landscape flat, since what earlier, in the pre-relativist sociology, was situated 'above' or 'below' remains side by side and firmly on the same plane as the other loci which they were trying to overlook or include. What is now highlighted much more vividly than before are all the connections, the cables, the means of transportation, the vehicles linking places together. 
Hence, for Latour, a good ANT account is a narrative in which all the actors do something. He uses the term actor to reveal the narrow space in which "all the grandiose ingredients of the world begin to be hatched," and network to explain "through which vehicles, which traces, which trails, which types of information, the world is being brought inside those places and then, after having been transformed there, being pumped back out of its narrow wells" (Latour, 2005, 180). His point in all of this is to ask, "How could putting things into a frame not be the most reasonable thing to do?” (Latour, 2005, 186). Latour argues instead that, "it is the very framing activity, this very activity of contextualizing, that should be brought into the foreground and that it cannot be done as long as the zoom effect is taken for granted. To settle scale in advance would be sticking to one measure and one absolute frame of reference only when it is measuring that we are after” (Latour, 2005, p186). Therefore, Latour offers three pieces of advice, which Holloway follows: “go slow, don’t jump, keep everything flat.” (Latour, 2005, 190). Holloway's use of Latour is the first of its kind in GOR circles, though hopefully it will not be the last as there is tremendous value in the use of ANT methodology at the scale of the individual. Yet, some comment is in order, as a complete refusal to frame would eliminate some very valuable streams of GOR. Should the discipline purge itself of the amazing aggregated atlases described above? Or, is it possible to jump scales without threatening, ignoring or negating the processes occurring at the scale of individual religious adherents? One assumption of this study is that critical realism has the metaphysical capacity to incorporate aspects of ANT without negating other methodological approaches. 
A second potential framework for approaching the thorny issue of scale in GOR is in using a less-hierarchical approach as demonstrated in Tweed's (2006) theory of religion coined “Crossing and Dwelling”. The key components of Tweed’s theory, as revealed in his definition of religion, are implicitly geographical in nature: religious (organic-cultural) flows moving through time and space, making homes, and crossing boundaries. Tweed $(2006,79)$ states, “as spatial practices, religions are active verbs linked with unsubstantial nouns by bridging prepositions: from, with, in, between, through, and most important across... religions designate where we are from, identify whom we are with, and prescribe how we move across.” For Tweed, religion and geography are not just linked, they are inseparable - 'religion is geography'.

Tweed describes his own perspective as pragmatic or representational realism, making clear that he means realism with a small ' $r$ ' - as opposed to metaphysical realism. Tweed $(2006,9)$ re-imagines theories as itineraries, drawing on dictionary definitions of this term to suggest "theories are embodied travels (a line or course of travel; a route), positioned representations (a record or journal of travel, an account of a journey), and proposed routes (a sketch of a proposed route; a plan or scheme of travel).”

The strong tie to scale in Tweed's theory involves conceptualizing religions as situating individuals and communities in time and space, positioning them in four chronotypes: the body, the home, the homeland, and the cosmos. Religions position the body in relation to other chronotypes, as the body itself serves as the initial watch and compass. The religious also orient themselves by constructing, adorning, and inhabiting domestic space. Hence, the "imagined boundaries of the home contract and expand 
across cultures and in different semantic contexts," (Tweed, 2006, 104) as the religious participate in finding a space and making a place, however small or large.

Tweed's theory of religion is fascinating in terms of scale, especially since it is so deeply rooted in geography. Yet, it is also still profoundly rooted in the individual since all scales - home, homeland, and cosmos - are interpreted through the body / individual. Tweed's theory lends itself to the powerful anchoring of scale to the individual believer and her / his identity throughout geography of religion literature. It is perhaps the most developed version, especially since it is promoted as a theory of religion itself, within religious studies. Yet, the activities of both crossing and dwelling are embodied, and therefore only the epistemic realm is considered.

\section{Conceptualizing Scale}

A major dilemma throughout this review continues to be the imposition in almost all GOR studies of a dominant scale. In one of the few discussions on scale in GOR literature, Roger Stump (2008) suggests that the primary scale for understanding religious territoriality is the ubiquitous community of religious adherents themselves - the local congregation. Stump argues that it is from this pivotal scale that "narrower scales" such as the body and family and "wider scales" such as denominations are illuminated. While other geographers of religion have been relatively quiet in regard to the scale debate, there are certainly scalar divisions within the discipline as described above. Like the scale debate from other fields, scale in GOR seems to be at an impasse. How shall we study a scaled geography of religion? Is scale in geography of religion beyond representation? In Kong's $(2001,226)$ most recent review of the field of geography of 
religion she identified "the need for analysis at various scales: global, national, regional, local, and indeed that of the body,” as one of the three primary agendas for research in the decade following her article. Note that she used the term "analysis" not "analyses." Might it be valuable, within the context of a single study, to also explore the geography of a religious phenomenon at multiple scales with scale itself as the primary subject?

In a recent issue of the Annals of the Association of American Geographers, Holloway (2006) went beyond ANT to chart new ground in an article that argues that the sacred is beyond representation. Holloway's essay is not about mapping religion, but instead concerns itself with what is felt in spaces somehow known as sacred. Holloway argues that sacred spaces, like ghosts, do not exist as a 'real' material thing, but at the same time they can touch us. Holloway closes his essay with the statement, "We must, then, attend to sacred space in a way that does not deaden and suck the life from an experience which for millions of people around the globe is precisely that: life giving, life fulfilling and life affirming. It is only through attempting to go beyond representation [emphasis added] that this sense of life can be respected." Holloway is headed in the right direction once again: he is pioneering a re-engagement of the politics of religion with the poetics. While his attempt to bridge the gap between ontology and epistemology is noble, this dissertation takes a less haunted approach.

\section{Questioning the Death of Scale}

One would assume from the above discussion that although scale is extremely complex it is nonetheless robust and merits celebration even in the midst, if not because of, its complexity. Yet, for some geographers, the complexity of scale is justification 
alone for its demise. Marston et al. $(2005,417)$ reject "hybrid, both / and solutions that link hierarchical with network conceptualizations of socio-spatial processes”. After yet another review of the scale debate, this time highlighting the plethora of frequently diametrically opposed or entirely convoluted definitions of scale, Marston et al. (2005, 419) argue that even among the network theorists "a verticality that structures the nesting so central to the concept of scale, and with it the local-global paradigm”, reigns supreme. Hence, geographers are forced into one of three responses to scale: 1) affirm it, 2) develop a hybrid model, or 3) abandon hierarchical scale in its entirety.

According to Martson et al. (2005), scale should be stricken from the geographical lexicon and banished to the annals of history for four reasons. First, from a definitional and operational perspective, there is too much confusion between "scale as size - what is also called a horizontal measure of 'scope' or 'extensiveness' - and scale as level - a vertically imagined, nested hierarchical ordering of space” (Marston, 2005, 420). Arguing that there is insufficient ground to maintain a distinction between the two, Marston et al. assert that they must be collapsed one into the other, and that more often than not the horizontal will fall victim to the vertical. Second, moving between scales such as the local and global requires a re-imagination of oppositional associates between phenomena such as place and space, difference and sameness, concrete and abstract, and agency and structure. Hence, there is the "difficulty, if not the impossibility, of disentangling scalar hierarchies from a Trojan horse” (Marston, 2005, 421). Third, "hierarchy has become the vertical equivalent of the spatial scientist's 'grid epistemology,' recruiting researchers to its scaffold imagery” (Marston, 2005, 422). Hence, empirical work is "lashed to" specific a priori determined levels such as "body, 
neighborhood, urban, regional, national, and global"; and therefore "scale is a classic case of form determining content" (ibid.). Finally, scale is bound to a "methodological perspectivism” whereby "levels of scale suggest an epistemological hoist - a methodological leg-up" granting a "transcendent position for the researcher" (ibid) that undermines every attempt of self-reflexivity. Hence, when Marston et al. consider these criticisms, they conclude that scale is "found deficient: it does the same heuristic work as its cousins of scope and extension; it is bound to reproduce a small-large imaginary and with that, pre-configured accounts of social life that hierarchize spaces of economy and culture, structure and agency, objectivity and subjectivity, and cosmopolitan and parochialism; and it cannot deliver engaged and self-reflexive accounts of social life” (ibid.). Therefore, the authors "elect to expurgate scale from the geographical vocabulary.” Scale is, for these geographers, dead!

After at least a thirty-year ongoing debate among human geographers, some have reached the position that a funeral for scale is in order. I disagree, even though many geographers might argue I am in denial, and dealing with this tragic demise through Kubler Ross's five stages of death. As noted above, the processes and relations that occur at various physical and social scales remain, whether or not we frame them in terms of hierarchical scale, ANT, or crossings and dwellings. Before singing a dirge for scale and ordering flowers, perhaps there is still hope for it as an epistemological and, dare I say, even an ontological tool. Death is always tragic, and when confronted with such dilemmas it seems appropriate to turn to one or both of two sources: religion or philosophy. Since religion (or at least the geography of religion) has already fallen short 
in addressing the problem of scale, let us turn to philosophy. The following chapter filters this debate through the philosophy of critical realism. 


\section{Chapter 3 An “emerging” solution}

\section{Introduction}

Questions concerning the social construction of scale and the reification of onotologies continue to resonate through human geography. In this work I seek to explore the multifaceted nature of scalar relationships and processes through critical realism (CR). In the social sciences, questions about the relationships that exist between an individual and society are critical, and many of the approaches discussed in chapter two attempt to connect cause and effect as well as scalar relationships between individuals and aggregates. According to Danermark et al. (1997) the relationship between the parts and the whole in the social sciences does not have to result in reductionism. In CR terms, the world is stratified hierarchically with physical mechanisms in one stratum, chemical mechanisms in another, biological in a third, and psychological and social strata at the highest levels (ibid). Each individual stratum is formed from the powers and mechanisms of the underlying strata (ibid, 1997). The various objects in these strata have emergent powers, defined by Sayer $(1992,119)$ as “powers or liabilities which cannot be reduced to those of their constituents.” Emergence occurs "when the properties of underlying strata have been combined," and "qualitatively new objects have come into existence, each with its own specific structures, forces, powers and mechanisms” (Danermark et al., 1997, 60). In CR the stratification of reality implies that researchers can move downwards through strata thereby enabling causal mechanisms to be isolated. Yet, possibly even more important for this study, new nonreducible properties and mechanisms are added at each specific stratum” (ibid). CR has 
the potential to avoid a major criticism of scaled approaches to geography, namely reductionism. Researchers may “jump scale,” but without reducing one strata to another.

Critical realism founder Roy Bhaskar and methodologist Berth Danermark (2006) argue for a necessarily laminated system comprised of several different levels of reality. These include a) the sub-individual or psychological level, b) the individual or biographical level, c) the level of micro- and small-group analysis studied by ethnomethodologists and others, d) the meso level concerned with functional roles such as disabled workers or capitalists, e) the macro level typically associated with societies, f) the mega level of civilizations and traditions, and f) the planetary level of globalization. Bhaskar and Danermark (2006) do not posit these levels as permanent structures, as was evidenced in the debate over these levels at the 2007 International Association of Critical Realism meeting in Philadelphia. In a discussion at this meeting Margaret Archer described the pursuit of emergence in the various fields of social science as an unending process with each hierarchical framework as being the best understanding "at the moment." What is important for this discussion of scale in the geography of religion is that a hierarchical understanding of scale is not inappropriate, because at each level the researcher is not reducing or conflating properties, powers and mechanisms, but is instead seeking and recognizing emergence. In order to utilize this framework, it is necessary to understand more about critical realist ontology and epistemology.

\section{Critical realist ontology and epistemology}

Critical realism offers more to a study of scale than does a focus on methodology alone. Despite confusion about CR as an epistemology that seeks to establish a method 
for knowing ultimate truth, (Cloke et al., 1991) this meta-philosophy is actually ontological and asserts as a basic premise that all knowledge is fallible (Danermark et. al, 1997). Many, like geographers Paul Cloke et al. (1991) and James Bird (1989), consider CR as providing "a privileged access to the truth,” and so argue the CR "involves a kind of foundationalism” or "a form of naïve objectivism, claiming unmediated access to the truth” (Sayer, 2000, 2). While CR does involve a switch from epistemology to ontology, and within ontology a switch from events to mechanisms (Danermark et al., 1997) this does not mean that at an epistemological level ultimate knowledge can be attained from a god-like position. The defining feature of realism is the belief that there is a world that exists independently from our knowledge of it and "independence of objects from knowledge immediately undermines any complacent assumptions about the relation between them. Sayer $(2000,2)$ argues that, "It is the evident fallibility of our knowledge - the experience of getting things wrong, of having our expectations confounded, and of crashing into things - that justifies us in believing that the world exists regardless of what we happen to think about it”. Or, as Danermark et al. $(1997,31)$ describe it, “whether we believe God or the Big Bang created the world, this does not affect how it was in fact created.”

The ontological approach of CR is distinct from that of empirical or positivist approaches, both of which have been historically important components of geography. From a CR perspective, both empirical and positivist methodologies incorporate an epistemic fallacy, which is the "view that statements about being can be reduced to or analyzed in terms of statements about knowledge” (Collier, 1994). Positivism, a philosophy often synonymous with the scientific method, is described as value-free, 
objective, testable, replicable, and predictive (Bird, 1989) because it essentially conflates epistemology and ontology. Ironically, the same epistemic fallacy is also present in much post-positivistic geographical thought such as humanism, postructuralism, and postmodernism. In these cases, the root of the fallacy is idealism where, in its extreme form, it is argued “we can’t know anything except by means of our own ideas, so we can’t know anything except our own ideas” (Collier, 1994). Here again statements about 'being' are reduced to statements about knowing. Danermark et al. (1997) argue that the epistemic fallacy is not only misguided but also quite dangerous, for they argue that many of the human disasters of the twentieth century, including the death camps of World War II and Stalin’s Gulags, were the direct result of epistemic fallacies. CR critiques empiricism and positivism, as well as idealist approaches such as phenomenology, existentialism, poststructuralism and postmodernism, as being impaired by a fundamental error in that reality is reduced to what can be perceived by our senses (ibid).

For the critical realist, three domains of reality differentiate the world: the empirical, the actual, and the real. The empirical domain consists of experiences of events, with our own experiences representing only a fraction of the events that actually exist. The domain of the 'actual' consists of events that occur whether or not they are experienced. "Events can occur unexperienced, can be inferred from their effects, and so on" (Collier, 1994, 42), or put another way, "what happens in the world is not the same as what is observed" (Danermark et al., 1997, 20). The observed and unobserved event is caused by something, and the 'somethings' (mechanisms) of the world comprise the domain of the real. These mechanisms have powers to affect events whether or not those 
powers are realized. Power is a "non-technical term designating what something can do," while mechanism is a "a technical term, designating a real something over and above and independent of patterns of events” (Collier, 1994, 62). Table 3.1 (taken from Bhaskar, 1975, 56) clarifies these domains with regard to experiences, mechanisms, and events:

Table 3.1 Critical Realism Domains

\begin{tabular}{|c|c|c|c|}
\hline & Domain of Real & Domain of Actual & Domain of Empirical \\
\hline Mechanisms & $\mathrm{X}$ & & \\
\hline Events & $\mathrm{X}$ & $\mathrm{X}$ & \\
\hline Experiences & $\mathrm{X}$ & $\mathrm{X}$ & $\mathrm{X}$ \\
\hline
\end{tabular}

The depth ontology of CR holds tremendous potential as a means to better understand scale in GOR. This is especially the case with regard to approaches that rely on aggregation and lean more toward quantitative analysis, which most frequently remains in the CR domain of the empirical. CR enables the incorporation of such studies without conflating the individual into its aggregate. An example of this is the CR

Figure 3.1 solution to the structure / agency debate.

Downwards conflation society

\section{Structure and Agency}

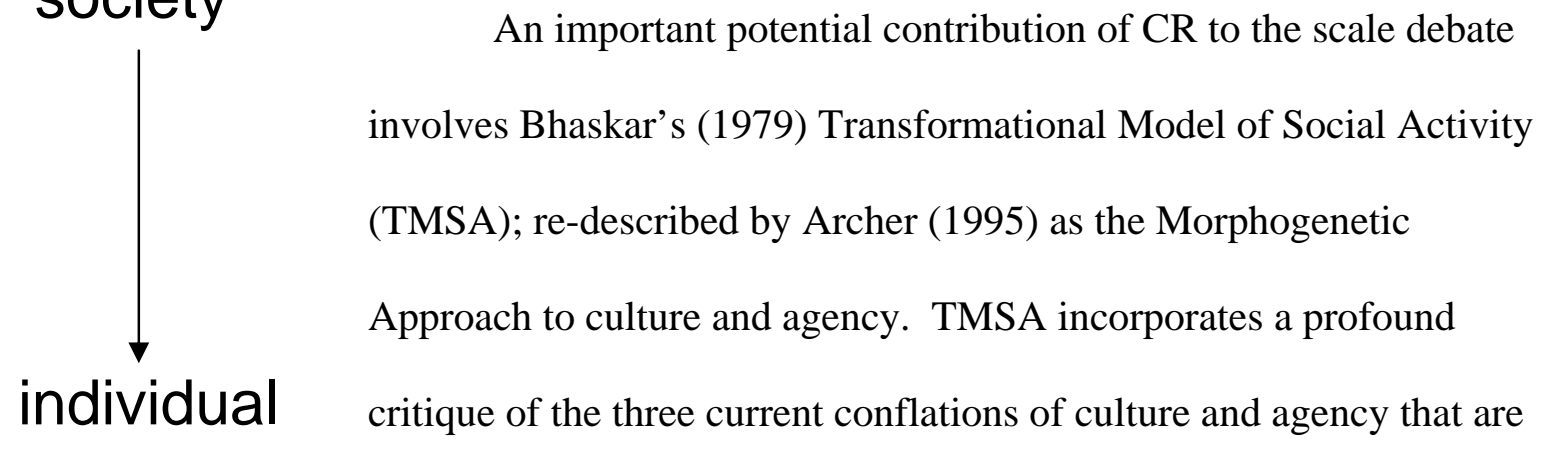


prevalent in geographic literature. The first conflation (Figure 3.1) meets the definition of what Archer (1995) describes as the myth of cultural integration and which Collier (1994) describes as the Durkheimian stereotype of reification. Here the cultural (Archer, 1995) or structural (Bhaskar, 1979) powers of society are conflated with, but emphasized over, the powers of agents Figure 3.2 Upwards Conflation interacting at the socio-cultural level. The second conflation (Figure 3.2) is that of upwards conflation (Archer, 1995), which operates in an opposite mode by neglecting the powers of a society through the conflation of the two by emphasizing human agency. The classic example of this conflation is neo-Marxism, where the role of power is society applied to the imposition of culture (Archer, 1995). A third central conflation flattens both society and the individual, but does so in a manner that denies the emergent powers of either (Figure 3.3). Gidden’s structuration theory and Berger and Luckmann's social constructivism are examples of this (Sayer, 2000). All three of these conflations are rectified in Bhaskar's (1979) dialectical conception of the individual and society which includes the emergent powers of both (Figure 3.4):

Fiaure 3.3: Central Conflation

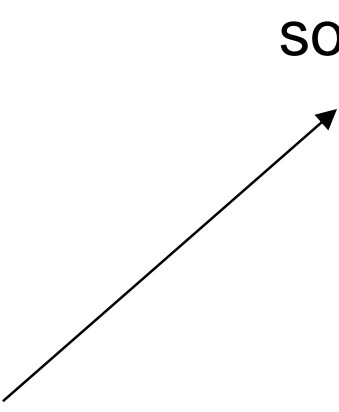

society

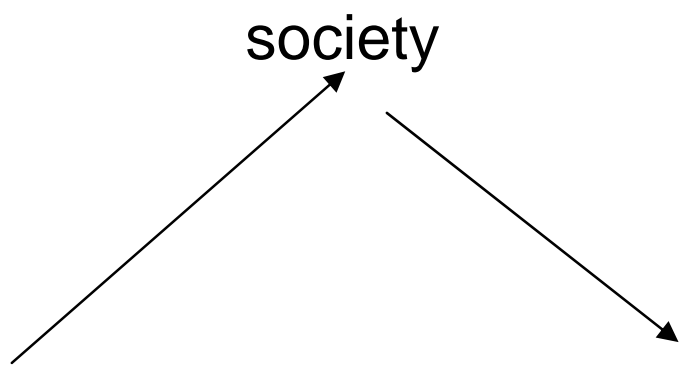
individual 
Figure 3.4: Transformational Model of Social Activity

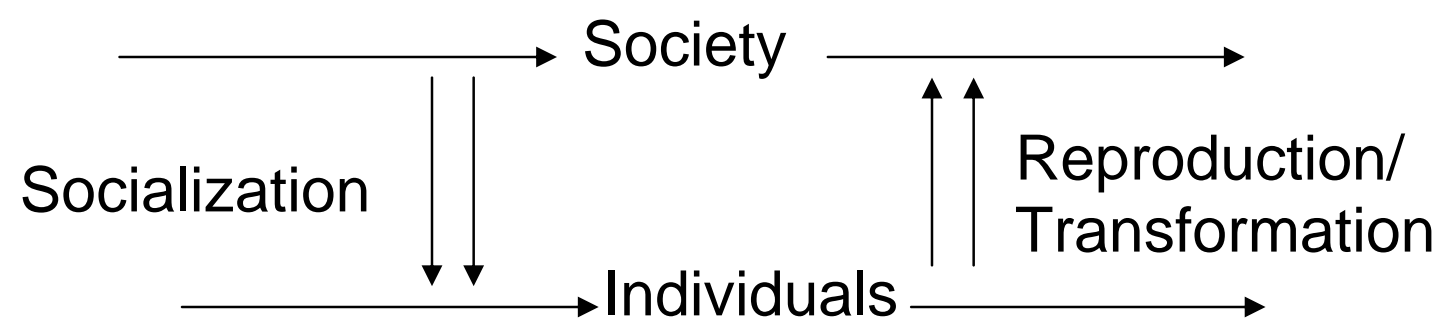

This dialectical conception is perhaps more clearly presented in the TMSA model.

In TMSA, culture is understood to assert power over an individual, who in turn has the power to either reproduce culture as received or to transform it. Archer's (1995) morphogenetic model involves the same concepts in a different manner (Figure 3.5).

Figure 3.5 Morphogenetic Approach

structure

interaction

structural elaboration

\begin{tabular}{|l|l|}
\hline Downwards Conflation & Upwards Conflation \\
\hline
\end{tabular}

Central Conflation 
Here the three types of conflation described above are delineated in the morphpogenetic model that describes Bhaskar’s (1979) transformation as elaboration and later as morphogenesis, with its opposite being morphostasis (Archer, 1995).

According to Bhaskar (1998b), it is no longer true to say that agents create society. Rather, one must say they reproduce or transform it. "If society is always already made, then any concrete human praxis, or if you like, act of objectification, can only modify it; and the totality of such acts sustain or change it. It is not the product of their activity, any more than human action is completely determined by it. Society stands to individuals, then, as something that they never make, but that exists only in virtue of their activity” (Bhaskar, 1998b, 34).

The distinction here is very important in terms of emergence, and hence scale, since "the importance of distinguishing categorically between people and societies is because the properties possessed by social forms may be very different from those possessed by the individuals upon whose activity they depend” (Archer et al., 1998). In other words, “people possess properties irreducible to those of matter” (Bhaskar, 1998b, 97) and people, even aggregated to scales naturally occurring in the world, possess properties irreducible to the individual. In a religious context, the organization of a church, whether or not agents are reproducing and transforming it, possesses properties that are worth investigating at scales beyond that of the individual. In like manner, the aggregations of churches, otherwise known as denominations, possess properties different from that of a church or an individual believer. Studies of these larger aggregated scales do not threaten the individual agent, nor does their existence equate to importance or power. Thus, emergence is not a case of arguing that the properties of 
larger scales are somehow more important than the scales that make them up. Rather, there are different relations and processes that occur at various scales. Instead of threatening the individual, CR interprets jumps in scale as strengthening our understanding of the power of a person to fundamentally change groups, societies and the world. This is an important point with regard to religious affiliation in GOR.

\section{Abstraction and Methodological Pluralism}

For the critical realist, conceptualization is the primary methodological tool of the researcher. Conceptual abstraction through structural analysis is a primary function of social science and from this follows realist causal analysis (Danermark et al., 1997). Sayer $(1992,86)$ begins his discussion on abstraction by stating, "To be practically adequate, knowledge must grasp the differentiations of the world; we need a way of individuating objects, and of characterizing their attributes and relationships”. An abstraction, then, is "something which is formed when we - albeit in thought - separate or isolate one particular aspect of a concrete object or phenomenon” (Danermark et al., 1997, 42). In many of the physical sciences, an experiment in a closed system can be used to determine the mechanisms causing a certain event. However, this is not possible in the social sciences. Rather, "when we wish to gain knowledge about generative powers and mechanisms in social worlds, one of the most splendid tools at our disposal is the isolation of certain aspects in thought - abstraction - rather than isolating them by manipulating events” (Ibid, 43). Examples of abstractions in the social sciences are numerous and include gender, class, and even religion. Like physical science abstractions such as density, energy, and gravity, these phenomena manifest themselves 
through their effects. However, it is not possible to immediately observe that which the concepts represent - the generative mechanisms (Danermark et al., 1997).

A particular kind of abstraction fundamental to CR is structural analysis, which is rooted in the idea that it is the nature of the object under study which is the fixed point from which to begin selecting appropriate methods of analysis because it is the nature of the object that determines the possibilities we have for gaining knowledge about it. In other words, "abstractions should lead back to those properties which determine what a certain object is” (Ibid, 1997, 45). In order to make useful abstractions, it is helpful to distinguish between the relations of different types (Sayer, 1992, 88). The primary way to differentiate between relations is to determine whether they are external (contingent) relations or internal (necessary) relations. For instance, the relationship between a rabbi and his congregation is internal because without a rabbi the congregation would just be a group of Jewish believers. Without the congregation, the rabbi's purpose would cease to exist. Each role causes the other's existence.

As we consider structural analysis, it is important to comprehend the notion that the objects of social science are relational in that they are what they are by virtue of the relations that exist with other objects (Danermark et al., 1997, 45). Structural analysis is the use of abstraction to isolate a structure, which can be defined as being sets of internally related objects or practices. According to Sayer, (1992, 91), “The structure of a system of interest can be discovered by asking simple questions about such relations: What does the existence of this object (in this form) presuppose? Can it exist on its own as such? If not, what else must be present? What is it about the object that makes it do such and such?”. Danermark et al. $(1997,47)$ add to this list, "What cannot be removed 
without making the object cease to exist in its present form.” Foundational to this process is the conceptual act of distinguishing between the occupant of a position and the position itself (Sayer, 1992). Danermark et al.(1997, 48) suggests, “everyday thinking constantly tends to identify people with positions and consequently attribute to individual people the properties held by positions, resulting in fatal consequences for the understanding of social life.” Hence, it is important that abstractions not be made trivially, mechanically, or routinely.

While important, structural analysis is not to be confused with causal analysis, since structures do not reveal much about processes or change. Causal analysis seeks to explain why what happens actually does happen (Danermark et al., 1997). “To ask for the cause of something is to ask what makes it happen, what produces, generates, creates, or determines it, or, more weakly, what enables or leads to it” (Sayer, 1992, 104). This is a matter of determining what causal powers or liabilities there are in a certain object or relation, which is synonymous with determining its mechanisms (Danermark et al., 1997). These powers and liabilities are in existence whether or not they are activated, as is demonstrated the following illustration (Figure 3.6):

Figure 3.6: Powers (Sayer,1992, 117)

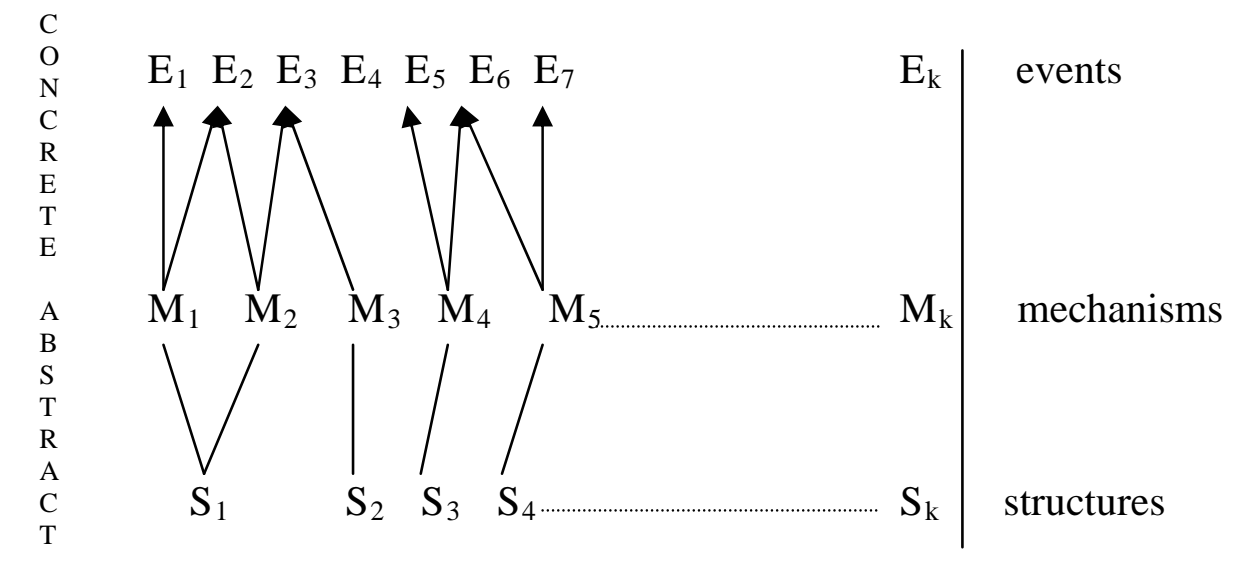


Collier (1994) describes how things have the powers that they do because of their structures, and how researchers can investigate the structures that generate the powers, and then predict the powers from the structures. "Structures cause powers to be exercised given some input, some efficient cause” (Collier, 1994, 43). Important to this understanding of cause are tendencies that exist in the domain of the actual where many mechanisms are working concurrently. Thus, “objects have powers whether exercised or not, mechanisms exist whether triggered or not and the effects of the mechanisms are contingent” which means we can say, “a certain object tends to act or behave in a certain way. Whether it will actually act or behave in this way, however, is a completely different matter” (Danermark et al., 1997, 56).

Figure 3.7: Tendencies (Sayer,1992, 109)

$\begin{array}{llll}\text { Cbject } & \begin{array}{l}\text { Causal powers } \\ \text { and liabilities }\end{array} & \text { Conditions (other objects } & \text { Events } \\ & \text { with powers and liabilities) } & \end{array}$

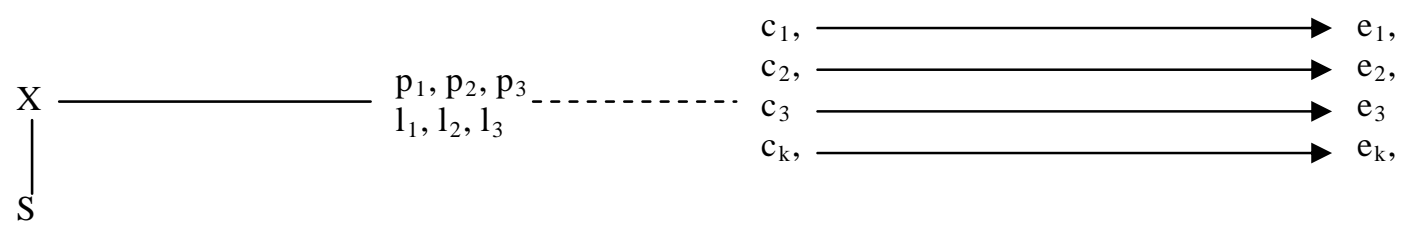

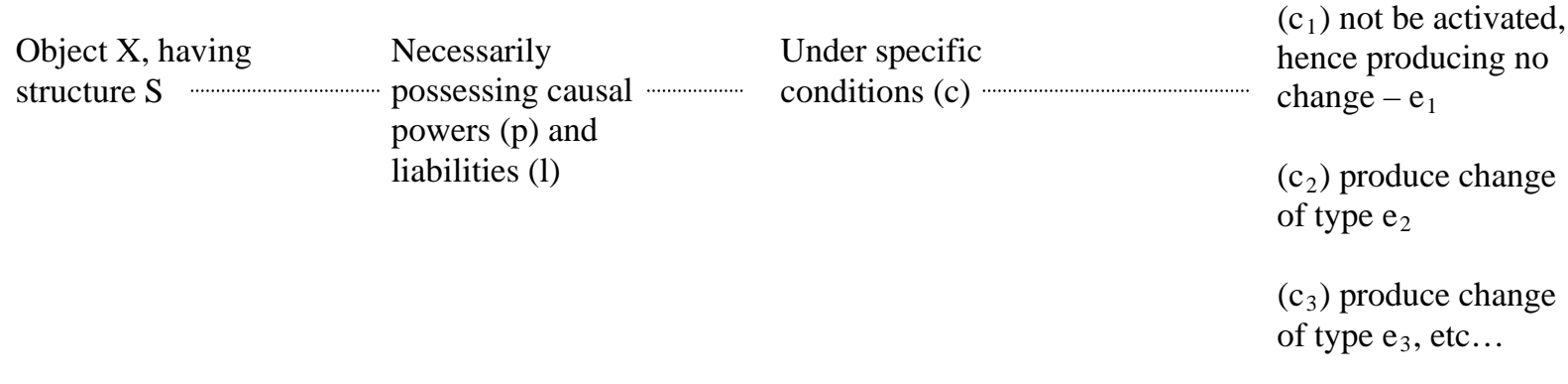


Tendencies (Figure 3.7) are, therefore, transfactual, meaning that "objects are working independently of the factual outcome, separated from the factual events," and "powers and mechanisms may be present and working without us being able to immediately perceive any connection between them and the effects they produce” (Danermark et al., 1997, 57).

Pawson and Tilley (1997) describe critical realist methodology as being realistic in the sense that it is real, realist, and realistic. It is real in light of the social ontology of $\mathrm{CR}$; it is realist in the sense that under the banner of realism it seeks to reassert the need for scientific investigation; and it is realistic in that it can not only be applied for the benefit of science as such, but is also relevant for practitioners, program participants and the public (ibid). Like other approaches, CR seeks laws, but defines them not as statements about universal empirical regularities, but rather as "a description of a mechanism existing as a property in reality, but whose observable effects strongly vary depending on concrete circumstances” (Danermark et al., 1997, 75). Therefore, since empirical studies do not reveal much about mechanisms, in CR there is a general shift in methodology from quantitative to qualitative approaches. Importantly, it should be reiterated that there is no such thing as a critical realist method. Rather, “critical realism offers guidelines for social science research and starting points for the evaluation of already established methods” (ibid, 73). In fact, quantitative approaches are used frequently and appreciated in CR circles for their ability to establish common properties and general patterns of a population as a whole (Sayer, 1992). "Realist research design employs no one standard formula, other than the base strategy of producing a clear theory 
of program mechanisms, contexts and outcomes, and then using them to design the appropriate empirical measures and comparisons” (Pawson and Tilley, 1997, xv).

Since CR is often confused with structuralism, in geography an important distinction should be drawn between the two. Hermeneutics packed a powerful punch to structuralism as literary theorists appropriately dismantled the lack of human agency present in the paradigm. However, as should be clear from the above discussion, critical realism recognizes the emergent powers of both human agents and culture itself. Hence, the structural causal powers discussed above are not strictly determinative and so, “critical realists argue that while interpretive understanding was an important and necessary feature of any social science, it did not mean that there was no scope for causal explanation” (Sayer, 2000) With the advent of postmodernism, "language could not continue to be taken as transparent and unproblematic by the philosophy of science” and hence, "discourse and textuality needed to be taken seriously" (ibid, 2000). These moves toward purely discursive science are unfortunate for CR, which is often misinterpreted as an empirically realist structuralism.

\section{The framework for this study: scale, critical realism, and geography of religion}

Through the ontology, epistemology and methodology of critical realism, it may be possible to recognize how the deep mechanisms and scalar structures of individual adherents, organized groups of adherents, and national associations of groups can be studied. Importantly, critical realism offers an approach that could identify and acknowledge emergent levels of relations and processes at different scales. The mechanisms underlying these relations and processes can be elucidated through structural 
and causal analysis using techniques of abstraction supported by both quantitative and qualitative research. 


\section{Chapter 4 Scale and emergent indicators in GOR Scale and the Geography of Religion}

Gaustad and Barlow (2001) identify ten traits that characterize American religion that include individualism, experientialism, radical diversity, primitivism, nativism, probabilism, denominationalism, volatility, fideism, and geography. A further list of American religion topics is described in the 2008 Religious Landscape Survey (Lugo et al., 2008) and includes the impact of demographic factors on the GOR such as age, ethnicity, nativity, education, income levels, gender, family composition and regional distribution, and non-demographic factors such as belief in God and the afterlife, attitudes toward the authority of sacred writings, frequency of worship attendance and prayer, views on abortion, attitudes about the proper roles of government and opinions on foreign affairs. These lists are complemented by the themes of geography of religion as detailed by Park (1994), which include the geographical distribution of religions, religious imprint on the cultural landscape, impacts of religion on lifestyle and commerce, religious taboos concerning food and wildlife, religion and demography, religion politics and conflict, religion and culture, and religion and environmental attitudes.

All of the themes listed above are subject to issues of scale, and most could fit into any study of emergence. For instance, Gaustad et al.’s (2001) theme of primitivism involves the common notion in the study of American religion that people seek a primitive, original, and arguably uncorrupted form of faith, including those portrayed in the Old and New Testaments as well as early Native American and African tribal religions. It would be possible for a researcher to investigate scale and emergence within the theme of primitivism by researching how individual believers congregate with, or disassociate from, other groups in order to form new primitive sects. Specific beliefs such as God and the afterlife could also be investigated in this 
manner in order to discern regional and national geo-political outcomes that result from belief systems about an afterlife and as displayed, for example, in nationalistic military movements in the Middle East and the use of suicide bombers. Or, scale and emergence could be utilized to investigate food and wildlife taboos by tracing the impact of individual ascetic practices at local, regional, and national scales. Scale and emergence permeate the discipline, even if this reality is currently generally unacknowledged

A major theme that underpins any untangling of scale and the GOR is fidelity. Fidelity involves loyalty or strict observance of promises or duties to a church and its doctrine (Random House, 2005). Gaustad et al. describe fideism as a distinguishing trait of American religion because, “for all the celebration and lamentation on various fronts about religion's decline in recent decades, Americans are far more apt to believe in God or to be attached to religious institutions than are citizens of Germany, France, Japan or virtually any other industrialized nation” (2001, 393). Yet, the level of this attachment varies among adherents of different congregations and between different individual adherents in specific congregations. "Not everyone is an equal participant in all the ritual events of the congregation. Within every group, however, there are differences in status and in levels of participation.” (Ammerman et al., 1998, 84).

In his study of religion in Wayne County, West Virginia, Leonard (2006) lists a number of factors contributing to our understanding of fidelity including local religious culture, accessibility to a preferred denomination, urbanization, and church distribution. His identified factors were generated by analyzing the religious life of a county at the level of the congregation rather than at the level of the individual adherent such that the factors could be measured through the quantitative analysis of church locations reinforced by broad surveys of adherents within 
churches. Unfortunately, insufficient adherents responded to Leonard's surveys to make them statistically significant, so the analyses are essentially dependent upon the quantitative analysis of church distributions. Leonard's difficulties in studying fidelity are consistent with Sopher's $(1967,107)$ assertion that, “data about religious fidelity are mostly qualitative and impressionistic, often providing only superficial indices such as the degree of observance of food taboos”. As a result, religious fidelity remains an enigma.

Another theme flowing from the geography of religion literature concerns faith - a subject that presumably leaves little need for justification in regard to its complexity. According to Stump (2008, 221), “religious belief informs the basic meanings that adherents attribute to many of the spaces they construct and use, so that the spaces themselves represent articulations and extensions of the adherents' faith.” Faith, then, is at the very center of the formation of the religious identity of an individual adherent. An act of conversion primarily involves fidelity to a religion, which in the case of this study is to Christianity. However, secondarily, a faith conversion propels an adherent into a social network that also inherently involves fidelity to a local community of believers and possibly a denomination. Adherence, denominationalism, fideism, and faith are all intricately linked across scales.

\section{Scale, fideism, and the adherent}

The foundational unit of many of these studies is the individual adherent as a member of a congregation and a person who owes allegiance to a denomination. Studies of religious adherence provide the bedrock upon which most studies in GOR are based and yet, ironically, most studies involving religious adherence usually operate at aggregated scales far above that of the individual. Adherents are defined in the Glenmary studies as "all members, including full 
members, their children and the estimated number of other participants who are not considered members” (Jones et al., 2002, vx). Bauer $(2006,40)$ rephrases this definition to suggest that "adherents are those people who consider themselves followers or worshipers in a religious group, regardless of whether they are committed, official members or casual, occasional attenders." Significantly, it is not the adherent who self-identifies in some formal manner. While "member" usually represents specific individuals affiliated with a church, the number of adherents is frequently an average of a church's annual attendance numbers, in some instances recorded on major religious days. Hence, in the Glenmary data an “adherent” does not necessarily represent even a real person sitting in a real seat in a real congregation, but is rather an average of a year's estimated attendance that may in reality be based on only a few days of special church celebration.

Furthermore, throughout the literature of religious adherence the terms "adherent," "adherence" and "affiliation" are often used interchangeably, but in reality there is a nationally scaled nuance to this usage. For instance, Lisa Jordan $(2007,4)$ defines a religious adherent as “someone who is recorded as being 'on the books' for a particular religious group”. Jordan clarifies that being 'on the books' "may not mean they are a full member or frequent attender of religious services." Curiously in the same article Jordan clarifies the definition of "adherence" by stating, "Again, religious adherence is not a measure of the extent or frequency of annual participation; it is simply a measure of the number of individuals that were reported in each group by county in the United States.” Even Newman and Halvorson $(1993,36)$ use the terms in a scaled fashion: "For denominations not reporting an adherents statistic, a standard formula for using the statistics for members and the populations in counties provides adherence estimates." Again, the organization of the data and the subsequent reporting of attendance takes 
place at the headquarters of religious denominations and may reflect a combination of real, averaged, or estimated numbers. Nationally reported numbers of church attendance can be remote from what is actually occurring at the level of the individual church. In these surveys an adherent does represent an actual person who sits in a real seat in a real congregation. Therefore, a targeted survey could theoretically illuminate specific characteristics in an individual religious body or a particular county. The surveys used in the GOR adherence literature, however, are intended to gather data used to represent an aggregate of a denomination or even a number of denominations. These studies are designed to be applied at the scale of the nation and, even in a substantial work such as the U.S. Religious Landscape Survey, are not refined sufficiently to enable a clear movement in scale from individual to denomination. A leap of faith is certainly needed to span the chasm left by a nationally-driven approach to church attendance.

Bauer (2006), the most recent major contributor to this field, wisely suggests that data on church adherence is useful in broad studies of religious affiliation, but should never be the final word in any geography of religion. Nationally aggregated adherence data, he suggests, does not provide a robust picture about what people believe, think, or feel as individuals. The data says “nothing about what Americans, both religious and irreligious, experience during their daily lives. They say nothing about how religion is lived-out on the landscape” (Bauer, 2006, 66). While aggregated county maps perform a role in identifying potential religious clusters or 'regions', and for identifying religious diversity, the data is too coarse to reveal the relationships and processes that led to the patterns displayed on the maps.

Studies in religious adherence are foundational to the study of GOR and yet the work on religious regionalism and religious diversity that so dominate national level denominational analyses represent the classic characteristics of ecological fallacy if they are used to make 
assumptions about other scales. Such studies are heavily driven by the patterns revealed at aggregated scales and the available county level adherent tally. The choice of scale, if indeed there is an explicit choice, has an undeniably powerful impact on our understanding of the geography of religious adherence and of religion. Scale permeates the geography of religious

adherence in several ways: 1) it influences, and is influenced by, the methodology used to collect data about adherents, 2) it impacts the very definition of “adherent” itself, 3) it impacts classification systems used on that data, and 4) it influences the kinds of questions that can be asked and the inferences drawn from the data. Any researcher studying the geography of religious adherence must acknowledge and address the impact of scale choice.

\section{Scale and adherent data gathering methodologies}

Data gathering methodologies in the geography of religious adherence are heavily linked to what can be called the national level. The primary data source used in adherence studies comes from the Religious Congregations and Membership in the United States published by the Glenmary Research Center (Jones et al., 2002), which presents data reported for the 149 religious bodies that participated in this particular study. The volume is part of a series of Church and Church Membership Studies that record adherence for a number of mainstream Christian denominations. The 2000 volume includes, in addition to traditional Christian denominations, data on Jewish, Muslim, Baha’i, Buddhist, Hindi, Jain, Sikh, Taoist, and Zoroastrian adherents. All information included in the surveys are self-reported by individual religious organizations and, necessarily, the quality of the data may vary from group to group. Unfortunately, a number of known flaws exist in these data sets. According to Bauer (2006) the most significant issue with the Glenmary data is the limited number of participating 
groups. The Encyclopedia of American Religions (Melton, 1999, xiii) contains entries for more than 2,100 religious bodies: a number Bauer $(2006,43)$ describes as “staggering.” Yet, only 149 total religious groups are represented in the most current Glenmary volume.

In the introduction to the most recent Glenmary study, Jones et al. (2002, xv) claim "the most critical methodological problem was that of defining membership. Since there was no generally acceptable statistical definition of membership, it was felt that the designation of members rested finally with the religious bodies themselves." This is obviously a very significant issue, as noted in the introduction to the larger Yearbook of American and Canadian Churches (Lindner 2006), which acknowledged that no standard exists for data collection that applies across the variety of ecclesiastical structures reported in the Yearbook. Additionally, the definition of church membership differs from one denomination to another. Significant data accuracy issues may also be present because, while most nationally-based denominations demand membership statistics, other smaller denominations and sects with more autonomy only request them, and these requests sometimes go unheard.

Also troublesome for the accuracy of these sources is that the Glenmary Research Center and National Council of Churches of Christ receive their data from the headquarters of major denominational groups and it is virtually impossible for independent and smaller nonmainstream congregations to participate in the census. The nationally-driven approach of the Glenmary survey thus neglects significant portions of the US religious population. The 2000 Glenmary study acknowledges this when it states, “There are independent and community churches, religious movements, and associations whose memberships are not reported to the Yearbook or other compilers. As a result, the total membership of these groups is unknown, and there is no way to determine what proportion of their membership has been included in this 
study” (Jones et al., 2002, xiii). To emphasize this point it should be noted that a significant number of the religious bodies reported in the Yearbook of American and Canadian Churches (Lindner, 2000) did not participate in the Glenmary study.

Other aspects of religious census taking are also problematic. For instance, some 39 counties in the United States reported more religious adherents than the population of the county. Explanations for this anomaly include census undercounts, church membership overcounts, and errors in identifying residence and county of church membership. Furthermore, Newman and Halvorson (1993) summarize four major issues concerning the Glenmary data with regard to the chronology of the datasets. First, mergers and schisms of denominational groups over time must be accommodated. Second, there are significant omissions as noted above. Third, the more evangelical groups remain largely underrepresented. Fourth, several denominations changed their procedures for estimating adherents during the period in question. As Jordan $(2007,5)$ states, "the measure of county-level adherents is neither comprehensive nor perfect, but it is the best available measure of religious affiliation that is currently accessible for mapping and assessing national trends.” Newman and Halvorson (1993) conclude that the surveys, "are neither more nor less accurate or reliable than other large scale census-type efforts, and are therefore especially useful for macro level analyses”.

A second source of data other than headcounts made by specific denominations is based on telephone surveys undertaken by research organizations. Some of these surveys, such as those undertaken by the Gallup organization, administer lengthy interviews on a wide range of topics to a small number of adherents. Other surveys, such as the American Religious Identification Survey, sample a larger number of people but ask only a few questions. The most recent and comprehensive survey is the 2008 U.S. Religious Landscape Survey conducted by the 
Pew Foundation, which produced national estimates of the demographic characteristics, religious beliefs and practices, and basic social and political values based on interviews with over 35,000 adherents (Lugo et al., 2008). While this approach is free from many of the shortcomings of the denominational census, they are nonetheless still tied to the national perspective. These surveys are more effective for collecting information on religious beliefs and practices than for identifying religious spatial patterns or distributions, especially at the local level. What is clear is that almost all data concerning adherents are collated at the national level and represent aggregate adherent data classified by (a limited) denominational structure.

\section{Scale and classifying the adherent}

A significant complication concerning studies of adherents is that a Christian adherent is not necessarily a member or frequent attendee of a congregation. In fact, particularly in the denominational censuses, an adherent in a particular church group does not self-identify as such. Rather, national denominational officials in a religious organization make their own determination of how to identify and classify adherents. In the light of this national determination, the definition of a religious adherent is vague and varies across entities included in the same datasets. To that end classification is important in denominational studies because of the large number of denominations that exist in North America.

If denominations were not classified using some standard and accepted terms, the data complexity and semantic nuances would be too overwhelming for meaningful interpretation. Two kinds of classifications have historically been used in studies of the geography of religious adherence (Corbett, 1993). The first technique, family group classification, combines religious groups according to specific characteristics such as polity or placement along a conservative - 
moderate - liberal framework (Bauer, 2006). Alternatively, a typological classification system separates religious organizations into four categories: black protestant, evangelical protestant, mainline protestant, and other affiliation (Steensland et al., 2000). These classification schemes are applied at the national scale of religious adherence in North America. Clearly the reductionism inherent in this process is substantial. Many of the religious groups combined in the family types classification methodology have histories of conflict and schism, and would not necessarily want to be combined with groups that share some, but not all, of the characteristics of the ‘family’ group. More importantly, as noted by religionist Robert Wuthnow (1988), individual adherents do not necessarily select one church or denomination over another based solely on doctrine or social history. Interpersonal relationships, worship style, and driving distance all influence adherence at the local scale. While arguably helpful at the national level, these classification schemes do not, and cannot, penetrate the complexity that occurs at the subnational level.

Bauer (2006, iii) created what he describes as the, "most recent, inclusive, and complete county-level religious adherence dataset yet to be assembled” by including previously omitted secular citizens and interpolating 'missing' adherents. He compiled the dataset by adjusting for gaps created by non-participating groups and the lack of data from secular Americans. His method is similar to that of Stark (1987), who used the Yearbook of American and Canadian Churches to estimate Jewish and African-American memberships. Bauer interpolated data for 39 missing groups by estimating the missing decades and interpolating forward and backward in time from known census counts. Bauer also generated a new classification of secular Americans by county, including those who do not actively practice the religion with which they identify, or who were not included in the Glenmary survey. He identifies this group as “nonaffiliated”. In 
order to generate a county estimate of the nonaffiliated population, Bauer used data from the 1990 National Survey of Religious Identification and the 2001 American Religious identification survey, both of which identified the percentage of people in each state that were either not included in the survey or were nonaffiliated. He estimated the number of secular Americans in each county by multiplying the county population with this number, and then he used a similar process on the NSRI survey, which drilled down to more specific metropolitan statistical areas. This approach is commendable for what it was intended to do. Yet again, however, these datasets use nationally-driven data estimations to address nationally-driven questions. County level aggregate data dominate these estimations.

The nationally-driven approaches tend to result in overcounts, undercounts and estimates. For example, West Virginia, eastern Kentucky and southern Ohio represent regions that are significantly undercounted even though these areas are known for their intense religiosity. Bauer (2006) attributes this undercount to the local folk culture and to the significant number of independent churches that lack a central organizing denomination or group that could act as a data clearinghouse. The undercount is similar to that of middle Tennessee, which Ethridge (1989) studied in depth using records from thirty-five county assessors. He notes, "The most glaring deficiency is the National Council of Churches failure to count the independent congregations. This omission is difficult to avoid since these churches are not associated with any of the denominational structures from which most of the National Council of Churches data are drawn” (Ethridge, 1989, 518).

In contrast to these national initiatives and datasets, James Leonard (2006) of Marshall University has initiated local studies on religious adherence in West Virginia. He analyzed the local geographic factors that influence church attendance in Wayne County because he noted that 
"geographical variables such as local religious culture, drive time to church, accessibility to a person’s preferred denomination, urbanization, and church distribution are not typically considered along with the demographic and individualistic variables that predominate in the literature” (Leonard, 2006, 30). He used a GPS enabled church census and resident survey to evaluate the county’s religious culture and its place in the US religious landscape. He also identified the existence of mountain churches as described in a sociological text by McCauley (1995). The results he found demonstrate how profoundly undercounted the Glenmary data is when it comes to religious adherence in Appalachia. Leonard extrapolated from pastor's counts and determined that the 154 congregations contained 12,500 weekly attendees and 22,000 members. This is three times the number reported by Jones et al. (2002). Clearly his work confirms Shortridge (1976) and later Bauer’s (2006) recognition of the Appalachian undercount. Leonard concludes that Appalachia may be a worst-case scenario for errors when denominational censuses are the primary mode of data gathering.

\section{Scale and the denomination}

While the basic non-modifiable unit in the GOR is the individual adherent, any discussion of adherence must include higher order units, and in particular the denominational congregation. According to the Encyclopedia of American Religions, a denomination is, “an organized group of affiliated congregations that hold the primary religious membership / affiliation of their adherents and whose congregations are the places where the members receive their regular ongoing weekly Christian nourishment and make their regular religious expression” (Melton, 2007, 153). Denominationalism is a term used primarily by scholars of religion to categorize churches. For instance, Roger Stump (2008, 253) defines a denomination as, “a union 
of local groups adhering to a common religious system within a larger tradition,” which “typically draw their identity from a specific set of beliefs, often codified in a formal text or confession, and from standardized religious practice.” Denominationalism is described by Gaustad et al. (2001) as one of the ten distinguishing traits in American religion not least because denominationalism itself asserts that no one church represents American Christianity. The root definition of a denomination, according to the American Heritage Dictionary (2006) is "a large group of religious congregations united under a common faith and name and organized under a single administrative and legal hierarchy.”

The categorization of denomination, however, is contested because many groups that are included by scholars and categorized as denominations eschew the term, preferring to selfdescribe their involvement with other congregations as fellowships of churches gathering together for encouragement and accountability rather than as denominations united by common beliefs and hierarchical structures or governance as implied by the process of categorization. While many congregations may be legally united, they are not always uniform in their commitment to a church hierarchy, and individual adherents may be even more scattered in their loyalty to the denomination even though they display a powerful fidelity to the local congregation. Or, individual adherents may have significant theological or practical disagreements with the larger body and yet remain in a church regardless of these differences. As Ammerman et al. (1998) state, it is not often that a researcher finds a "single, coherent theology binding a congregation together.” Instead, “a congregation’s relation to any larger body may be the subject of practical theological work and the source of different implicit theologies. A small Baptist congregation may feel little need for denominational identity, 
whereas a United Methodist congregation down the street may be struggling to revive its sense of connection with the denomination” (Ammerman et al., 1998, 33).

Understanding the degree of denominationalism within specific congregations or among groups of religious adherents is important in the light of the dominating national-level studies in GOR from which most inferences about religious patterns and worship trends in North America are made. Despite concerns about categorizing denominations, works such as the New Historical Atlas of Religion in America (2001) use denominational predominance to draw conclusions regarding religion in America, even though, as recounted in earlier chapters, these denominations do not utilize standard methodologies of data collection to count adherents. Possibly more significant, the denominations are themselves not theologically or ritualistically cohesive, and different denominations allow for differing degrees of heterogeneity. Independent churches, for example, may not be formally associated with a specific denomination, but may be connected nonetheless to broader regional, or even national, groups by rallying around para-church ministries such as Compassion International and World Vision, or television and radio ministries such as The 700 Club or the K-LOVE Radio Network. Local congregations, both denominational and independent, may also be involved in local, regional, and national politics to varying degrees.

\section{Scale, national patterns, national questions}

Denominationalism, then, is complex and contested, yet it still represents the major approach used in GOR to infer North American religious patterns and trends at the regional and national scales. Due to the imposition of county level aggregation, these national level studies are particularly susceptible to ecological fallacy and to MAUP if applied to the scales of 
congregations or adherents. Almost all national religious censuses are based on the aggregation of county level data that especially impacts two areas of GOR study: religious regionalism and religious diversity. Zelinsky (1961) was the first to use empirical census-type church affiliation data to map patterns of Jewish, Mormon, Catholic and Protestant groups in the continental United States. The data initially utilized came from the volume of Churches and Church Membership in the United States (1952). Zelinsky closely examined county-based denominational distribution maps and from them defined "religious regions". He confessed that the church membership data was not sufficient to categorize religious regions, and he lamented that "What we need are not only tabulations of formal adherence... but also some adequate measures of intensity of religious belief, frequency or regularity in religious observances, locus on the liberal - fundamentalist spectrum, and statistics on religious behavior with social, demographic, and economic characteristics” (Zelinsky, 1961, 166).

Shortridge (1976) built on Zelinsky’s foundation, but took his advice and expanded his work by mapping, again using the county as the base aggregation unit, a continuum of liberal and conservative Protestant church adherence and measures of religious intensity. Shortridge used a statistical technique based on data collected in 1971 by the National Council of Churches of Christ. His procedures were based on the degree of participation in larger ecumenical bodies, and proved to be highly controversial for mapping liberal and conservative groups. Liberal groups were defined as those that participated in the National Council of Churches, the World Council of Churches, and the Consultation on Church Union. Conservative groups were identified by their participation in the National Association of Evangelicals, the Pentecostal Fellowship of North America, and the Christian Holiness Association. While Shortridge's work 
was premised on coarse data aggregation, the questions that he posed spanned the spectrum from national to local scales. Ecological fallacy rears its ugly head once again.

Newman and Halvorson $(1978,1980)$ further expanded upon the work of Zelinsky and Shortridge and compared changes in US adherence between 1952 and 1971. They repeated their work in 2000 through an updated atlas that spanned 1952 to 1990 (Newman and Halvorson, 2000). This work is very well respected among scholars in GOR because of the disciplinary expertise of the two authors. Peter Halvorson serves as Professor of Geography and William Newman is Professor of Sociology, both at the University of Connecticut. Martin Marty (2001) acknowledged this confidence in the disciplinary strengths of Newman and Halvorson in a review of Newman and Halvorson (2000) when he criticized Gaustad and Barlow's The New Historical Atlas of Religion in America as, "the work of a historian who borrows from their specialties (sociology and geography) for his own purposes.” While both volumes are important contributions that contain numerous maps of the spatial distributions of denominations and religions in North America based on adherents, the vast majority of these maps and analyses are based on county level aggregated units. The geography of religious adherence in North America is thus filtered and aggregated in complex ways invariably from county level data and focused toward 'national' perspectives and explanation. As a result of this nationally driven data gathering using nationally driven classification schemes, the geography of religious adherence in its present form is problematic in its inability to reveal insight into patterns and processes at anything other than the county unit. Even this statement is questionable given the significant problems at the county level with classification, data collection, representation and the types of questions that have been posed. 
Leonard's (2006) study of a specific county in West Virginia is one of the best available that seeks to move away from national aggregate data but even here he does not reach the scale of the individual adherent, who remains reduced to an aggregate value. Leonard's work, though valuable, is also unhelpful in understanding the relationships and processes ongoing at the scale of the adherent, or with how these relationships and processes impact or affect church or denomination/association, or reveal local patterns or processes. Here the implications of changing scales in GOR remain a mystery.

In contrast to studies in the geography of religious adherence, Stump (2008) suggests that the primary scale required to understand religious territoriality lies at the local community of religious adherents. It is from this pivotal scale, he suggests, that "narrower scales” such as the body and family and "wider scales” such as denominations are illuminated. He states, "Of the various scales at which internal expressions of territoriality develop, the most fundamental is the communal, the scale that comprises the local community of believers. It is at this scale that the most significant interactions among adherents take place, group interactions that are essential for the immediate enactment and reproduction of religions as cultural systems” (Stump, 2008, 225). While the narrower scales of the body and family have more direct connections with an individual adherent's religious identity and the wider scales such as the denomination connect the local community to a larger, shared tradition, Stump places greater importance to the scale of the local community because it represents the nexus of interaction across scales. 


\section{Chapter 5: Emergent indicators across scales: a case study in GOR}

An important part of this study into scale and the GOR is to emphasize that no one scale of analysis has pre-eminence over any other scale of analysis. Rather, this work suggests that the significance of scale to GOR is dependent upon the questions being asked. It has been suggested in earlier chapters that the national scale dominates the geographic study of religious adherence even though Stump (2008) argues that the scale of the congregation is the dominant scale. Attempts to infer findings about adherents and denominations based on national level studies become quickly mired in ecological fallacy even though I have yet to see the term ecological fallacy used in the context of GOR studies. It may seem obvious to suggest that the questions that can be asked about denominations or adherents must be addressed at an appropriate scale of analysis. To pursue these questions a case study was undertaken in Harrison County, West Virginia, that sought to unravel, and shed light on, the complexities of scalar approaches to the study of religious fidelity and to explore further the CR notion of emergence as a major contributor to these scaled discussions.

For the purpose of this study I focus on the issue of fidelity, which is closely linked to denominational fidelity and to issues of faith which in turn is inherently a dimension of congregational fidelity. The reader should note that the focus on fidelity is not to imply a conflation of the terms denominationalism, fidelity, and faith as a form of reductionism, but rather to provide a vehicle with which to explore these complex scalar and emergent issues.

\section{The case study}

The location for this case study is Harrison County, West Virginia. Harrison County provides an excellent setting because it is within the region of the Appalachian undercount 
discussed in chapter four. Harrison County is located in the north central region of West

Virginia. The breakdown of congregations in Religious Congregations and Membership in the

United States (Jones et al., 2002) for Harrison County is as follows:

Table 5.1 Harrison County Adherents (Jones et al., 2002. 496-497)

\begin{tabular}{|c|c|c|c|c|c|c|c|}
\hline \multirow[b]{2}{*}{$\begin{array}{c}\text { Rel } \\
\text { Grp } \\
\#\end{array}$} & \multirow[b]{2}{*}{ Religious Group Name } & \multirow[b]{2}{*}{$\begin{array}{c}\text { \# Churches, } \\
\text { Synagogues, } \\
\text { Mosques, } \\
\text { Temples }\end{array}$} & \multirow[b]{2}{*}{$\begin{array}{c}\text { \# } \\
\text { Adherents }\end{array}$} & \multirow[b]{2}{*}{$\begin{array}{c}\# \\
\text { Attendees }\end{array}$} & \multicolumn{3}{|c|}{ Total Adherents } \\
\hline & & & & & $\begin{array}{c}\text { \# of } \\
\text { Adherents }\end{array}$ & $\begin{array}{l}\% \\
\text { Popula- } \\
\text { tion }\end{array}$ & $\begin{array}{c}\text { \% } \\
\text { Total } \\
\text { Adher- } \\
\text { ents }\end{array}$ \\
\hline 011 & $\begin{array}{l}\text { Allegheny Wesleyan } \\
\text { Methodist Connection }\end{array}$ & 2 & 35 & 100 & 35 & .1 & .1 \\
\hline 019 & $\begin{array}{l}\text { The American Baptist } \\
\text { Association }\end{array}$ & 33 & 5898 & 2464 & 7142 & 10.4 & 23 \\
\hline 053 & Assembly of God & 2 & 226 & 221 & 327 & .5 & 1.1 \\
\hline 056 & Baha’i & 0 & 4 & NR & 4 & - & - \\
\hline 081 & Catholic & 7 & NR & NR & 8488 & 12.4 & 27.3 \\
\hline 089 & $\begin{array}{l}\text { Christian \& } \\
\text { Missionary Alliance }\end{array}$ & 1 & 62 & NR & 140 & .2 & .5 \\
\hline 093 & $\begin{array}{l}\text { Church of Christ } \\
\text { (Disc) }\end{array}$ & 2 & 162 & 61 & 196 & .3 & .6 \\
\hline 123 & $\begin{array}{l}\text { Church of God } \\
\text { (Anderson) }\end{array}$ & 2 & NR & 70 & 70 & .1 & .2 \\
\hline 127 & $\begin{array}{l}\text { Church of God } \\
\text { (Cleveland) }\end{array}$ & 3 & 468 & 151 & 567 & .8 & 1.8 \\
\hline 145 & $\begin{array}{l}\text { Church of God } \\
\text { Prophecy }\end{array}$ & 1 & 32 & NR & 39 & .1 & .1 \\
\hline 151 & Latter Day Saints & 1 & NR & NR & 366 & .5 & 1.2 \\
\hline 165 & $\begin{array}{l}\text { Church of the } \\
\text { Nazarene }\end{array}$ & 2 & 134 & 94 & 134 & .2 & .4 \\
\hline 167 & Churches of Christ & 8 & 584 & 556 & 773 & 1.1 & 2.5 \\
\hline 193 & Episcopal & 3 & NR & 130 & 282 & .4 & .9 \\
\hline 207 & $\begin{array}{l}\text { Evangelical Lutheran } \\
\text { Church of America }\end{array}$ & 1 & 310 & 147 & 374 & .5 & 1.2 \\
\hline 221 & Free Methodist & 1 & 17 & 27 & 27 & - & .1 \\
\hline 223 & Free Will Baptist & 1 & 51 & NR & 61 & .1 & .2 \\
\hline 246 & Greek Orthodox & 1 & NR & NR & 150 & .2 & .5 \\
\hline 339 & $\begin{array}{l}\text { Pentecostal Church of } \\
\text { God }\end{array}$ & 1 & 21 & NR & 36 & .1 & .1 \\
\hline 355 & Presb. Church (USA) & 4 & 567 & 290 & 686 & 1 & 2.2 \\
\hline 360 & $\begin{array}{l}\text { Primitive Baptist } \\
\text { Church }\end{array}$ & 1 & NR & NR & NR & - & - \\
\hline
\end{tabular}




\begin{tabular}{|l|l|l|l|l|l|l|l|}
\hline 388 & $\begin{array}{l}\text { Regular Baptist } \\
\text { General Assembly }\end{array}$ & 1 & 300 & 225 & 363 & .5 & 1.2 \\
\hline 403 & Salavation Army & 1 & 109 & 39 & 225 & .3 & .7 \\
\hline 413 & S.D.A. & 1 & 119 & NR & 142 & .2 & .5 \\
\hline 419 & So Bapt Co & 5 & 719 & 300 & 871 & 1.3 & 2.8 \\
\hline 449 & United Methodist & 57 & 7527 & 3092 & 9107 & 13.3 & 29.3 \\
\hline 496 & Jewish & 1 & NR & NR & 110 & .2 & .4 \\
\hline 499 & $\begin{array}{l}\text { Independent Non- } \\
\text { Charismatic }\end{array}$ & 1 & 0 & 320 & 320 & .5 & 1 \\
\hline & Total Harrison County & $\mathbf{1 4 4}$ & $\mathbf{1 7 3 4 5}$ & $\mathbf{8 2 8 7}$ & $\mathbf{3 1 0 3 5}$ & $\mathbf{4 5 . 2}$ & $\mathbf{1 0 0}$ \\
\hline
\end{tabular}

In the tradition of CR, this study utilizes multiple methodologies in order to investigate scale and the geography of religious fidelity. The five forms of inquiry involved in this study seek to reveal the scalar process and mechanisms at work among adherents and within congregations and denominations concerning fidelity. The questions seek to explore fidelity in order to investigate emergent scales in the geography of religious adherence and to compare and contrast this approach with traditional approaches in GOR. These methodologies include surveys of members of congregations, semi-structured interviews or focus groups of congregational leaders, semi-structured interviews with pastors, semi-structured interviews with denominational leaders, and quantitative mapping of congregational geographies.

To this end a survey of congregational members was undertaken in each of the churches (Appendix A). Surveys were provided in the weekly bulletins and attendees were encouraged but not obligated to respond. Secondly, a semi-structured interview was undertaken with the churches and congregational leaders and separately with the pastors and with denominational leaders. Congregational leaders were selected by the pastors, who were asked to identify active lay leaders in the church who led sub-congregational entities such as small groups, Sunday School classes or committees. In two of the churches all of the congregational leaders were interviewed separately and in the Catholic Church a focus group was conducted. Finally, as Ammerman et al. (1998) recommends, the "geographic community” of each congregation was 
ascertained by having congregational members place push pins representing their domestic residences into a map of the region. The outlying pins effectively described the distribution perimeter of the congregation, and the pins closer to the church building defined the immediate neighborhood(s) of church influence. The maps provided displayed roads and hydro overlayed upon orthophotography. Members were instructed to place their push pins somewhere within the census block geography of their block group and not on the precise location of their house, thus allowing the residential anonymity required by human subject guidelines to be maintained. One of the churches requested to alter this methodology by printing $81 / 2$ by 11 inch maps of the county with the same locational information in the weekly bulletin and requested adherents to mark their residence with a pen.

The specific churches selected for investigation were chosen based on a number of criteria. A church representing each of the two largest denominations from the Religious Congregations and Membership in the United States (Jones et al., 2002) data was selected and these included First United Methodist Church of Clarksburg, a United Methodist congregation, and Our Lady of Perpetual Help, a Roman Catholic congregation. These two denominations organize themselves differently both hierarchically and administratively. A third independent congregation not directly linked to a denomination, Horizons Church, was also selected. Significantly, since this congregation is independent, it has never been represented in the Glenmary studies despite the fact that, if it were included, it would be the fourth largest denomination in the county. Within independent churches all aspects of orthodoxy and orthopraxy are implicitly in the hands of the local adherents.

The Roman Catholic Church is traditionally organized according to vicariates, dioceses and archdioceses, and in Harrison County the church is the second largest denomination in the 
county. The Diocese of Wheeling-Charleston comprises the entire state of West Virginia. When established in 1850, the Diocese of Wheeling was entirely within the state of Virginia. In 1863 when West Virginia seceded from Virginia, eight counties in the eastern panhandle of West Virginia continued as part of the Diocese of Richmond, while the Diocese of Wheeling included seventeen and one-half counties in Southwest Virginia. On August 13 1974, the Diocese of Wheeling was realigned to be coterminous with the State of West Virginia. The counties then within Virginia became part of the Diocese of Richmond. The Diocese of Wheeling contains seven Vicariates. The Clarksburg Vicariate extends across north-central West Virginia and includes 24 congregations, five of which are in Harrison County. The specific congregation used in this study was originally founded in 1925 as a predominantly Italian parish. As other nationalities moved into the area, the church was re-established as a territorial parish. In 1978, the church was entrusted to the Franciscan Fathers and in 1983 a new parish center was built in order to accommodate growth in the congregation. In 2002, a Diocesan Priest took over from the Franciscans and he remains with the church to this day. The church did not report 2008 attendance figures, but in mid-2008 it produced 350 church bulletins for congregants per week for their multiples services. One hundred and fifty-three individuals responded to a survey that was undertaken. Eight congregational leaders, who were identified and invited by the priest, also participated in a focus group meeting, and the priest was interviewed. The Vicar overseeing the Clarksburg Vicariate declined the opportunity to participate in the study. 
Table 5.2: Study Participants

\begin{tabular}{|l|c|c|c|c|}
\hline & Catholic & $\begin{array}{c}\text { United } \\
\text { Methodist }\end{array}$ & Independent & TOTAL \\
\hline Average Attendance & 350 & 125 & 950 & 1425 \\
\hline Congregational Members Surveyed & 153 & 51 & 282 & 486 \\
\hline \% Congregational Participation & $43.7 \%$ & $40.8 \%$ & $29.7 \%$ & $34.1 \%$ \\
\hline Congregational Leaders Participating & 8 & 5 & 8 & 21 \\
\hline Pastor Interviewed & 1 & 1 & 1 & 3 \\
\hline Denominational Leaders Interviewed & 0 & 1 & 0 & 1 \\
\hline
\end{tabular}

In contrast, the United Methodist Church organizes itself geographically according to parishes, districts and conferences, and is the largest denomination in Harrison County. The church combines with 195 other churches to form the Wesleyan District of the United Methodist Conference; a district that boasts the largest number of churches in all of Methodism, albeit largely due to small congregational units. The particular congregation selected for this study first had a presence in the county in 1788. When the congregation outgrew its original wooden facility another was constructed in 1822, which was ultimately used as a barracks in the Civil War. In 1866, the congregation built a third church, which it quickly outgrew, and subsequently built a fourth in 1909. The present building was constructed in 1956 after a fire destroyed the 1909 building, an event that still holds significant meaning for congregants. In 1968, the Methodist Episcopal Denomination merged with the Evangelical United Brethren Denomination to become the United Methodist Church. In 2008 the congregation averaged 125 attendees per week, and on the week of the congregational survey 110 people, including children and youth, participated in the service. Fifty-one adult respondents completed surveys, five congregational leaders participated in interviews, and both the pastor and the District Superintendent also participated in interviews. 
The independent church is a relatively recent entity in Harrison County. It was conceived in 1996 and was formally launched on Easter Sunday in 1997 with 50 people in attendance. The church now boasts well over 1100 attendees every week, including members at the two congregations it has since planted in Fairmont and Morgantown. This number makes its omission from the Glenmary study even more telling. For most of its short history the church met in a local high school, but in 2001 it purchased property near I-79 and met for the first time in its own building in March of 2004, exactly seven years after its first service. Within a year the new facility reached capacity even with three Sunday services. The congregation has no formal allegiance to a denomination nor does it report to another body though it does associate itself with Purpose Driven Churches and the Willow Creek Network entirely for the purpose of resourcing. The highest administrative authority in the church is the four member elder board, of which one member is the head pastor. The church also has seventeen deacons serving in various capacities. Sunday attendance at the main campus averages around 950, many of which are children and youth. Two hundred and eighty-two people responded to a survey. Additionally, five small group leaders who were identified and invited by the pastor participated in interviews and the pastor was also interviewed. 
Figure 5.1 Locations of Churches Studied

\section{Locations of Churches}

Harrison County, W

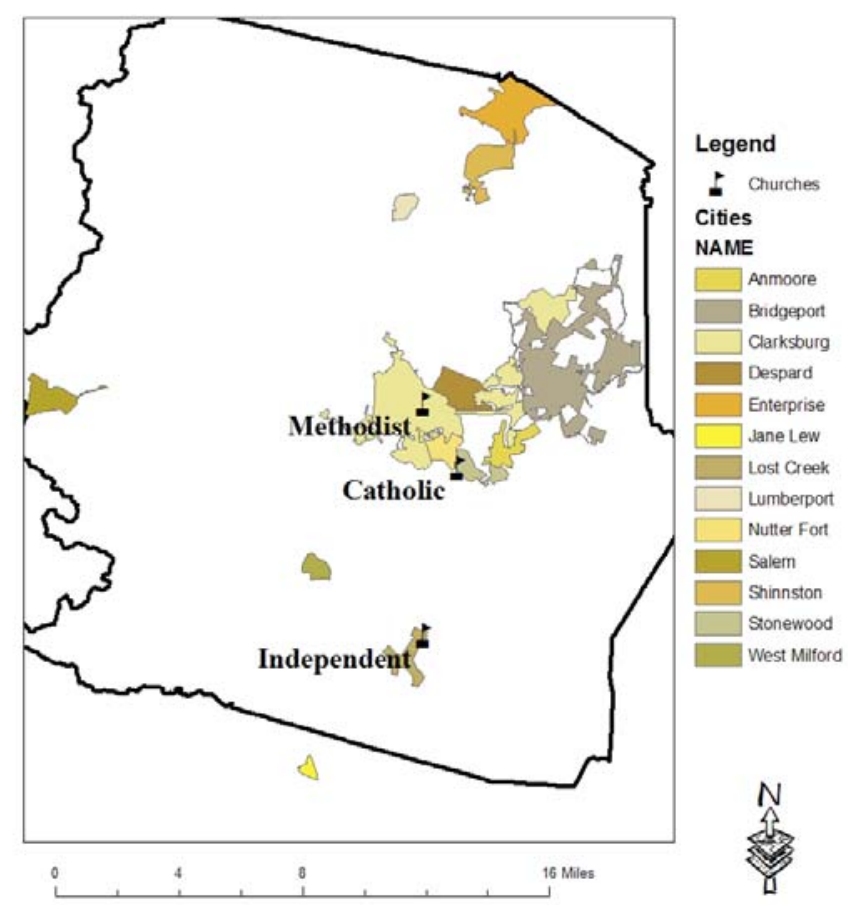

While all three churches are located in Harrison County, WV, each is from a different municipality (Figure 5.1). The Methodist Church is in Clarksburg, the Catholic Church in Stonewood, and the independent Church is just outside of Lost Creek.

\section{Fidelity in Harrison County, WV}

Before reviewing the results of these surveys, it is appropriate to refine the term fidelity in the light of the many different forms that it took in Harrison County and as provided by survey respondents and pastors, denominational leaders, and congregational leaders. The most common answer to "What is fidelity?” was “faithfulness.” As one pastor answered, “The first word that 
comes to my mind is faithfulness." A denominational leader stated, "I would always break the root word down and talk about faithfulness. Faith. Faithfulness. Loyalty. Commitment. Those would apply both ways and I'm thinking it would apply to adherence as well.” One pastor linked the question to another area of his life: "Semper Fi. The Marines. Faithfulness."

Some responses clarified the term still further, such as one pastor who used the term loyalty to define fidelity. However, he quickly backed away from using loyalty as the primary standard in his congregation. "I don’t use the term loyalty. I prefer the concept of connectedness. Relationships are essential... What does it mean to be a disciple of Jesus Christ? People get these bumper sticker answers and I wanted to get beyond that... What does it mean in the here and now. With each other. Connected."

One congregational leader qualified the term fidelity by describing it as a minor virtue. His initial definition was, "Loyalty or faithfulness to something.” Then he clarified that statement by saying, "Something that always comes to mind is that fidelity is a minor virtue. It is dependent upon that to which you are faithful. If you are faithful to Satan, you could be incredibly faithful, but it's not a good thing. So fidelity is always a minor virtue, based on that to which you are being faithful.”

Using this sense of fidelity as a minor virtue, it is possible to compare fidelity in congregational activities with fidelity to other civic or recreational events. Competition from opportunities outside of churches was mentioned by both pastors and congregational leaders. One pastor stated,

"One of the things that does concern me, and concerns most ministers, is that because you have both parents working nowadays all kinds of stuff that goes on Sundays and Wednesdays which was traditionally church time. I don't know how you get back to that. If we go to high school religious education on Sunday night, all hell would break lose. You have enough trouble as it is even the original church tie. You don't know where the answer is." 
One congregational leader was frustrated with the local YMCA for hosting sporting events on Sunday mornings. He stated,

"I thought about writing a letter to the YMCA. 'How dare you Christians schedule something on Sunday morning? I'm guessing you didn’t schedule it on Saturday because there was a WVU game!' But I have to hold the family accountable too. I think there are church people that need to be held accountable. It's their decision not to be here. To what are we loyal?”

Measuring fidelity in churches and denominations is challenging and varies from congregation to congregation and even within denominations. The most common responses included the measurement of attendance or financial giving, but these brief answers always required further clarification due to the complexity of how to quantify them. In the interviews, four major methodological practices appeared in the extensive discussions on measuring congregational fidelity. These were: 1) Fidelity of attendance 2) Fidelity of participation 3) Fidelity of giving 4) Fidelity of service.

Fidelity in attendance appears on the surface to be the simplest method of assessment, and yet its complexity is exposed in the above discussion. A family might attend three out of four weeks, yet every time another activity, such as a sporting event, occurs on a Sunday morning they choose the other event over church attendance. The same congregational leader who was considering writing a letter to the YMCA came up with a unique methodology for measuring attendance that would be worthy of its own study. When asked how to measure fidelity he stated, "By comparison to what else folks are faithful to. Maybe by asking a series of questions, 'If WVU played on a Sunday morning, where would you be and what would you be feeling? Would you experience internal conflict? Why did you make the choice you did? I think there would be a way of measuring in that case.'” Measuring fidelity based on participation in church activities other than the main service, giving patterns, or service to the church are just as 
complex. The pastor of the Methodist Church suggested an alternative route by linking

congregational fidelity to connection, yet he struggled to clarify how this could be measured.

"I suppose in terms of an unconscious level. One of the first things that comes to mind is participation and there has to be a quality of consistency that is selfcomposed. You don't stay connected simply because someone keeps pulling you back in. That's part of church life. Some of the worship participation is key, but it's not the whole matter. I think that at another level, giving really is. Just because it's symptomatic of ownership. I think it gets connected with relationship with God, it's not just a financial matter. You can't just look at it as a business matter. How do folk care for each other? How much aware are they of each other? There's a soulful quality about touching lives.”

The complexities involving the measurement of fidelity at the local level casts a shadow over the use of aggregated methodologies used at the national scale. Aggregations at the scale of the county may say one thing about fidelity, but local leaders describe and define fidelity in terms that transcend estimated church attendance.

Fidelity, then, remains a challenging concept to measure even at the scale of the individual or congregation because fidelity itself is contextually defined at the local level. The Methodist Superintendent summed this up when he stated, "I think that a community of faith has a way of encouraging and measuring faithfulness that might not be able to be quantified.” 


\section{Chapter 6 Scaled religious adherence in Harrison County, West Virginia Introduction}

Attaining an understanding of fidelity, a central theme in the GOR, particularly across the multiple scales that may apply to a church organization, ranging as it does from the individual congregant to the supra-organizational, is complex and difficult to disentangle. It has been suggested in previous chapters that CR, with its focus on identifying the emergence of new non-reducible relations as scale changes, is a potentially valuable concept to explore in examining the impact of changing scale in GOR. To examine these issues a Roman Catholic parish, a United Methodist congregation, and an independent congregation were identified for detailed investigation in order to delve into the complexities of scale, CR, and fidelity.

To set the scene, it is interesting to mention the use by the Roman Catholic priest of a well known metaphor that serves as a guiding framework for this chapter - that of not seeing the forest for the trees. While there are tendencies for studies to make these issues of scale appear academic, they are nonetheless real issues for people even though they may not know the more technical terms of scale and ecological fallacy. During his interview the priest observed “I'm sure every pastor fights this battle, can't see the forest [the denomination] for the tree [the local parish] is the way I see it. My struggle is to get people to see the forest, not the tree.” In this statement the local congregational leader was as much concerned with the issue of denominational fidelity than congregational fidelity and in so doing he was grappling with the base issues of scale and changing scale. According to the Priest, the mechanisms of this church, such as preaching, liturgy and 
small groups, were to function to enhance denominational fidelity over and above congregational fidelity.

These three churches illuminate aspects of the scaled nature of religious adherence in Harrison County, WV. Based on the surveys and interviews it will be seen, as with the above example, that mechanisms in the Catholic parish strongly encourage denominational fidelity even over congregational fidelity; whereas mechanisms in the United Methodist Church encourage almost the reciprocal in terms of congregational fidelity over denominational fidelity. The mechanisms in the independent church are focused solely on the local congregation. These varying emphases in congregational focus will be seen to have significant implications in formulating a scaled understanding of religious adherence and fidelity in Harrison County.

The methodology used in this study is a CR analysis of the mechanisms and processes acting to enhance congregational and denominational fidelity in the structures of the various congregations and denominations. The focus of each congregational and denominational analysis is to analyze the scale at which mechanisms and processes emerge such that these forms represent new and irreducible relations that were not present at other scale levels in the church.

\section{The Catholic Congregation}

Of the three churches in this study, the Catholic congregation displayed the greatest level of denominational fidelity, in line with the concern of the priest about his congregants seeing the forest through the trees. Survey respondents reported that the denomination impacted their daily spiritual lives more than did the congregation or small 
groups. The Catholic adherents also reported a stronger sense of belonging to the denomination (see Tables 6.1 and 6.2).

Table 6.1: Catholic Adherents View of Influences on Daily Life

Put the following in order of its impact on your daily spiritual life $(1=$ most impact and 3 = least impact):

Denomination Median Average

Congregation $\quad 2 \quad 1.86$

$\begin{array}{lll}\text { Small group } & 3 & 2.50\end{array}$

Table 6.2: Catholic Adherents Sense of Belonging

With 1 being very much and 5 being very little, how much do you feel a sense of belonging to each of the following:

$\begin{array}{lcc} & \text { Median: } & \text { Average: } \\ \text { Denomination } & 1 & 1.41 \\ \text { Church } & 1 & 1.70 \\ \text { Small group } & 3 & 3.33\end{array}$

In an interview with one of the Catholic congregational leaders the question was asked, "Is being Catholic more important than being a member of this congregation?" The response was, “Oh, yes. We are members here because we are Catholic.” Another Catholic congregational leader suggested that his fidelity to the denomination was reflected more in terms of his not questioning dogma. "I do not question dogma, and if my opinion is different from something - not a dogma but a stance the church has on an issue - then I drive myself to understand it more because I have to accept their position as being right and founded. Now on little operational issues I am wide open to blast that, but the fundamentals of our faith are not up for debate. I can't take a position opposite of 
that.” These Catholic leaders were squarely focused on the church hierarchy and were more loyal to the denominational forest than to the congregational tree. According to the priest, “We're the largest single Christian denomination [and] that entails certain responsibilities locally, nationally, and internationally.” The priest felt that the primary tie to the denomination was liturgical. "One of the great symbols for us is our liturgy, its closed liturgy. It means that no matter where you go, the same prayers are used throughout the Church. In the old days when it was in Latin, it was exactly the same thing. Now it's the same thing but it's in the vernacular.” The priest believed that his congregants were deeply tied to the denomination. "I would say the tie of our members to the denomination is pretty intense.”

While denominational fidelity is extremely important to members of this Catholic congregation, mechanisms and processes at the congregational level also serve to enhance congregational fidelity. Congregants are loyal to the parish and at the same time remain fiercely loyal to the denomination. Congregational leaders made statements in the interviews such as, “I feel a great spiritual desire to attend Sunday Mass and I do feel very connected to those in our congregation," and "I feel a strong sense of satisfaction, acceptance and happiness by my membership at this parish.” In the open-ended survey question asking why congregants attended this particular church the most commonly occurring response involved the Catholic denomination followed second by relationships with people in the congregation. The role of the pastoral staff ranked third while ranked fourth was the distance that had to be traveled to church or the time of service.

This particular Catholic congregation lacked a structured system of small study groups, though individual members could choose to participate in denominationally- 
organized regionally-based small groups with other local Catholic churches. Only 15\% of adults at the Catholic church were involved in organized groups below the scale of the congregation such as a small group or Sunday school. Yet, for those who did attend a small group, the experience had a profound impact. One congregational leader stated, "I think the family-ness of the small groups help to strengthen your faith and make you more committed. That is the uniqueness that we all have a different perspective and are all at a different place.” Another leader stated, “For me, it starts out the sense of being associated to a small group, you feel a tighter knit there. You're still committed to your church but you recognize your small family group. You have the capability to build a larger family group and foundation in your church.” However, 85\% of the remaining congregation did not attend any small group activities. The priest ascribed the lack of small groups in the congregation as a result of the church’s structure for Christian education, “We don’t have the tradition in our structure of Sunday School for all ages. We look at religious education as running in the academic years.” As one congregational leader stated, "I belong to a Bible Study made up of 4 or 5 churches. We develop around the Catholic faith, but not at a local level.” Hence, the mechanism of the small groups, although limited in their presence, also served to augment denominational fidelity.

The geographic distribution of the congregants (Figure 6.1), coupled with responses from the open-ended questions in the survey, served to demonstrate the prominent impact of the Catholic church hierarchy on local adherents. The map of the parish's adherents demonstrates a tight clustering of member homes in the immediate vicinity of the church. The smaller clusters of families to the south and the north are along Interstate 79, which provides quick access to the congregation. The geography 
reveals the scaled nature of this church hierarchy, which is acutely focused on the scale of the denomination. Furthermore, based on the open-ended written responses to questions as to why individuals attended answers pertaining to church distance and time of service were most common. The proximity of the church to the domicile of the congregants and / or the time of church service were mentioned by $27 \%$ of the respondents in the openended questions, likely because the potential adherents were looking for the closest or most convenient Catholic Church.

Figure 6.1 Residential Locations of Catholic Members

\section{Catholic Families}

Harrison County, WW

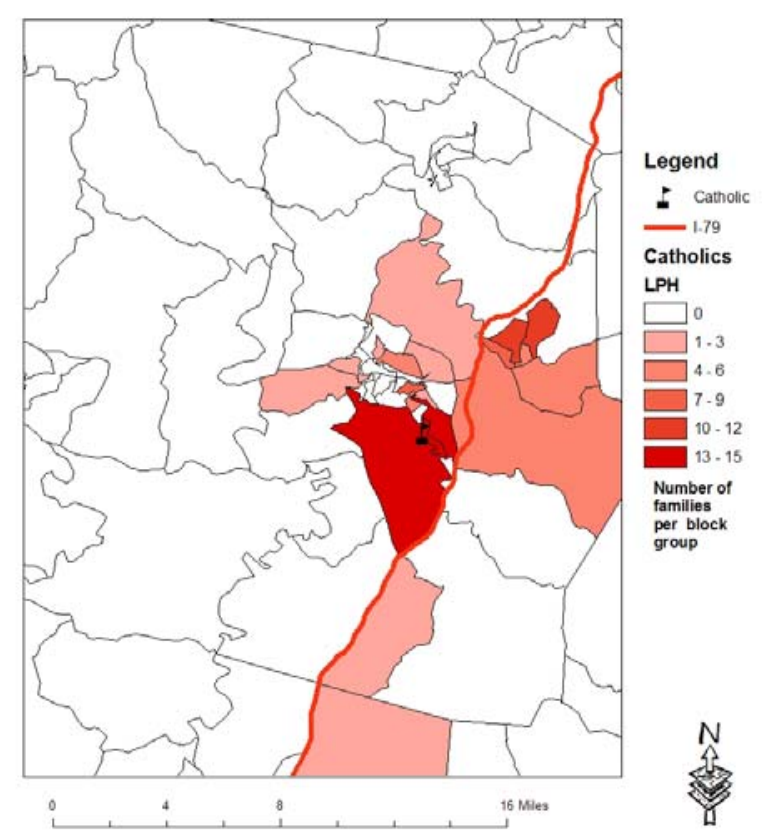

In the congregational survey respondents also selected the denomination as the most important reason they attended the Catholic church services but some confusion does seem to be discernible here (Table 6.3). While only 5\% of the respondents wrote 
Table 6.3: Catholic Adherents Reason for Attending

\begin{tabular}{|c|c|c|}
\hline & Median: & Average \\
\hline Denomination & 1 & 2.1 \\
\hline Worship style & 2 & 2.4 \\
\hline Pastor & 3 & 3.2 \\
\hline Distance & 4 & 3.9 \\
\hline Size of Congregation & 4 & 4.2 \\
\hline Family ministry & 5 & 4.3 \\
\hline Small group & 6 & 5.7 \\
\hline
\end{tabular}

"denomination" as a reason for attending the church in the open-ended section many congregants indicated in their response that this was the 'closest parish'. One can reasonably deduce from this that this was the closest "Catholic" parish, or the "Catholic" parish that offered the most convenient service times. It is likely no other denomination would be considered.

An adherent's fidelity to God is deeply linked to fidelity to congregation and denomination. According to the priest, attendance at Mass in the Catholic Church is directly linked to salvation. He stated, "if you miss mass on Sunday that's a mortal sin. You do not go to heaven, you do not pass go, you do not collect \$200.” This theology might help explain why the Catholic congregation in this study reported an extraordinary frequency of attendance compared to the other congregations, with $97 \%$ of respondents claiming to attend weekly (Table 6.4).

Table 6.4: Catholic Adherents Frequency of Attendance

How frequently do you attend your weekly church service? once a twice a once a week month quarter $\begin{array}{lll}147 & 3 & 2\end{array}$ 
Fidelity to God also came to the surface in the focus group discussions, where the congregational leaders agreed that mass was the primary reason for attending the parish and interpersonal relationships were a great fringe benefit. One summed this up by saying, "I was just thinking about the Eucharist being the center of our celebrations and I think what we are saying to you is that fellowship is second to our centeredness in Christ." For this congregation, fidelity to the denomination, congregation and small groups somehow come together in the Eucharist, which brings together these scales through sacred ritual, albeit a ritual emanating from, and remaining focused upon, the scale of the denomination and the church hierarchy. Mechanisms and processes in the Catholic Church as revealed in this study were theologically and ritualistically more focused on the denominational forest than the congregational tree.

\section{The Methodist Congregation}

Mechanisms and processes in the Methodist congregation enhance both congregational and denominational fidelity, but the primary focus is very much on congregational fidelity. Congregational leaders and survey respondents from the Methodist church expressed positive sentiments toward their denomination, but the deep level of commitment that pervaded the Catholic church was much less apparent. One member stated, “I grew up in the Methodist church. I don’t know as much as I probably should.” Another expressed, “I don’t think people really understand what it is to be United Methodist and what makes that different.”

Even the pastor appeared to be concerned more with the mechanisms and processes that enhance congregational fidelity than with those that ensure loyalty to the 
denominational hierarchy. Where the Catholic Priest felt compelled to ensure his congregants saw themselves as part of the denominational forest, the Methodist pastor was considerably more concerned about 'the tree' of his congregation. When asked if he used preaching to enhance denominational loyalty he stated, “I don’t work at that a whole lot. I refer to it at times. I refer to what's going on in the church. I talk about our tradition ... I would say it's more coincidental than intentional.” When asked if he was more concerned with congregational connectedness than denominational connectedness he responded, "I'm hesitant to answer that... I think that if we could be doing things on the congregational level then things would fall into place on the denominational level.”

When asked to further break this down he stated,

"If I were going to give loyalty to the denomination then I would need to have small group conversations, one on ones, conversations where I talk about concerns that are really important. I can easily reach to the denomination and say, "Here's a place we can go for ministry. Here's a place we can go to touch on social issues." All those kinds of ministries you see on television about other ministries reaching out- we do all of that very well as a denomination. When that becomes a burning passion, the denomination can help you out. I do not any longer look at the denomination to bring leadership down to the local church.”

In stark contrast to the Catholic church, the Methodist pastor did not believe many of his congregants thought about denominational issues at all. "The only really hot topics are lay members to annual conference and that's because they get some floor there. I've heard them come back and talk about homosexuality, abortion, and that sort of thing. Otherwise, I do not hear in this congregation verbalization of where the denomination is on almost anything. It is almost zero.”

This seemingly laissez faire attitude toward the denominational hierarchy and the heavy focus on the congregation was also reflected in the comments of the Methodist 
congregational leaders. One stated, "The local church always takes priority to me. It seems like more things get done in the local church. I know the people in the local church. Things don't seem so organized on the conference level. I guess I'm just more involved in the local church. I don't really know why.” Yet, despite this apparent statement of focus the same member later expressed loyalty to the denomination. "I'm tied to the denomination. I would never leave the United Methodist Church.” This sentiment was echoed by another participant in the study:

"I was in Rotary here a few years ago and it is a great organization. At the time I was in, there was a great polio push that helped eradicate immense amounts of polio around the world. I quit Rotary, not because I didn't like what they were doing but because of a fidelity issue. They asked their members to wear a rotary lapel pin about the time that the United Methodist women gave me a lapel pin. That simple act put me into conflict because I had to decide to which organization I was most loyal. They were both great organizations, but I felt I could not do both and I had to make a decision. I dropped out of Rotary.”

Despite loyalty to the United Methodist Church, however, this leader also perceived that the local church was not denominationally-oriented:

"Our United Methodist Women disassociated themselves with the conference. They didn’t feel like they had the time to participate. Instead of being a networked part of the denominational organization now they only associate with our local church. The men have rarely had a United Methodist Men's group. The youth and children, a little bit but not a lot. Things like conference camps and parish booth festivals, some of those things. Occasionally adults will go to conference.”

Survey respondents in the Methodist church ranked "congregation" and "small groups” as very important with regard to their impact on daily spiritual life (Table 6.5). 
Table 6.5: Methodist Adherents View of Influences on Daily Life

Put the following in order of its impact

on your daily spiritual life $(1=$ most impact

and 3 = least impact):

Average Median

congregation $\quad 1.6 \quad 1$

small group $\quad 1.9 \quad 2$

denomination $\quad 2.8 \quad 3$

The denomination has little impact on spiritual fidelity in this Methodist congregation, particularly when compared to the influence and importance of the congregation and small groups. This again is in stark contrast to perspectives of the Catholic congregation.

Methodist respondents ranked the congregation, denomination and small groups as being similar in terms of a sense of belonging, but there remains a preference for the congregation (Table 6.6). Despite comments about not closely identifying or aligning themselves to their denomination, it can be seen that adherents in this particular Methodist congregation have both a sense of belonging to their congregation and to their denomination, but with a clear preference to the congregational scale. Respondents seem to associate positively with the United Methodist brand, but not necessarily to the hierarchy and its initiatives.

Table 6.6: Methodist Adherents Sense of Belonging

With 1 being very much and 5 being very

little, how much do you feel a sense of

belonging to each of the following:

$\begin{array}{lcc} & \text { Average } & \text { Median } \\ \text { Church } & 1.8 & 1 \\ \text { Denomination } & 2.02 & 1 \\ \text { Small Group } & 2.18 & 2\end{array}$

According to the open-ended survey, individuals and families primarily attend the Methodist church due to relationships with other people and programs in the church, which is again quite different from the Catholic responses who mentioned the 
denomination as significantly more important than any other factor. Some sample

responses as to why families first attended this Methodist church include,

"Ours and neighborhood kids participating in church already"

"I knew someone who attended and they invited me to come."

"The congregation was very kind."

"When we moved to this city we joined new neighbors and friends in attending this church."

Respondents also provided additional reasons why they remain in the congregation, with the most frequent responses again revolving around personal relationships and church programs. For instance,

"I enjoy it here and feel that my week is complete when I come to church"

"Traditional type of service"

"I am becoming more involved and more connected through the worship service.”

"The congregation has become a substitute for the family I do not have"

One congregational leader stated in an interview, “When I don’t attend worship, I know that something’s missing.” Another stated, “When my children were young, the weekly worship service was one way we connected as a family. Sunday school and church were given, even when football, basketball, boy scouts might pull us in different directions, church was something that we did together.”

The Methodist Church was the only congregation of the three churches surveyed where a majority of the respondents reported significant involvement in small group worship activities. The form of small group involvement in this Methodist church primarily involved Sunday school and home-based Bible Study. 
Table 6.7: Methodist Adherents Small Group Attendance

Do you participate in a weekly

small group such as a Sunday

School or Bible Study?

Yes No

$29 \quad 22$

$57 \% \quad 43 \%$

Table 6.8: Methodist Adherents Small Group Frequency

$\begin{array}{cccc}\text { If so, how often do you attend? } & \\ \text { once a } & \text { twice a } & \text { once a } & \text { once a } \\ \text { week } & \text { month } & \text { month } & \text { quarter } \\ 23 & 6 & 0 & 0\end{array}$

While most respondents attend small group worship and bible study (Tables 6.7

and 6.8), few reported them as the direct reason for attending the church. Reasons

mentioned in the open-ended responses as to why families first attended the church

included "invitation to Sunday School" and "We were invited and liked the minister and

Sunday School.” Similarly, relationships were reported as being very important to

congregants and were mentioned more than any other reason as to why people attended

this church. This emphasis on relationship formation is reflected in the marked

preference for small group church activities.

The pastor of the Methodist church fully reinforced this focus on small group

worship as, "Entry points, connectedness with others, a degree of intimacy with others

and fellowship.” He provided a personal story to emphasize his point:

"I am going to share a lot more closely out of my own involvement. When I did a small group with the men, most of the men that were involved were new and they were younger. They were folk just coming into the church looking for entry points, connecting with me because I'm pastor. A good bit of intimacy developed. We actually talked about faith. It encouraged that and was a safe place to talk about that kind of intimacy with God. When I look at men's group, it served that way. My Sunday School class has new people. They're looking for places to connect. We have other groups that are the same groups that have always been. It seems to sustain a fellowship among 
those people. It does not seem to be content driven. I don't sense that any of these have a goal of equipping us to do ministry in the world. It's very inward."

The mechanism of small groups is a significant factor in this congregation and according to the respondents was more significant than the small group activities of the much larger independent church in this survey. Many of the small group leaders interviewed at the Methodist Church had positive things to say about the role of small groups in the congregation. One stated, "It feels like a very tight knit family atmosphere here. You see the groups here and think you'd like to be a part of it and for me that was a drawing feature for the church.” This theme of connectedness also came through in many of the interviews with small group leaders. One stated, "The small groups are the glue. They're what bind a group of people together.”

"I would say that the small groups have the bigger impact in folks spiritually or at least the folks that participate in small groups are more vocal about that impact. Maybe they've learned the language to evaluate their spirituality. Maybe someone has grown spiritually; they just don't know how to say so. I would say small groups have the larger impact on spiritual growth.”

In the Methodist church it appears that members sense a greater belonging to the local congregation, but that the small groups greatly enhance their relationships with others in the church and so in turn enhance congregational loyalty. As one small group leader put it, "Small seems to be a key word for most anything that we do invariably. Small group is the core. It's the fidelity factor.”

According to the pastor, the Methodist congregation found early cohesiveness around issues of class, though this is changing over time. He stated, "Most of the people in the church live fairly far away from the church in other socio-economically privileged areas. And because of the location downtown, we're starting to pick up folks of a 
different nature so we're kind of a church in transition.” The pastor then clarified "folks of a different nature" indicated a different socio-economic level - that the church was seeking to reach out to and thereby assimilate families from a mix of income ranges. This was demonstrated in the map of adherents' homes where most members of the congregation are clustered around three high socio-economic communities: Lake Floyd, Country Club Road and the west side of Bridgeport. These communities have some of the highest aggregate income levels in the county.

Figure 6.2 Residential Locations of Methodist Members

\section{Methodist Families}

Harrison County, WW

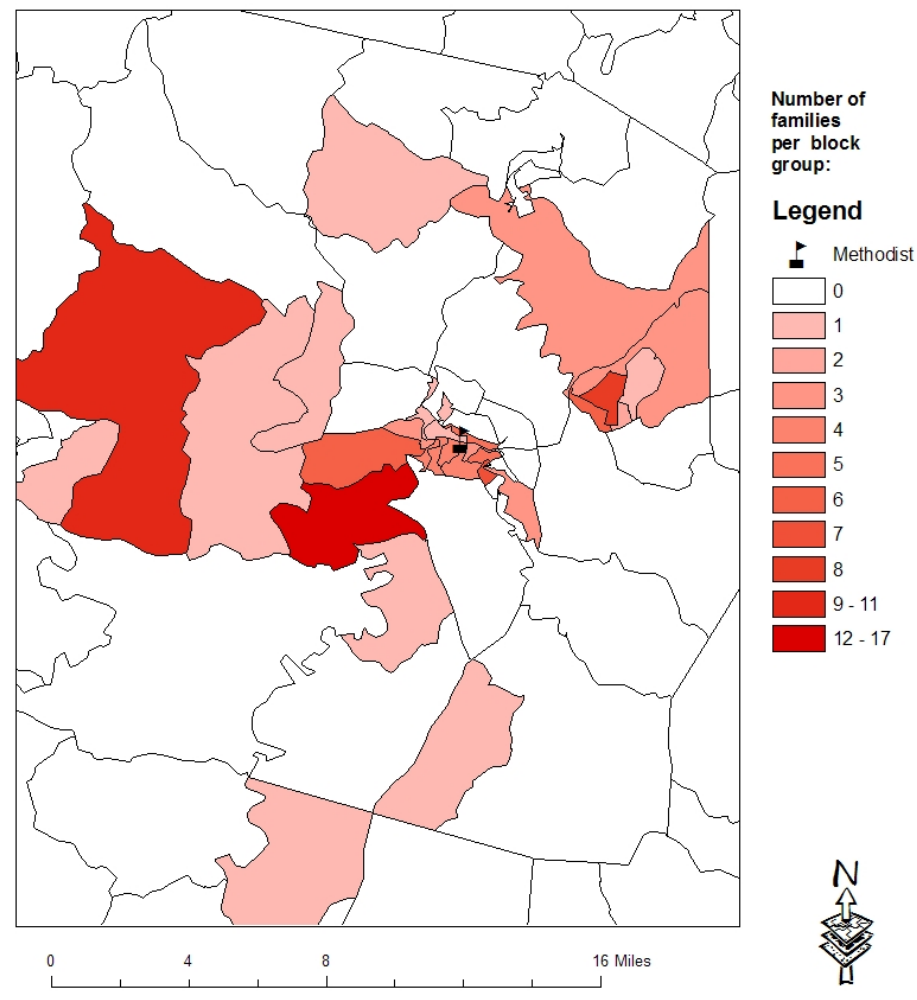


The mechanisms for reinforcing fidelity in the United Methodist Church such as preaching and small group ministries strategically enhance and focus on congregational fidelity. Denominational fidelity is not ignored, but it is not as important in the functioning of congregational mechanisms as was demonstrated in the Catholic congregation.

\section{The Independent Congregation}

Not surprisingly, respondents from the Independent church demonstrated congregational fidelity almost to the total exclusion of denominational fidelity. Denominational connections did show up in both the small group leader interviews and the open-ended questions in the survey, but only in the sense that these congregants wanted to avoid ties to a denomination by attending an independent church. Lay leaders in the church came from a number of denominations, and most did not reflect positively upon their previous denominational experiences. For example, one member stated,

"Being part of a denominational church for a long time, I was frustrated with the conflict and desired to leave. There were a lot of decisions made on a large scale. There was probably $98 \%$ of the congregation that disagreed with decisions the larger church made. If you're part of a denomination and something in the world happens, the church decides and that's part of you and your family. A decree affects you directly.”

This respondent did not want to be tied to decisions made at a national scale, and preferred the autonomy of a local congregation that had sole authority over all aspects of theology, ritual and church discipline.

Another lay leader in the Independent church was critical of denominational churches, but justified this with arguments rooted at the scale of congregational mechanisms: 
“I wasn’t happy in my denomination. It was a routine. I didn't know the name of anybody in the church. No one said hello. No one hugged you. In our church you didn't touch. Here you do that. You raise your hands during worship. Here I was like, 'What is wrong with these people? You're supposed to behave in church."”

Another lay leader couched it in more insubordinate terms. "My experience has grown out from those walls. A non-denominational church believes in all those things but they don’t want to put it all in one package. We don’t submit.” An Independent congregation was more appealing to this respondent precisely because it was not structurally connected to a church hierarchy and did not have congregational mechanisms seeking to enhance loyalty to any structure outside of the immediate congregation.

Some Independent congregants who filled out the open-ended questions in the survey also stated that it was the issue of denominationalism that was the primary reason for their gravitating toward and attending an Independent church. Some examples of these responses include:

"Because there is no denomination the Word of God is spoken here."

“Non-denominational services, real people."

"We really took hold to the fact it was non-denominational"

"Because it's a non-denominational church, and is not under control of a denomination's laws.”

In the light of these responses one would assume that the pastor was antidenominational and hesitant to be connected to a church hierarchy. However, this was not the case. When asked whether the word "denomination" was a positive or negative term the Independent church pastor stated,

"Neutral word. When we first started the church, we felt like we wanted to be part of a denomination. I thought it would be important for our folks. We looked at Assemblies, Four Square, Evangelical Free, Mission. All of them 
we felt would be awesome to be affiliated with. All the folks from my leadership circle came from independent backgrounds. We couldn't get over apportionments. That much money. Then it wasn't much money. Now it would be $\$ 300,000$ a year for us. We could really do some missions work with that. The top ten percent of our budget goes to mission. It was the money that convinced us to not become part of a denomination."

As will be seen in chapter seven, the Independent church participates in mission work, but these activities are entirely separate from any supra-congregational structures. This congregation seeks complete functional and financial autonomy to select its own missionaries and missionary emphases.

While the Independent church is not part of a formal denomination, it does associate with other churches to meet some of its organizational needs. According to the pastor, "Informally, we are hooked up with Purpose Driven Churches - Rick Warren. Formally, in a sense, also the Willow Creek Association. We are affiliated with them... It's purely a fellowship and for resourcing." Hence, some of the benefits of being connected to a church hierarchy are present even in the Independent church, particularly where there was no attempt by these agencies to control aspects of church government or church discipline at the local level. The Independent church was, then, loosely connected to other churches through very informal networks and not through the organizational hierarchies characteristic of the Catholic or even United Methodist denominations.

As far as congregants are concerned, however, the existence of these informal networks of churches was not significant. Respondents felt very connected to the congregation as a result of the worship style, the pastor, and programs in the church. As would be expected, any consideration of denominational affiliation was very low on the congregation's list of priorities (Table 6.9). 
Table 6.9: Independent Adherents Reason for Attending

Rate the following $(1=$ most, 7 = least $)$ in regard to the reasons you attend your particular congregation:

$\begin{array}{lcr} & \text { Median } & \text { Average } \\ \text { Worship Style } & 1 & 1.7 \\ \text { Pastor } & 2 & 1.9 \\ \text { Family Ministry } & 3 & 3.3 \\ \text { Small Groups } & 4 & 4.0 \\ \text { Distance } & 5 & 5.0 \\ \text { Size of Congregation } & 6 & 5.3 \\ \text { Denomination } & 7 & 5.9\end{array}$

The worship style of the Independent church and the pastoral staff were the two primary reasons why people attended, and both of these are mechanisms tied to the scale of the congregation itself. Responses in the open-ended survey question as to why families first attended the Independent church included,

"I know what kind of man (the pastor) is."

"We liked the contemporary music and the style of preaching"

"Love the Pastor's way of teaching”

"To find a pastor we could relate to"

Interviews with small group leaders revealed similar motivations for attending the church. "I know from personal experience that this church and the members are approachable. The one thing for me is going from suits to no suits. [The pastor] and these other people are naturally disarming." Another small group leader stated, "I don’t miss church unless it snows. I just need to feel that praise and worship.”

Many people also attended the church for reasons linked to their families and the local church community:

"Wife brought me" 
"My mom and sister heard how great a church it was so my wife and I started attending and loved it”

"My sister"

"My daughter was attending”

"Our son had been attending here for about a year. We were looking for a new church. So, here we are!”

While people initially attended primarily due to worship style and the pastoral staff, without question many more remained due to the influence of the pastor. In the open-ended questions asking why congregants originally began attending the church, some $23 \%$ mentioned something about the pastor, while in the question about why they remained 34\% mentioned his influence. In the short history of the congregation, the pastor has left on two occasions for an extended period of time to serve as a chaplain in the military. During both of these absences church attendance declined. One respondent to the survey acknowledged, "When [our pastor] went overseas we went from weekly to quarterly attendance.” In the light of this one might ask whether there is more fidelity to the pastor in the Independent church than there is to congregational fidelity. Regardless, the scale of the congregation as the focal point of group fidelity was dominant even in comparison with the influence of the small group activities (Table 6.10). Table 6.10: Independent Adherents View of Influences on Daily Life

Put the following in order of its impact to your daily spiritual life ( 1 = most impact and 3 = least impact):

$\begin{array}{lcc} & \text { Median } & \text { Average } \\ \text { congregation } & 1 & 1.4 \\ \text { small group } & 2 & 1.8 \\ \text { denomination } & 3 & 2.7\end{array}$


This is logical since less than half of the 279 individuals responding to the question attended a small group (Table 6.11). Of those who did, $83 \%$ attend the small group every week.

Table 6.11: Independent Adherents Small Group Attendance

Do you participate in a weekly small group such as a Sunday School or Bible Study?

$\begin{array}{lll}\text { Yes } & 112 & 40 \% \\ \text { No } & 167 & 60 \%\end{array}$

According to the survey, small groups are the $4^{\text {th }}$ most important reason why people attended the Independent church. The most passionate statement regarding small groups at the church came from the pastor, who stated, "When I was gone this last time for six months, what I missed the most, second to my family, was my Monday night men’s group. The first time I was deployed I didn’t remember having that experience. But this time I really missed it.”

The small group structure of the Independent church was very different from the denominationally-driven Catholic model of youth education or the Sunday School of the United Methodist congregation. Small groups at the Independent church consist of weekly meetings led by lay small group leaders centered on a number of topics from Bible Study to bicycling. According to one small group leader, "We have life groups for weight loss, mother’s raising boys, sportsmen, single mothers, married women.” The pastor described the small group structure in depth:

"We use the pre-market cell system, we stole it from Ted Haggert's New Life Church. He had a book out, Life Giving Churches, and they had a loose association there. One of the chapters was the pre-market cell system... The idea here is to give everybody freedom. If you have an idea and it meets a certain criteria, you let them have it. You let go. Looking back, six years later, I don't think we're happy with the results. We had attendance results, 
but we don't think we were doing the job there. You gotta focus on relating to one another and growing with Christ.”

So, even small groups are not uniform in the functions they serve in this congregation.

When asked specifically what was not functioning as intended in the small group system the pastor tellingly stated,

“Fidelity. We didn’t think we were doing the job there. Before you could call yourself a life group you must focus on relating to one another and growing in your relationship to Christ. Before you could call yourself a life group if you only connected socially - like bicycling together. A lot of churches are social rather than theological. Attendance was great but looking at the results, we think we need something different than that... We've always thought of them as the Velcro of the church. We thought if someone got involved in a life group they would stick to us. That hasn't always been the case."

While members of the Independent church appear to be more connected to the congregation and especially to the pastoral staff, small groups do serve in an assimilative role in the congregation. One small group leader stated, "Without small groups, it would be much more difficult for someone to grow in their faith without a team of people they can talk to, feel comfortable with. In any church, there's a certain face you put on. When someone asks how you're doing, they don't really want to hear how you're doing. In small groups, you can focus on helping others and yourself." Another stated, "When you come to a church this size, it's overwhelming sometimes. When you get involved one on one, it helps you grow spiritually.” Hence, for many, the mechanisms of small groups are very important for enhancing congregational fidelity.

Even though the pastor claims that small groups are not optimally functional, every statement made by small group leaders was complimentary about the role of small groups in the overall activities of the church. One leader stated, "Our life group is a hoot!” Another explained, "I just believe the people need to be involved in small groups 
so they know they have someone they can trust and turn to. Encourage you if you miss church, if you're feeling down and depressed. Sometimes that's the only call you get all week.” Another claimed, "they become sort of your family.” Finally, one stated, "We wouldn't have the congregation we have without the life groups.”

Many of the small group leaders commented on how difficult it was to get to know people in such a large congregation. For instance, one stated, “If there’s 1200 people coming here on a weekend, it's very easy to slip in and out. Somebody says, 'You went to church?' 'Yea, I was there.' 'Oh really? I didn’t see ya. Oh, you went to 9:00, I went to 11:00.' You can kind of be lost in here. If you go to a small group, you join in more.” Another claimed, “In a church this size, if you aren’t in a small group you don’t know anyone. I come on Saturday night so I hardly see the Sunday people.” Another said, "Being [that] this is a fairly large church, it's hard to get to know people. That's how it got started with us, we wanted to get to know people better on a smaller scale.” Hence, small groups provide a scalar function in this large congregation. They enable congregants to connect to other believers at a local level that would be difficult in a church with 1200 in attendance.

Adherents at the Catholic church tended to live close to the church whereas at the Methodist Church congregants tended to live further afield. A map of member domiciles for the Independent church revealed a tendency for members to also be geographically dispersed. The spatial extent of the residential locations of Independent church families is much greater than the other churches in this study (Figure 6.3). This is possibly because this is a large congregation that offers programs that draw congregants from a 
larger catchment area. As one survey respondent shared, "We have to drive quite a ways but it is worth it.”

Figure 6.3 Residential Locations of Independent Members

\section{Independent Families Harrison County, WW}

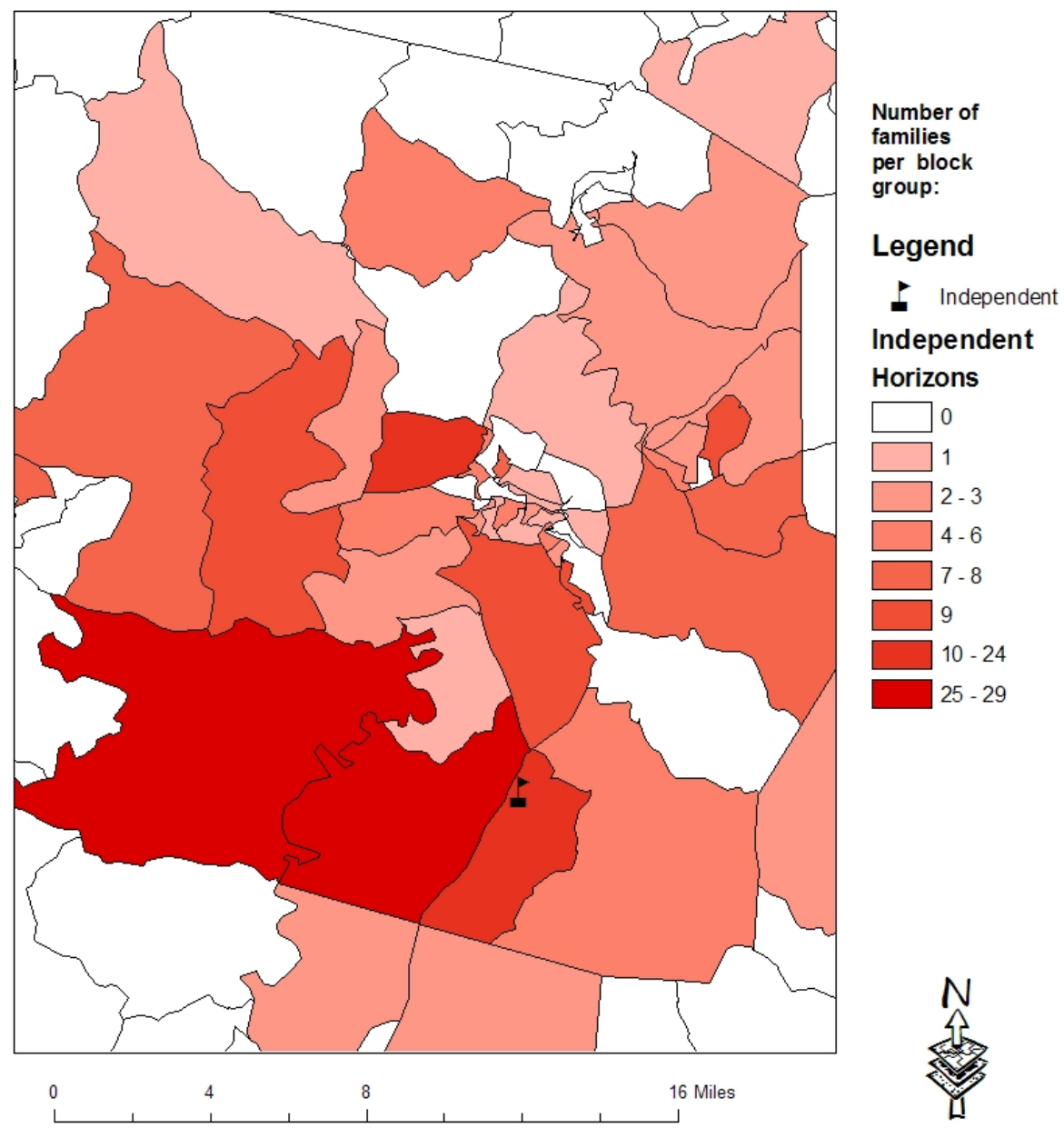

An interesting dynamic of the organizational structure of the Independent church is that the pastor is one of four elders who have sole authority over the congregation. When in jest he was asked whether he was $25 \%$ of his own boss he replied, "Some would say I 
am more than that! [laughing] The other elders don't go with everything I say.

Sometimes they push back a little bit. But, being a founding pastor of a church is a totally different experience.” In this Independent church the pastor wields administrative power not present in congregations with more connected church hierarchies. This power is directly related to the scale at which the congregation operates, complemented by the style of church governance.

In this particular Independent church, references to fidelity to God appeared in the surveys and interview answers quite frequently, even though this was not explicitly asked. The pastor asserted, "All of our sermons come back to Christ. We used to try an invitation to receive Christ after every sermon... We try to make loyalty to Jesus first, church second.” The effects of this approach are evident in the open-ended responses for why congregants attend the church:

"I feel more connected to God here"

"I feel that God has led me and my family here.”

"For my spiritual feeling”

"Because of the love of the Holy Spirit here"

"God's leading”

Fidelity to God was also a very common reason as to why congregants remained in the church. For example,

"God has planted me there"

"We feel God has led us here"

"The love of God is here"

"God's command"

"I know its what God wants us to do." 
“The Lord brings me back”

"I feel closer to God at this church than I ever have"

"The Lord has not told me to leave"

Compared to the other congregations in this study, the Independent congregation is a rather isolated tree in a loosely defined and very broadly dispersed forest. From an administrative perspective, the congregation is not part of a denominational forest, yet the congregation is resourced through networks without the denominational controls and structures. This Independent church exemplifies the transformation that is occurring at the national scale of the geography of religious adherence in North America - a transformation that traditional approaches cannot measure and do not articulate. This church certainly has mechanisms that transcend the scale of the congregation, but not in ways that are akin to churches set within more traditional and hierarchical denominational networks.

\section{Conclusion}

Each of the three congregations in this study demonstrates mechanisms and processes emphasizing different scales in terms of focus, function and administration. The Catholic congregation is dominated by the administrative and ritualistic authority of the Catholic Church hierarchy. The Methodist church remains loosely connected to its denomination while placing greater emphasis upon the congregation and small groups. The Independent church is entirely focused on 
the scale of the congregation and small groups and only reaches out to informal national networks for specific forms of resourcing.

The scaled mechanisms and processes of these three congregations are not measured or evaluated in traditional approaches to the geography of religious adherence, which rely almost exclusively on aggregations of adherent data at the county level and to the neglect of analyses at other stratums of the church hierarchy. What becomes apparent from this analysis is that the nature of adherence and fidelity is considerably more sophisticated and differentiated than can be understood from county-based aggregations of attendance data. Furthermore, and importantly, differing emergent processes and mechanisms are to be found within differing churches at differing levels of church activity. In the context of a critical realist approach to geography of religion, the scaled dimensions of religious adherence neglected in traditional approaches become apparent. The next chapter will delineate these implications for the study of religious adherence and fidelity. 


\section{Chapter 7 An Emergent Geography of Religion}

\section{Introduction}

Christian adherents in Harrison County, WV demonstrated differing forms of fidelity to religious associations that are emphasized at scales that include the denomination, the congregation, and the small group. What was evident from the survey and semi-structured interview responses was the scalar nature of religious adherence and its differentiation in the three churches. Interestingly, the Catholic parish was characterized as more denominationally focused than was the United Methodist church, which was focused more on the congregation and to a lesser extent on the denomination. In contrast, the Independent church focused almost exclusively on the congregation itself and small groups. To pursue an earlier metaphor, the Catholic church was most concerned with identifying itself as part of a particular denominational forest; the United Methodist congregation was concerned with their particular congregational tree without neglecting their forest; and the Independent congregation defined itself as a tree unassociated with, and disconnected from, any particular forest. Issues of scale appear to permeate the responses from the congregants and raise important questions regarding emergence, irreducibility and methodological pluralism.

\section{An Emergent Geography of Religion}

It is proposed here that a critical realist concept of emergence is a valuable framework for addressing the scaled complexity of adherence and fidelity and the geography of religion in Harrison County, WV. CR recognizes a stratified structure to reality that is characterized by synchronic emergent powers materialism in which reality 
is divided into strata in a similar sense to that of geological strata under the earth's surface. According to Inkpen (2005), "each stratum of reality is composed of entities that are composed of, but not reducible to, entities found at lower strata. In other words, each stratum may have unique entities which interact according to sets of laws as well as obeying, or rather interacting, according to laws found in lower strata.” Thus the national United Methodist Church is organized in specific ways at different scales in what the denomination describes as "a structure for connectionalism". According to the denomination's Book of Discipline (2004), "it is primarily at the level of the local church that the church encounters the world. The local church is a strategic base from which Christians move out to the structures of society." In this sense "local church" refers to a specific body of believers meeting in a specific community, and "church" refers to the larger denomination. This extract from the Book of Discipline emphasizes that local churches are not isolated from society at large. Rather, they are "linked to other parts of the community through the multiple memberships and loyalties of their members, but they are also linked as organizations to larger organizational networks” (Ammerman, 2003).

While the local church is the primary unit in most ecclesiastical bodies, it is possible to discern two other sub-church scales: the adherents themselves and small groups. The scale of the individual adherent represents the most basic level at which the geography of religious adherence can be analyzed because it is impossible to disaggregate beyond the individual. This is the non-modifiable unit in the geography of religious adherence. Numerous small groups made up of individual adherents meet 
within the context of the church umbrella for specific administrative and spiritual purposes.

An important question to arise from this framework concerns the point at which small group adherents “emerge” into a new phenomenon with new powers and mechanisms that are different from those of the individual adherent or the larger church congregation? Arguably, small groups could qualify as a new emergent stratum, particularly those groups that impact the decision-making capacities for the church itself. One could also argue that most small groups are simply amalgamations of individual adherents, and that any new powers and mechanisms are, in reality, not new but already present in the adherents themselves. Hence, when adherents come together on a committee to make decisions representing the local congregation it is actually the actors (the adherents) themselves that are activating mechanisms and making decisions on behalf of the rest of the church. Yet, from a critical realist perspective, it is the structure of the committee that imparts the authority to make decisions and this structure is not available to other congregants. It is from this scaled structure of the small group that new powers emerge. Members of a finance committee, for example, have the power as agents of the church to spend money on behalf of the rest of the congregation who, although they give money to the organization, do not have such power. This example is in contrast to a small group that meets to satisfy the individual needs of adherents rather than to act for the congregation as a whole, in which case new emergent powers and mechanisms do not necessarily exist at the structure of the small group. Hence, "jumping scale" from individual adherent to small group may reveal new powers and mechanisms in some instances but not in others. 
While the emergence of new powers at the scale of the small group is perhaps intermittent, it is arguably less so at the scale of the congregation where powers and mechanisms not present at the scale of the individual or the small group are revealed. A local "church" congregation is discussed in the singular tense, even though the adherents within the church are discussed in the plural. This linguistic distinction alone reveals that something new has formed, a fact reified in a legal sense in that churches are legal entities. The physical structure of the church building itself can be an ideological icon and even, as in the case of many New England towns, be an icon for entire communities. This was the case for one of the churches in this study, whose pastor responded to a question about the church’s identity by stating, “Congregational identity? I think that if you ask the people of Clarksburg what is [the church], it would be recognized by the structure - the building. It's an imposing building.” Obviously, churches cannot be reduced to a mere physical structure but rather, they exist as an intricate and multifarious web of relationships spun between families and friends, neighbors and neighborhoods. Nonetheless, it is at the scale of the church that the faces, and sometimes the fingerprints, of adherents begin to merge and emerge into more generalized, though still highly complex, structures of ideologies and programs that represent the emergence of the church. For example, one congregational leader in the independent church stated, “If you think about what we've been able to do as a congregation - the money we've been able to contribute to the poor. We supported thirty families this week from our pantry. We've built five orphanages in Cambodia and sustained them. I don't think there's any way you could get 1100 individuals in Harrison County to do that. God intends for churches to carry heavy loads not individuals since the Bible says God's yoke is easy and his burden light but churches - congregations. Something in our DNA says we should be doing great things. That couldn't be done without the congregation, without the collection of individuals.” 
Similarly, a Methodist congregational leader described the corporate processes of her denomination as "synergistic. The sum of the whole is greater than the sum of all the parts. It amazes me.” Another independent leader described it as "impact - the idea of the horse. What one horse can pull versus many. I've seen that in lots of ways.”

Like congregations, church hierarchies also demonstrate emergent powers, and both the Catholic Church and United Methodist Church are structured according to a very connected and well defined hierarchy. Local groups of churches in these hierarchical denominations coalesce to form vicariates or districts that provide for and enable training activities and mission opportunities. In both the Catholic and the United Methodist denominations, churches are subdivided into parishes that are less formal networks lacking a central office or paid administrative staff. Representatives of churches, especially local clergy, serve the parish in ways similar to that of a non-governing committee in a local church. The parish does not make decisions that affect the governance of the local churches, nor does the parish have any authority over the staff or lay members of a local congregation. Hence, like the spiritually oriented small groups of a local church, the parish may or may not have its own emergent powers that are different from those of individual churches.

However, parishes are organized into vicariates or districts that do have central offices and paid staff. A Vicar or District Superintendent oversees the operations of all local churches in the district, and has direct authority over the clergy in those locations. The existence of a central office with a staff and a budget represents new emergent powers at this level of the hierarchy. These powers are further removed from those present at the scale of the individual adherent. One interview respondent described this 
as, "The larger the group is, the more likely you are to do good things. We can combine our resources to do more good through service in Christ on a global level as a denomination than we can congregationally or individually. It's more powerful and transformative than as an individual.” Another local leader celebrated projects emerging from the combined work of the denomination such as,

"United Methodist sponsored schools, colleges, hospitals, clinics, United Methodist Committee on relief which has an incredible global impact on being a first responder. Those things are possible because we work together. I'm not sure a loosely structured association would do as well. I've always been supportive of the apportionment - Why? Some of it is because it provides those kinds of things. It is self-serving sometimes. It provides safety nets. If an independent church is struggling it will likely go under. In the United Methodist Church there can be help that comes out of a belief that probably comes out of our Anglican history that churches that last a long time are more effective. The apportionments help to provide that. It provides administrative support so that when I provide a gift for a specific ministry $100 \%$ of my money goes to that ministry because the denomination picks up the administrative costs."

Other emergent powers that arise from these high-level entities were described by the United Methodist Superintendent such as,

"the enormous resource base in the United Methodist church, they have enormous resources... and I think that part works fairly well assuming people avail themselves of it. Because you have your own publishing house, your own discipleship resources arm of the church, constantly putting out materials relating to every single ministry we have.”

Perhaps the best example of the emergent powers present at the level of the denomination was shared once again by the United Methodist District Superintendent through a description of a campaign to alleviate poverty that was well coordinated but that was only possible due to the presence of dedicated staff in the denominational offices.

““Nothing but Nets’ was started by a Sports Illustrated guy, Rick Riley, and various people got on board to send these mosquito nets to Africa, specially 
treated mosquito nets. Well, there was a really secular beginning point. A lot of people got involved. The United Methodist church got involved because people wanted the United Methodist church to get involved because they had more mission outposts in these areas than anyone else and the infrastructure to distribute the nets was already there. There are mission outposts all over Africa, working in conjunction with the United Nations and others who have worked closely with those types of organizations. You put out a call worldwide, $\$ 10$ to buy a net, and hundreds of thousands of those nets have been bought through our local churches all over the country. How are they going to pass them out? How are they going to get them hanging over the children's beds? Well, that's the reason the United Methodist Church got involved. There's already a huge network out there. By the time you take in churches, missionary compounds and mission projects, it would just overlap in a web in those regions that they're trying to reach.”

'Nothing But Nets' is not the only work of advocacy undertaken by the denomination. The Superintendent noted that,

"Advocacy in terms of the poor, is an extremely strong emphasis. We advocate for developing countries. Our ministries in third world countries. Our role in those areas. The marginalized. We advocate for those types of groups. Suffering, depression, go down the list I suppose, addressing poverty. Health, global health is also a huge advocacy issue. There are a lot of initiatives in regard to global health from HIV aids to malaria. We have huge programs for that and that's done well locally as well, that's a part of our conference.”

When asked how the United Methodist Church accomplishes this through its networks he

responded,

"That's actually one of the stronger suits I would think. The communication church-wide in regard to helping the poor, addressing suffering, healthcare, all of those things I mentioned, that network, both in terms of communication as well as on-site help is outstanding. Most local people know that. They know, for instance, in regard to world hunger. They know if they give to a feeding ministry in west Africa then $100 \%$ of those dollars will go to that ministry. Administration, fundraising, everything else is paid elsewhere. Someone designated they wanted to see $\$ 1000$, a $\$ 1000$ goes to the hospital. The communication has been very good."

This perspective of the District Superintendent was confirmed by the congregational leader responsible for local missions in the local United Methodist church. 
"It's easy to get people to respond to poverty if they can put a face to what they're doing. Poverty's such a big thing and it is hard to know how to make a difference. I started to think about UMCOR (United Methodist Committee On Relief). If you send your money there, $100 \%$ goes to their causes. I thought it would be neat to educate this congregation on UMCOR...We're going to start [a] trip with a mission and visit all the United Methodist missions in West Virginia just so someone in the church can see all the different projects. They'll be more likely to donate. People can come back and talk about what they've experienced. I'm trying to connect this church more to the United Methodist.”

United Methodism is not the only church hierarchy with structures that are organization-wide and that seek to bring transformation on many levels. The denominationally-sponsored organization Catholic Charities draws on local Catholic Churches to present a global outreach program to impact communities and countries in need. According to the Catholic Priest interviewed in this study, "In Catholic Charities we have a local social concerns committee that mirrors what's done at the national level. There's not a flow up of funds. Not that there couldn't be. It's not necessarily a flow. We have a lot of special collections for this, that, and the other and so that is how they are funded.”

These emergent denominational powers and properties, which are facilitated through national and international offices with trained staff members, look very different from the approaches utilized by the Independent church in Harrison County, particularly in terms of strategic intervention in national and international initiatives. In the Independent church, missions beyond the community are based on relationships and networks of local congregational adherents with other individuals or churches in another State or country. According to the local pastor,

"Specifically for us, it's rather focused on Cambodia. Around 1999 or 2000 we were a few years old. We prayed for God to give us a mission's focus. I had been a part of a church where we supported twenty-five missionaries. We 
decided we really wanted to focus on a single church instead. The nature of how we were sent there was partially Holy Spirit and partially connections. We connected with Four Square and Christian \& Missionary Alliance Churches. We connected with those denominations because they were already on the ground. Most specifically, the Fourth Square.”

When asked if the church contacted these mission fields through the denominational offices or through the local congregations themselves he responded,

"Local. We don't go through any national denominational entity. It's a direct relationship and direct support. That causes some tension with the missionaries. We support specific projects. We send about $\$ 20,000$ every quarter, so about $\$ 100,000$ a year to orphanages. It doesn’t go to the pocket of the pastor. It's for the orphan hall. That's our big focus. We have a few missionaries from our church and we support them. We have a few missionaries who have grown up in our church and we support them, but almost all of the foreign missions are in Cambodia.

The contrast between mission support and outreach in the Independent church and outreach in the denominational churches are effective and important demonstrations of congregational outreach and yet they are operationalized in very different ways.

Emergent powers and mechanisms exist in the denominational structures that are not possible in the present structure of the Independent church. Powers and mechanisms exist in local churches, including independent churches even though they do not have a strictly defined hierarchical structure, that have an impact at national and international scales. Yet, without the emergent powers of a church hierarchy this impact is arguably different. Thus while all three churches supported global outreach, the mechanisms and the emergent powers arising from these three church initiatives differed as the emergent powers of the church hierarchy came into play.

Over the course of the last forty years more independent churches have entered the religious landscape of North America, leading to a growing loss of the emergent stratum previously present in the upper levels of most church hierarchies. The adjacent 
counties to Harrison County, that of Marion County and Monongalia County, West Virginia, have both been significantly impacted through the growth of independent megachurches. This trend is notable in the Appalachian undercount, but it is also significant as more and more churches function without the emergent hierarchical church strata. This was illustrated through the Independent church's international mission strategy that was centered entirely upon local contacts rather than through a hierarchical church international strategy.

\section{A Non-Reductionist Geography of Religion}

An important aspect of emergence in CR is that it is non-reductionist. Phenomena at one layer, such as water, cannot meaningfully be reduced to the interactions of the parts such as the molecules of hydrogen or oxygen in water. Phenomena at each level are irreducible, even though one stratum may be composed of others. Denominations cannot be reduced to churches, nor can churches be reduced to small-groups or individual adherents. The emergence of a church is the magnification of powers already present, but not reduced to those found among individual adherents. Churches and entities can give or take, build or destroy, forgive or accuse, or even sue or be sued, just like individual adherents. Yet, the congregation cannot be reduced. Conflict within churches exemplify this aspect of irreducibility because conflict demonstrates that even while churches may appear to act as though they are in one accord, there is actually significant contestation and disagreement that occurs 'beneath the surface'. Occasionally disagreement and conflict exists within and between the relationships of adherents in congregations, even though the church itself might seem to 
act as one body. Many issues of contestation and disagreement came to the surface in the interviews with congregational leaders, and these conflicts and disagreements testify to the irreducibility of the emergence of a congregation. In the Catholic church this issue included disagreements along generational lines about broader denominational issues, as well as about local ethnic tension. As the Priest stated,

"Every denomination that I am aware of has a problem with a group out there who thinks if we go back to 1950 everything will be hunky dorey. For us that means going back to Latin. Understand that I do not have a problem with the Latin liturgy. What I have a concern with is that people are not being honest with some of the younger generation and saying that the Latin was the vernacular."

A perhaps less contentious quote came from a member who boldly proclaimed, "Only Italians can make real meatballs!”

Disagreements were also found among the United Methodist congregation regarding both denominational and local issues. One leader was very critical of the process used by the church hierarchy to select pastors, stating,

“Supposedly they pray about it and they pray to be led by God. I just don't believe that that happens. It's political, without a doubt. If someone says they pray about it, but when everyone can look at the structure and figure out who's going to be sent where, that's not all prayer. I think sometimes it's just political period. Just like everything else.”

Conflict within a church can be very intense and can elicit considerable pathos. The United Methodist pastor in his interview stated, “A conflict at a congregational level versus a denomination level is night and day. A small group could even be more intense. They feel it more intensely. It is more personal. It hits closer to home.” One congregational leader lamented,

"Within the local church, I think the pastor maneuvers the committees especially nominating and key leadership committees to get people in key positions that they want people in. This is in all United Methodist Churches - 
not just here. The pastor always wants to know who's going to be on certain committees. I understand it, but sometimes I get cynical over that. I've seen a lot of politics in the church.”

One of the more interesting comments came from a lay Methodist leader who was frustrated about the local church's neglect of the church hierarchy. "One of my pet peeves is that it's ok to blow off the denomination. They downplay district meetings; they downplay the things the conference sponsors. They don't give much participation and when they do, it's grudging.”

The Independent church also had disagreements and conflicts. One small group leader stated,

"We had a couple of men that were gay... This church had counseled them. I can't say they were frustrated but they didn't want to change. The love's still there but they didn't want to give up their lifestyle. I always felt that God made them and we're supposed to love everybody. I know a few people left the church because they found out they were in the church. At first they were singing and they backed them off of that. They backed them off of leading a cell group. I think [they] probably lied to the leadership. It was really a tough time. I was having problems with my heart and that didn't help anything. My worry was if I was doing the right thing. I had to get some counseling myself."

The powers of the ideologies that knit together the complex relational fabric of a church are multi-faceted and contested. To picture a church as a collection of completely like-minded individuals acting in one accord without conflict or contestation would be as perilous as Zelinsky (1961) arguing for one superorganic culture in America while race riots were occurring in its streets. The agency and uniqueness of each adherent must remain in the complexity of the voluntary fellowship of a church. An emergent geography of religious adherence captures this and allows both the church as a corporate whole, and the individuals of which it is comprised, to co-exist without reducing one to the other. 


\section{A Methodologically Pluralistic Geography of Religion}

A final implication of emergence is that the questions pertaining to adherents, churches and church hierarchy are unique to the powers and mechanisms functioning at each stratum. CR recognizes that the object of study is the critical determining factor in selecting an appropriate methodology. What is argued in this work is that as a conceptual framework CR's methodological pluralism and stratified emergent powers can be used not only to expose and illuminate the scaled nature of the geography of religious adherence and fidelity, but also permit a spectrum of methodologies by which this scale dilemma could be addressed and perhaps resolved.

In order to critically reframe the issues of scale dependence in the geography of religious adherence, it is necessary to acknowledge the stratification inherent in the concept of adherence. Studies on adherence to date are predominately based on the aggregation of county estimates using denominationally reported data. This emphasis results in the identification of nominal regions, religious concentration clusters, distributions, and diversity. Curiously, even though church hierarchies and national leaders collate the data, very little reflection is made in the literature concerning the powers and mechanisms that operate at the national scale of analysis, nor have the implications of this neglect been investigated. Specific choices are made by particular agents in positions of power that determine the parameters of adherence for denominations such as the characteristics that determine membership and the geographic boundaries of ecclesiastical jurisdictions., These agents can also manipulate these parameters over time because of their position in the church hierarchy power structure. As discussed above, a denomination is not just an aggregation of adherents. Rather, it is 
a robust and complex network of relationships that functions according to a specified leadership structure, aligning the mission, vision and values of member churches and adherents while expending resources to impact social and even geo-political realities at national and international scales. This complexity is not reflected through the prevalent choroplethic county-boundary based maps of adherents. Scale and methodology matter!

The discussion of scaled relations and processes in chapter two is helpful in understanding the methodological complexities involved in the scale dependence of current studies in the geography of religious adherence. Ecologist Nathan Sayre (2005), not to be confused with critical realist Andrew Sayer (1992, 2000), noted that in nature, different processes occur at different scales and that processes change with scale. T. F. Allen (1998) had previously elucidated this idea through the illustration of the pond skater and the elephant by recognizing that the relationships between the size of the organisms and the surface tension of water is scaled, and that if a pond-skater could be genetically transformed into the size of an elephant it would no longer be able to stand on water because the physical processes that once enabled it to do so would not be functional.

By using adherent data aggregated to choroplethic county-based maps, the traditional approach to denominational mapping in GOR is framed in the epistemological moment of scale, in which one's choice of scale determines what is seen. In contrast, the ontological moment of scale conceptualizes scale in terms of relations, and therefore as being intrinsic to external realities. In the ontological moment, the magnified pond-skater would sink because of its relation to the surface tension of water. Traditional studies of religious adherence in North America, in the epistemological moment of scale, neglect 
the processes in churches that exist across levels of social organization. Churches do not emerge into a stratified layer of predefined and artificially constructed county boundaries, and national studies based on counties do not easily enable the discovery of new powers and mechanisms buried in the strata. Rather, churches emerge into sects, denominations and associations whose spatial extents vary. Some denominations use county boundaries to bureaucratically delineate districts, parishes or conferences, in which new powers and mechanisms could arguably emerge, but these are not consistent across religious entities. The adoption of the county as the base areal unit yields subsequently forced questions and influences, if not determines, the insights that can be gained concerning the geography of religious adherence in North America.

An interesting point in this case study regarding this methodological dilemma is to be seen in the geography of the Wesleyan District of the United Methodist church. To the best knowledge of the District Superintendent, the only existing map of the churches in his district is patched together on his office wall from a number of West Virginia highway maps. Colored flags mark various circuits on the map that includes all of Upshur, Lewis, Gilmer, Braxton, Randolph, and portions of Nicholas, Pocahontas, Webster and Harrison Counties. According to the Superintendent, "Harrison is probably, 
Figure 7.1: The only existing map of churches in the Wesleyan

District of the West Virginia United Methodist Conference.

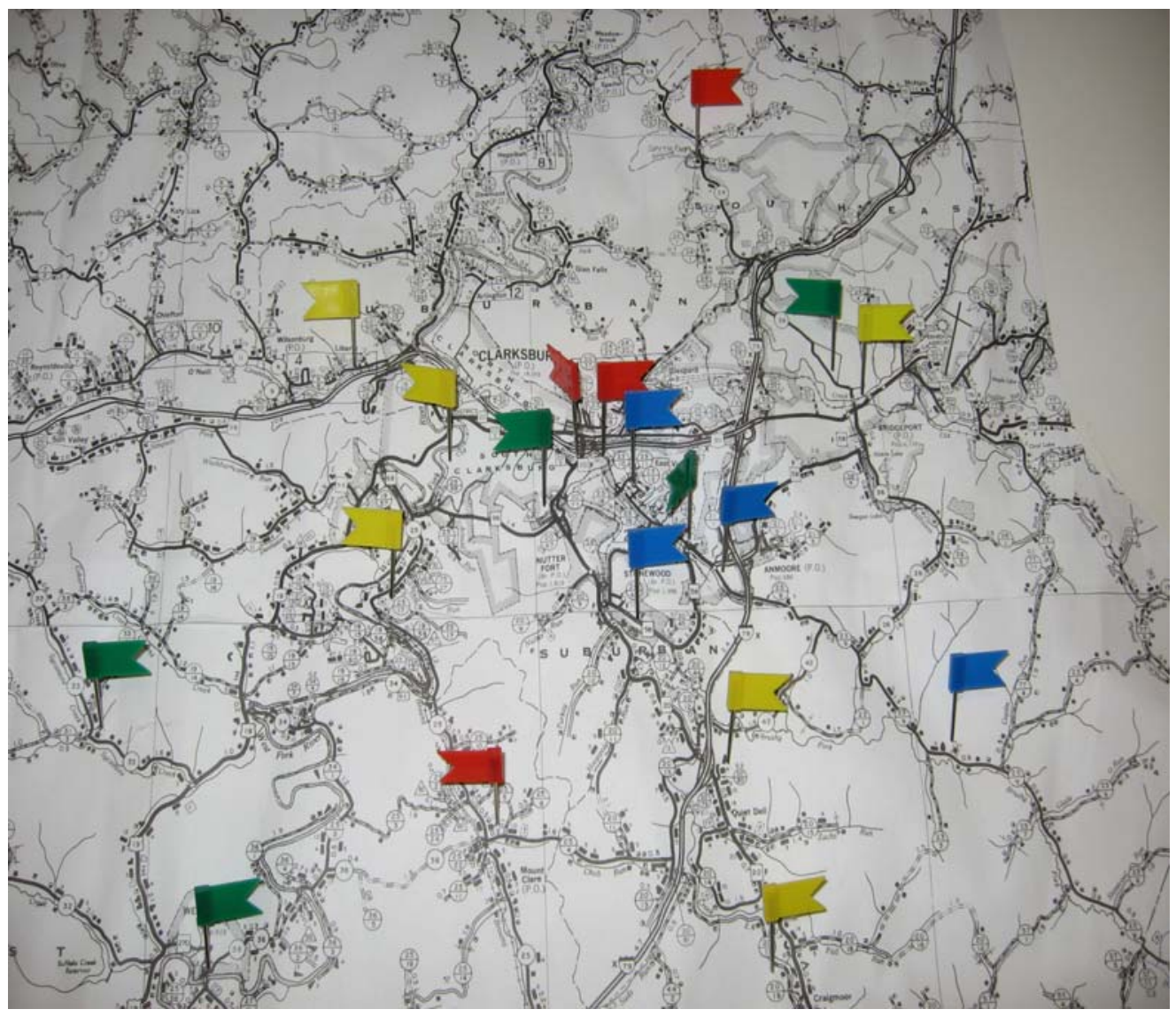

in terms of my district, the most split county. In the other ones I just bleed into the counties with two or three churches." Circuits are groups of churches that are connected through a common clergy member. Some circuits include churches with such small populations that a single pastor can oversee up to six congregations. Significantly, some of the circuits cross county boundaries, a fact that was not at all disconcerting to the Superintendent. "Why they did it, I'm not sure. See, we went some years back from eleven districts to nine. And so they had to reconfigure the boundaries and I think it had to do more with people's travel patterns more than anything else.” Yet, each church is 
also numbered and is connected to a specific geography, which is later separated from this administrative structure and aggregated by county boundaries. Hence, a single church in a charge of six led by the same pastor could be included in the statistics of other churches belonging to an entirely different district. This locally-driven boundary determination, and its jurisdictional implications across ecclesiastical boundaries, is not revealed at the national level at which the church hierarchy reports its data. Traditional aggregative methodologies do not account for these complexities.

Furthermore, national studies of denominations using adherent data that is aggregated to the scale of the county do not consider the emergence of new powers and mechanisms that enable church hierarchies to impact national and global geo-political realities. These powers have emerged from the individual adherents, but now have new powers and mechanisms based in the emergent denominational structure that were not present at the scale of the congregation. The parallel described in chapter three involved chemists attempting to describe the powers and mechanisms of water only by discussing the powers and mechanisms of hydrogen and oxygen molecules. The fusion of these atomic elements has created something entirely new with new powers and mechanisms that were not present at the subatomic scale. Churches have powers that individual adherents do not possess, even though churches emerge from the combined actions of adherents. In turn, churches organize themselves into denominations and associations, with accompanying powers, mechanisms, relationships and processes not previously present at the scale of the individual church. This distinction can only be ascertained through emergence, irreducibility and the use of pluralistic methodologies. 
The structure of the United Methodist church can once again serve to illustrate the need for pluralistic methodologies in that the district, which is comprised of several congregations, has its own staffed office that supervises and mentors local pastors and represents local issues at the conference level, which is comprised of districts. A methodology based upon simply aggregating the adherents to county units neglects the other important methodologies such as interviewing crucial agents in the upper echelons of the denominational structure. For instance, the United Methodist District Superintendent describes his role as "an extension of the Episcopal office in a certain region... I've become a face and a voice for what's happening at the larger level.”

Figure 7.2: Office of the Wesleyan District of the West Virginia United Methodist Conference.

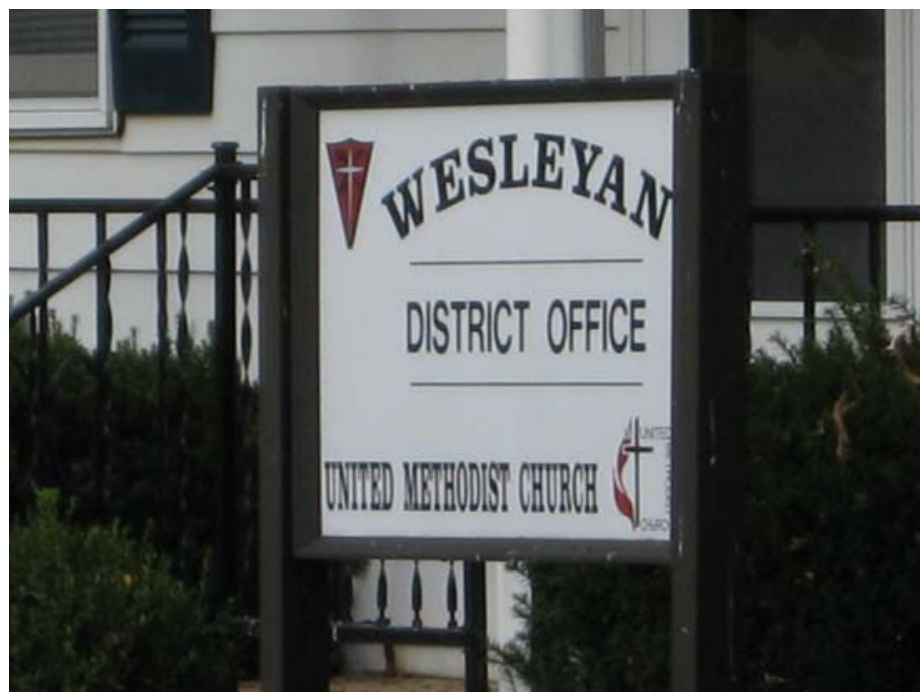

Similarly, a Vicar in the Wheeling-Charleston Diocese of the Catholic Church supervises and mentors numerous priests, yet according to one priest the role of the priest is not as powerful as the District Superintendent in the United Methodist Church.

"In the Catholic community, we're organized along dioceses. The Vicars do not have much power in the Catholic community, but he is the Bishop's direct representative. His role is to coordinate all the parishes, but he doesn't have 
the power to force the issue. What the pastors do is try to take the teaching of the bishops and then put that into practice within parishes so there's a tie in between parish, dioceses and then tied to the bishop of Rome so there's a unity in that process. We're community builders. We try to develop the idea that there is a central deposit of faith.”

Approaches that utilize pluralistic methodologies capture these important nuances and better reveal the scaled emergent nature of geography of religion.

\section{Geography of Religious Adherence and Geography of Religious Adherents}

The transition from a geography of religion focused on adherents to a geography of religion focused on emergent irreducible entities, and the methodological implications of this distinction, requires a specific nomenclature. It is suggested here that beginning at the scale of the church, it may be necessary to distinguish between a geography of religious 'adherence' and a geography of religious 'adherents'. A geography of religious adherence would involve the relations, processes and mechanisms surrounding why, when, where and how a specific adherent attends, participates and relates to a specific congregation and how this participation impacts the organization at other scales such as the church, parish or denomination. The geography of religious 'adherents' would involve a statistical accounting or estimate of how many adherents attend a specific church in a particular place and include general, aggregated characteristics of those adherents.

A study in the geography of religious adherence would, by necessity, incorporate the scale of the adherent, but would not neglect emergent bodies through aggregation. The geography of religious adherents would generally function in the same manner as the nationally-driven approach discussed in chapter four. This definitional distinction is 
important, as it associates the study of adherence with relations, processes and mechanisms and the study of adherents with statistical aggregations. In the past the geography of adherents has been used as a surrogate for the geography of adherence and, in turn, county-based aggregate totals have been used to evaluate the health of a corporate ecclesial body, be it a church or a denomination. In the geography of religious adherence, other important criteria become apparent. A methodologically pluralistic critical realist study in the GOR could be oriented toward either approach, but would arguably be more concerned with adherence without neglecting the value of adherent studies because it would place central importance on the relations and processes that emerge at differing scales.

A geography of religious adherence is focused on asking questions rooted in relationships and processes in order to discern emergent properties and mechanisms. A geography of religious adherents on the other hand, is interested in asking questions rooted in tallies and statistics in order to gauge the state of a religious body that is then based primarily on numbers.

\section{Conclusion}

The geography of religion in Harrison County has been shown to be emergent and irreducible. A robust understanding of the geography of religion cannot simply consist of choroplethic maps aggregated to county boundaries. This approach neglects the presence of agents and offices operating in church hierarchies at scales beyond, or below, that of the congregation. While the individual adherent is the non-modifiable unit in the geography of religious adherence, numerous scales with associated emergent powers 
exist beyond the adherent including the congregation and the denomination. These emergent congregational and denominational powers and properties, which are facilitated through scaled structures and hierarchies, do not reduce the non-modifiable adherents. Rather, the new mechanisms and powers functioning at these emergent scales must be explored using approaches appropriate to the scale in question. Because questions pertaining to adherents, churches and church hierarchies are unique to the powers and mechanisms functioning at each stratum, methodological pluralism is necessary for a robust geography of religion.

In the light of this study, a new nomenclature is necessary to distinguish between traditional aggregative numerical approaches and the insight provided by an emergent and irreducible approach as proposed in this study. It is suggested that this latter approach is better described as the geography of religious 'adherence,' and involve the relations, processes and mechanisms surrounding why, when, where and how a specific adherent attends, participates and relates to a specific congregation, and how this participation impacts the organization at other scales such as the church, parish or denomination. The traditional approach is more appropriately described as the geography of religious 'adherents,' and involves a numerical accounting of how many adherents attend a specific church in a particular place and include general, aggregated characteristics of those adherents. Importantly, these aggregate statistics are irreducible and could only be used to assess the geography of religious adherence with extreme caution - if at all. 


\section{Chapter 8 Conclusion}

It should be evident from the preceding chapters that the implications of a scaled and stratified GOR are significant. This is not surprising given that a review of the scale question in human geography in general reveals a staggering array of perspectives, definitions, and oftentimes total disagreement for a subject that many claim lies at the core of Geography. This study explored both the issues surrounding scale in the context of the geography of religious adherence and examined the contributions of critical realism (CR) as a means of unpacking the term scale and introducing perhaps more meaningful conceptions of what is a scaled GOR. This final chapter summarizes the findings of this study and suggests avenues for future enquiry.

\section{Summary of Findings}

In seeking to answer the question, "What is scale?” chapter two explored the epistemological and ontological dimensions of cartographic, methodological, and geographical conceptions of scale. Four common metaphors for scale were identified in the literature: the ladder, the circle, the Matryoshka doll, and the network. The ladder, or hierarchical scale, is by far the most common conception and approach to scalar issues in geography. It is also evident that ecological fallacy and the MAUP are common if not endemic problems in spatial studies. The recent Marston / Brenner debate in human geography, which focused on how scale is socially produced, positioned scale not as a hierarchical structure but as a process in which multiple scales are intertwined and work together as relational processes or dimensions of social practice. While there has been little debate concerning the epistemological and ontological dimensions of scale in GOR 
literature, in practice many levels of scaled analysis are used, either explicitly or implicitly. Chapter four provided a general review of scale as currently used in GOR and then focused more specifically on the issue of scale in the geography of religious adherence. The foundational unit in the geography of religious adherence is the individual, and yet most GOR studies aggregate this 'unit' to focus on other scales, the most prominent being the county, especially in national level studies.

The second objective of this study was to conceptually examine the potential of CR as a means of exploring scalar issues in GOR and more broadly in human geography. Chapter three explored the epistemological and ontological complexities of CR and firmly rooted the discussion of scale in a hierarchy of mechanistic strata. The various objects in these strata have emergent and irreducible powers and liabilities. Emergence occurs "when the properties of underlying strata have been combined," and "qualitatively new objects have come into existence, each with its own specific structures, forces, powers and mechanisms” (Danermark et al., 1997, 60). Using the concept of emergence as a lens through which to examine scaled GOR represents a significant theme in this study. Chapter four expanded upon the literature reviews of scale and critical realism to specifically address these scalar challenges in the geography of religious adherence using emergence and CR. Through the ontology, epistemology and methodology of CR, it is possible to recognize how the deep mechanisms and scalar structures of individual religious adherents, organized groups of adherents, and national associations of churches and denominations can be studied by identifying and acknowledging emergent levels of relations and processes at different scales. 
The third objective was to undertake a case study in West Virginia to explore Christian religious adherence at multiple scales of investigation. In the light of the complex ways that adherence, denominationalism, fideism, and faith are intricately linked across scales, fidelity in three Harrison County, WV churches was selected as a theme for further scalar inquiry. The results of this work are reflected in chapter six which identifies mechanisms and operational powers that emerge in the congregation and church structures that function to enhance congregational or denominational fidelity. A telling metaphor was a quote from the Roman Catholic priest who was interviewed in the study: “I’m sure every pastor fights this battle, can't see the forest [the denomination] for the tree [the local parish] is the way I see it. My struggle is to get people to see the forest, not the tree.” Surveys, interviews and focus groups in the case study demonstrated that the Roman Catholic congregation is dominated by the "forest" of the Catholic Church hierarchy, whereas the Methodist Church remained loosely connected to its "forest" while placing greater emphasis upon the "tree", and the Independent church was almost entirely focused on the scale of the "tree".

Chapter seven demonstrated how the emergent congregational and denominational powers and properties are facilitated through scaled structures and hierarchies. Congregations were shown to possess emergent properties that were not reducible to the scale of the adherent such as the physical structure of the church building, collective ideologies, and a number of church programs. Additionally, denominational hierarchies were shown to possess emergent properties that were not present at, nor reducible to, the scale of the congregation or adherent such as the operation of denominational agents and offices, denominational missions and advocacy work. This study concluded with the 
proposition that a new nomenclature is necessary in GOR to help distinguish between traditional aggregative numerical approaches and a critical realist emergent and irreducible approach. Using this nomenclature, the geography of religious 'adherence' involves the relations, processes and mechanisms surrounding why, when, where and how a specific adherent attends, participates and relates to a specific congregation, and how this participation impacts the organization at other scales such as the church, parish or denomination. In contrast the geography of religious 'adherents' involves the quantitative analysis of churches and aggregated groups of churches.

Finally, the fifth objective of this research was to evaluate scale in GOR and explore how this particular study might contribute to the understanding of scale in human geography. In the context of this study fidelity was used as a means to investigate scale and emergence. Table 8.1 illustrates a summary representation of three potential types of fidelity seen to be present across scales in a Christian religious hierarchy.

Table 8.1: Three Types of Fidelity

\begin{tabular}{|c|c|c|c|c|c|c|c|}
\hline & & \multicolumn{6}{|c|}{ Fidelity of: } \\
\hline \multirow{4}{*}{$\begin{array}{c}\text { Fidelity } \\
\text { to: }\end{array}$} & & Adherent & Family & Small Group & Congregation & $\begin{array}{c}\text { Denominational } \\
\text { Sub-structure }\end{array}$ & Denomination \\
\hline & God & $\begin{array}{l}\text { Loyalty of an } \\
\text { adherent to } \\
\text { God }\end{array}$ & $\begin{array}{l}\text { Loyalty of a } \\
\text { family to } \\
\text { God }\end{array}$ & $\begin{array}{l}\text { Loyalty of a } \\
\text { small group } \\
\text { to God }\end{array}$ & $\begin{array}{l}\text { Loyalty of a } \\
\text { congregation } \\
\text { to God }\end{array}$ & $\begin{array}{l}\text { Loyalty of a } \\
\text { denominational } \\
\text { sub-structure to } \\
\text { God }\end{array}$ & $\begin{array}{l}\text { Loyalty of a } \\
\text { denomination } \\
\text { to God }\end{array}$ \\
\hline & $\begin{array}{l}\text { The } \\
\text { Congregation }\end{array}$ & $\begin{array}{l}\text { Loyalty of } \\
\text { the adherent } \\
\text { to a } \\
\text { congregation }\end{array}$ & $\begin{array}{l}\text { Loyalty of } \\
\text { the family to } \\
\text { a } \\
\text { congregation }\end{array}$ & $\begin{array}{l}\text { Loyalty of } \\
\text { the small } \\
\text { group to a } \\
\text { congregation }\end{array}$ & & $\begin{array}{l}\text { Loyalty of the } \\
\text { denominational } \\
\text { sub-structure to } \\
\text { a particular } \\
\text { congregation }\end{array}$ & $\begin{array}{l}\text { Loyalty of the } \\
\text { denomination } \\
\text { to a particular } \\
\text { congregation }\end{array}$ \\
\hline & $\begin{array}{l}\text { The } \\
\text { Denomination }\end{array}$ & $\begin{array}{l}\text { Loyalty of } \\
\text { the adherent } \\
\text { to a } \\
\text { denomination }\end{array}$ & $\begin{array}{l}\text { Loyalty of } \\
\text { the family to } \\
\text { a } \\
\text { denomination }\end{array}$ & $\begin{array}{l}\text { Loyalty of } \\
\text { the small } \\
\text { group to a } \\
\text { denomination }\end{array}$ & $\begin{array}{l}\text { Loyalty of } \\
\text { the } \\
\text { congregation } \\
\text { to a } \\
\text { denomination }\end{array}$ & $\begin{array}{l}\text { Loyalty of the } \\
\text { denominational } \\
\text { sub-structure to } \\
\text { a denomination }\end{array}$ & \\
\hline
\end{tabular}

Hypothetically, a researcher studying fidelity to a congregation would potentially utilize multiple scales as indicated by the table, yet the study would nonetheless be posing questions from the perspective of the congregational scale. The major point is 
that the scale at which a question is asked must determine the pre-eminent scale of the study because it reveals the processes and patterns that arise at that scale. Yet, other scales impact the congregation in substantial ways. For instance, a denomination lays out the doctrine, beliefs, practices and norms of the collective body, which is further reinforced in the denominational sub-structure, congregations, and most likely in the small church groups such as Sunday School and Bible Study groups. Additionally, the scale of the family is important because it is, according to Stump (2008, 250), "the foundation of the larger social order" and "the immediate setting for the reproduction of core beliefs and practices.” The congregation may be considered a critical scale since again according to Stump (2008, 224), “social and cultural processes operating at the communal scale represent the principal means by which believers promote orthodoxy and orthopraxy within their group, typically through the intersecting influences of familial and peer pressures, community sanctions, formal institutions, and local religious and lay leaders.” Yet, the scale of the congregation is not pre-eminent for ontological reasons, but rather because it is from this scale that the research questions are being posed. Questions are scale dependent.

This discussion leads to the conclusion that in order to avoid ecological fallacy specific insights can only reasonably be gleaned depending on the symbiotic relationship between the question(s) being asked and the scale at which a study is undertaken. For instance, consider a research program investigating fidelity to God (Table 8.2). 
Table 8.2: Fidelity to God

\begin{tabular}{|l|l|}
\hline \multicolumn{1}{|c|}{ Scale: } & \multicolumn{1}{c|}{ Insights that emerge in regard to fidelity to God: } \\
\hline Individual & $\begin{array}{l}\text { Degree of fidelity to God; Beliefs and practices; Conflict and } \\
\text { contestation with denominational beliefs and practices }\end{array}$ \\
\hline Family & $\begin{array}{l}\text { Consistency with faith of family members; Pressure to conform / } \\
\text { convert / reject faith; Place of primary spiritual education of children } \\
\text { (faith development). }\end{array}$ \\
\hline Small Group & $\begin{array}{l}\text { Beliefs and practices confirmed, questioned, rejected. Small group as } \\
\text { hub of evangelism (spread the faith); “Cell group model” - small groups } \\
\text { grow and multiply like cells of an organism to increase the number of the } \\
\text { faithful. }\end{array}$ \\
\hline Congregation & $\begin{array}{l}\text { Beliefs and practices confirmed, questioned, rejected; Practices / beliefs } \\
\text { impact the scale of the broader community (homeless / hungry); Number } \\
\text { of faithful (report to denomination); Corporate conflict and contestation } \\
\text { with beliefs / practices of the denomination }\end{array}$ \\
\hline $\begin{array}{l}\text { Denomination } \\
\text { Sub-structure }\end{array}$ & $\begin{array}{l}\text { Orthodoxy and Orthopraxy communicated / enforced among } \\
\text { congregations }\end{array}$ \\
\hline Denomination & \begin{tabular}{l} 
Standards of Orthodoxy (belief), Standards of Orthopraxy (practice) \\
\hline
\end{tabular} \\
\hline
\end{tabular}

These insights are in contrast to table 8.3 and table 8.4, which demonstrate the insight that could emerge in pursuit of questions surrounding fidelity to a congregation or to a denomination. 
Table 8.3: Fidelity to Congregation

\begin{tabular}{|c|c|}
\hline Scale: & Insights that emerge with regard to fidelity to Congregation: \\
\hline Individual & $\begin{array}{l}\text { Degree of fidelity to congregation; Evangelism - bringing others into } \\
\text { congregation; Competition of congregational activities with other life } \\
\text { roles; Frequency of attendance; Sense of belonging; Participation in } \\
\text { leadership, Impact of ministry constellation to congregational fidelity } \\
\text { (family ministry / worship style / size of congregation) }\end{array}$ \\
\hline Family & Place of formation of congregational fidelity for children \\
\hline Small Group & $\begin{array}{l}\text { Small group as hub of evangelism (increase congregational fidelity); } \\
\text { Relationships with people in small group compared to relationship with } \\
\text { pastor; Worship style }\end{array}$ \\
\hline Congregation & PRIMARY SCALE \\
\hline $\begin{array}{l}\text { Denomination } \\
\text { Sub-structure }\end{array}$ & $\begin{array}{l}\text { Leadership and empowerment to congregation; Enhanced impact in } \\
\text { community (positive feedback loop in congregation) }\end{array}$ \\
\hline Denomination & $\begin{array}{l}\text { How to resource congregations to continue fostering congregational } \\
\text { fidelity; Direction of doctrine / polity / mission for congregation; } \\
\text { Provision of training / retreats / conferences; Enhanced impact globally } \\
\text { (positive feedback loop in congregation) }\end{array}$ \\
\hline
\end{tabular}

Table 8.4: Fidelity to Denomination

\begin{tabular}{|l|l|}
\hline Scale: & \multicolumn{1}{|c|}{$\begin{array}{c}\text { Insights that emerge with regard to fidelity to Denomination } \\
\text { (Denominationalism): }\end{array}$} \\
\hline Individual & $\begin{array}{l}\text { Commitment of individual to denomination; Financial giving; Number } \\
\text { of adherents; Location of adherents; Longevity of adherence to } \\
\text { denomination (especially after a move) }\end{array}$ \\
\hline Family & $\begin{array}{l}\text { Impact of denominational norms on family practices (especially gender, } \\
\text { discipline of children, educational preference - home school or Christian } \\
\text { schooling) }\end{array}$ \\
\hline Congregation & $\begin{array}{l}\text { Commitment of congregation to denomination (money / apportionments } \\
\text { / leadership); Number of churches; Location of churches; Use of } \\
\text { preaching to enhance denominational loyalty. }\end{array}$ \\
\hline $\begin{array}{l}\text { Denomination } \\
\text { Sub-structure }\end{array}$ & $\begin{array}{l}\text { Interaction of constellation of local churches. Staff; Central Office; } \\
\text { How organized; Bridge between denomination and local congregations } \\
\text { (fostering denominational loyalty) }\end{array}$ \\
\hline Denomination & \begin{tabular}{l} 
Primary Scale \\
\hline
\end{tabular} \\
\hline
\end{tabular}


These tables reveal the complex and intricate ways in which scale, questions posed, and resulting explanation are entwined. Yet, while queries can be posed at a spectrum of levels of analysis from individual to congregation to denomination, they cannot be infinitely simplified. The individual adherent is ultimately the nonmodifiable unit in the geography of religious adherence.

\section{Future Research}

There are many potential points of further research that arise based on the outcomes of this study. First, the concept of an emergent GOR is valuable as it brings attention to the inherent dangers of ecological fallacy and provides a means by which studies might proceed in a more informed and scale sensitive fashion. Subsequent studies could reveal more valuable insights into GOR through the use of an emergent geography than traditional 'scaled' studies have produced to date.

Second, the use of methodological pluralism in studies of GOR could make valuable contributions to the field. This study focused upon scale in GOR and used surveys, interviews and focus groups to critique other scaled approaches used in GOR that, to date, have relied heavily on aggregations of adherent data with all the baggage that ecological fallacy entails. It is suggested that a methodological pluralism as propounded under CR would provide a valuable approach to uncovering ecclesiastical mechanisms and processes that remain hid in traditional single method studies.

Third, the preceding study was based on three Christian denominations that organize themselves in similar yet different ways. From the hierarchical structure of the Roman Catholic Church to the more cellular structure of the Independent church, it is 
interesting to speculate on how the structure of other Christian churches, and indeed nonChristian entities, are represented in an emergent geography of religion. Such a consideration, it is suggested, will not only cast further questions on national level studies of GOR but also shed light into how other belief systems operate, inter-relate and interact at emergent scales that are not drawn simply from a hierarchical notion of scaled space.

Fourth, this study demonstrates how scale is socially produced in different ways in different ecclesiastical settings in GOR. Chapter two described the significant contributions made by human geographers to our understanding of the social construction of scale in sub-disciplines such as economic and feminist geography. Further studies should be conducted in GOR to better understand how scale is socially constructed in other faith traditions.

Fifth, the implications of ecclesiastical emergence in other subdisciplines of geography should be explored. Actors at the scale of the Christian denomination frequently attempt to influence geopolitical entities and policies, such as federal poverty legislation and environmental policies. While communicated through denominational channels, it is clear from this study of emergent powers and relations that such positions may not be uniform across other church scales. Research on advocacy and lobbying from an ecclesiastic emergent perspective could illuminate these processes.

Sixth, scalar emergence should be explored in other subdisciplines of human geography. This study demonstrated the scaled nature of Christian religious organization and hierarchy. Countless other social, cultural and political institutions also possess emergent tendencies. 
Finally, investigation into the potential connections of actor network theory (ANT) and CR is warranted. Bruno Latour's theory is deeply realist in nature, but it is realist about the individual. ANT would be a significant critique of emergence in GOR because it would not recognize a stratified ontology. Scale in ANT would instead involve tracing the numerous networks involved in the various levels. One finding of this dissertation is that critical realism has the metaphysical capacity to incorporate ANT, but given the ANT focus on the scale of the individual acting adherents, it would be valuable to conduct a similar study to the one in this paper using only ANT.

\section{Conclusion}

GOR is a substantial and coherent sub-discipline of human geography that provides significant insight into the breadth and depth of religious traditions in their multifaceted contexts. Based on an analysis of the Christian tradition, this study has elucidated the complex nature of religious processes and mechanisms that operate at various ecclesiastical scales. This research has focused on unraveling the tight linkage that exists between scale and understanding in GOR that is rarely acknowledged or questioned by geographers of religion. By incorporating ecclesiastical emergence into GOR, religionists gain a valuable tool to appropriately examine the substantial ways in which religion impacts social, economic and environmental life. Furthermore, this study makes contributions to the broader scale debate in human geography by suggesting that a critical realist framework of emergence is a valuable contribution in acknowledging and understanding the complex dimensions of scale. 


\section{Bibliography}

Adams, P.C. (1996). Protest and scale politics of telecommunications. Political geography. 15, 419-42.

Agnew, J. (1997). The dramaturgy of horizons: geographical scale in the 'reconstruction of Italy' by the new Italian political parties, 1992-95. Political geography 16, 99122.

Alker, H. R. Jr. (1969). "A typology of ecological fallacies". In Mattei Dogan and Stein Rokkan (eds.), Quantitative ecological analysis in the social sciences, Cambridge: MIT press, 69-86.

Allen, T. (1998). The landscape 'level' is dead: persuading the family to take it off the respirator. In Peterson, D. and Parker, V. Ecological scale: Theory and applications. New York: Columbia university press. 35-54.

Ammerman, N.; Carroll, J; Dudley, C.; Eiesland, N.; McKinney, W.; Schreiter, S.; Thumma, S.; Warner, S. (2006). Studying Congregations. Nashville: Abingdon Press.

Ammerman, N. (2003). Congregation and community. New Brunswick: Rutgers university press.

Andrews, A. (1990). "Religious geography of Union County, Georgia" Journal of cultural geography. 10/2 1-19.

Archer, M. (1998). "Introduction: Realism in the social sciences.” In Archer M, Bhaskar B, Collier A, Lawson T; Norrie A. (ed). Critical realism: Essential readings. Routledge: New York.

. (1995). Realist social theory: The morphogenetic approach. New York: Cambridge.

. (1988.) Culture and agency: The place of culture in social theory. New York: Cambridge.

Bascom, J. (1998). The religious geography of evangelical Christians in North America. The Pennsylvania geographer. 36:1.

Bauer, J. (2006). Stability and change in United States religious regions, 1980 - 2000. $\mathrm{PhD}$ Dissertation, University of Kansas.

Bhaskar, R. and Danermark, B. (2006). Metatheory, interdisciplinarity and disability research: A critical realist perspective. Scandanavian journal of disability research. 8:4. 
Bhaskar, R. (1998). “General introduction.” In Archer, M; Bhaskar, B; Collier, A; Lawson, T; Norrie, A. (ed). Critical realism: Essential readings. Routledge: New York. (1998b). The possibility of naturalism. Harvester Press: Hassocks. (1979). The possibility of naturalism. $3^{\text {rd }}$ Edition. Routledge: New York. (1975). A realist theory of science. Verso: New York.

Bird, J. 1989. The changing worlds of geography, A critical guide to concepts and methods. Oxford, England: Clarendon press.

Brenner, N. (2001). The limits to scale? Methodological reflections on scalar structuration. Progress in human geography. 25:4. 591-614. . (1997). State territorial restructuring and the production of spatial scale: urban and regional planning in the Federal Republic of Germany, 1960-1990. Political geography. 16, 273-306.

(1997b). Global, fragmented, hierarchical: Henri Lefebvre’s geographies of globalization. Public culture. 24, 135-67.

Brown, M. (1995). Sex, scale and the 'new urban politics': HIV-prevention strategies from Yaletown, Vancouver. In Bell, D and Valentine, G. (eds) Mapping desire: Geographies of sexualities. London and New York: Routledge, 245-63.

Brown, S. Cannon, Donald. Jackson, Richard. (1994). Historical atlas of Mormonism. New York, NY: Simon and Schuster.

Carroll, B. (2000). The Routledge historical atlas of religion in America. New York: Routledge.

Casey, E. (1987). Remembering: A phenomenological study. Bloomington IN: Indiana University Press.

Chidester, D. \& Linenthal, E. (1995). Introduction. In Chidester, D. \& Linenthal, E. (eds.) American sacred space. Bloomington, IN: Indiana university press.

Cloke, P. Philo, C., Sadler, D. (1991). Approaching human geography: An introduction to contemporary theoretical debates. New York: Guilford.

Collier, A. 1994. Critical realism: An introduction to Roy Bhaskar's philosophy. Verso: New York. 
Colwell, R. (2004). The new landscape of science: A geographical portal. Annals of the association of American geographers. 94:4.

Corbett, J. M. (1993). Religion in the United States: Notes toward a new classification. Religion and American culture. 3: 91-112.

Cox, K. (1998). Spaces of dependence, spaces of engagement and the politics of scale, or: looking for local politics. Political geography. 17, 1-24. (1996). Editorial: the difference that scale makes. Political geography. 15, 667-70. . (1995). Globalization, competition and the politics of local economic development. Urban studies. 32, 213-24.

Danermark, B., Ekstrom, M., Jakobsen, L., Karlsson, J. (1997). Explaining society: Critical realism in the social sciences. New York: Routledge.

Deleuze, G. Guatarrie, F. (1987). A thousand plateaus: Capitalism and schizophrenia. University of Minnesota press: Minneapolis.

Editors of the American heritage dictionaries. (2006). American heritage dictionary. Fourth Edition. Boston: Houghton Mifflin.

Eliade, M. (1968). The sacred and profane: the nature of religion. Harvest Books.

Ferber, M. (2010). “Religion, geography and.” Encyclopedia of geography. Sage. B. Warf (ed.). (2006). “Critical realism and religion: objectivity and the insider / outsider problem.” Annals of the association of American geographers. 96(1) 176-181.

Ferber, M. Harris, T. (2003). "A Critique of cartographic approaches to mapping religion in North America", The association of American geographers 99th annual meeting. New Orleans, LA.

Gaustad, E., Barlow, P, Dishno, R. (2001). New historical atlas of religion in America. Ney York, NY: Oxford University Press.

Gaustad, E. (1962). Historical atlas of religion in America. New York: Harper \& Row.

Gibson, J. (1966). The senses as perceptual systems, New York: Houghton Mifflin Co.

Haggett, P. (1965). Scale components in geographical problems. In R.J. Chorley, and P. Haggett (eds) Frontiers in geographical teaching. Methuen and Co Ltd, pp. 164185. 
Halvorson, P. Newman, W. (1978). Atlas of religious change in America. Washington: Glenmary.

Harre, R. and Secord, P. (1972.) The explanation of social behavior. Oxford: Blackwell.

Harre, R. (1979.) Social being. Oxford: Blackwell.

Harris, T. (2006). Scale as artifact: GIS, ecological fallacy, and archaeological analysis. In Lock, G. and Molyneaux, B. Confronting scale in archaeology. New York: Springer.

Henkel, R. (2005). Geography of religion: Rediscovering a sub-discipline. Hrvatski Geografski Glasnik. 67/1 5-25.

Herod, A. (editor). (1998). Organizing the Landscape: Geographical Perspectives on Labor Unionism. University of Minnesota Press: Minneapolis and London.

Herod, A \& Wright, M. (2002). Placing scale: An introduction. In Herod, A. \& Wright, M. Geographies of power: Placing scale. Oxford: Blackwell.

Hess, M. (2004). 'Spatial' relationships? Towards a reconceptualization of embeddedness. Progress in human geography. 28:2. 165-186.

Holloway J, (2006) Enchanted spaces: The séance, affect and geographies of religion, Annals of the association of American geographers, 96(1), 182-187.

. (2000). Institutional geographies of the New Age movement. Geoforum. 31:553565.

Howitt, R. (1998). Scale as relation: Musical metaphors of geographical scale. Area. 30, 49-58.

Inkpen, R. (2005). Science, philosophy and physical geography. New York: Routledge.

Johnson, D. Picard, P. Quinn, B. (1974). Churches and church membership in the United States. Washington: Glenmary.

Johnston, R.J. (1999). Geography and GIS. In P. Longley, M. Goodchild, D. Macguire, D. Rhind. (eds.) Geographical information systems. New York: John Wiley \& Sons.

Johnston, R.J., Gregory, D., Pratt, G., Watts, M. (eds.) (2000). The dictionary of human geography. Oxford: Blackwell.

Jordan, L. (2007). Religious adherence in the United States: A geographic analysis. Geographies of religions and belief systems. 2:1. 
Jones, D. Doty, S. Grammich, C. Horsch, J. Houseal, R. Lynn, M. Marcum, J., Sanchagrin, K. Taylor, R. (2002). Religious congregations and membership in the United States. Nashville: Glenmary.

Knippenberg, H. (1992). De Religieuze Kaart von Nederland. Assen: Maastricht.

Kong, L. (2001). Mapping 'new' geographies of religion: politics and poetics in modernity. Progress in human geography. 25:2 211-233.

.(1990). Geography and religion: trends and prospects. Progress in human geography. 14: 355-371.

Lam, N. and Quatrocchi, D.A. (1992). On the issues of scale, resolution, and fractal analysis in the mapping sciences. Professional geographer. 44, 88-98.

Land, K., Deane, G., Blau, J. (1991). Religious pluralism and church membership: a spatial diffusion model. American sociological review. v56, 237-49.

Lane, B. (2001). Landscapes of the sacred: Geography and narrative in American spirituality. John Hopkins University Press: Baltimore.

Latour, B. (2005). Reassembling the social: An introduction to actor-network-theory, Oxford University Press. . (1996). Aramis, or the love of technology, Harvard University Press, Cambridge.

Lefebvre, H. (1974). The production of space. Paris: Anthropos.

Leitner, H. (1997). Reconfiguring the spatiality of power: the construction of a supranational migration framework from the European Union. Political geography. 16, 123-44.

Leonard, J. (2006). “Local Geography and Church Attendance.” Gorabs Journal. 1:1.

Lindner, E. (2006). Yearbook of American and Canadian churches: Nashville: Abingdon. . (2000). Yearbook of American and Canadian churches: Nashville: Abingdon.

Longley, P., Goodchild, M., MaGuire, D., Rhind, D. (1999). Introduction. In P. Longley, M. Goodchild, D. Macguire, D. Rhind. (eds.) Geographical information systems. New York: John Wiley \& Sons.

Lugo, L., Stencel, S., Green, J., Smith, G., Cox, D., Pond, A., Miller, T., Podrebarac, E., Ralston, M. (2008). Religious landscape survey. Pew Forum on Religion and Public Life. 
Mansfield, B. (2005). Beyond rescaling: Reintegrating the 'national' as a dimension of scalar relations. Progress in human geography. 458-473.

Marston, S. Jones, JP. Woodward, K. (2005) Human geography without scale. Transactions of the institute of British geographers. 30:416-432.

Marston, S. and Smith, N. (2001). States, scale and households: limits to scale thinking? A response to Brenner. Progress in human geography. 25 615-19.

Marston, S. (2000). The social construction of scale. Progress in human geography. 24:2. 219-242.

Martin, D.J. (1999) Spatial representation: the social scientist's perspective. In P. Longley, M. Goodchild, D. Macguire, D. Rhind. (eds.) Geographical information systems. New York: John Wiley \& Sons.

Marty, M. (2001). Review of Atlas of American religion: The Denominational era, 1776 - 1990. Annals of the association of American geographers. 91(3).

Melton, G. (ed). (1999). Encyclopedia of American religions. $6^{\text {th }}$ ed. Detroit: Gale Research.

Miller, B. (1997). Political action and the geography of defense investment: geographical scale and the representation of the Massachusetts miracle. Political geography. $16,171-85$.

. (1994). Political empowerment, local-state relations, and geographically shifting political opportunity structures. Political geography. 13, 393-406.

Mitchell, D. (2000). Cultural geography: A critical introduction. Oxford, England: Blackwell.

Murdoch, J. (1997). Towards a geography of heterogeneous associations. Progress in human geography. 21:3 321-337.

National Council of Churches. (1952). Churches and church membership in the United States. National Council of Churches.

Newman, W. \& Halvorson, P. (2000). The atlas of American religion. Walnut Creek, CA: AltaMira Press. - (1993). The church membership studies: An assessment of four decades of institutional research. Review of religious research. 35. 55-61. 
Openshaw, S. (1983). The modifiable areal unit problem. Concepts and techniques in modern geography, 38. Geo Books, Norwich, UK.

Paasi, A. (2004). Place and region: Looking through the prism of scale. Progress in human geography. 28:4 536-546.

Park, C. (1994). Sacred worlds: An introduction to geography and religion. New York, NY: Routledge.

Pawson, R. and Tilley, N. (1997). Realistic evaluation. Sage: London.

Purcell, M. (2003). Islands of practice and the Marston / Brenner debate: Toward a more synthetic critical human geography. Progress in human geography. 27 317-32.

Quinn, B. Herman, A. Martin, B. Goetting, P. Shriver, P. 1982. Churches and church membership in the United States. Atlanta: Glenmary.

Random House. (2009). Random House Unabridged Dictionary. Random House Reference.

Raper, J.F. (1999) Spatial representation: the scientist's perspective. In P. Longley, M. Goodchild, D. Macguire, D. Rhind. (eds.) Geographical information systems. New York: John Wiley \& Sons.

Sayer, A. (2000). Realism and social science. Sage. (1992). Method in social science. New York, NY: Routledge.

Sayre, N. (2005). Ecological and geographical scale: parallels and potentials for integration. Progress in human geography. 29:3 276-290.

Shepherd, E. and McMaster, B. (2004). Scale and geographic inquiry: Contrasts, intersections, and boundaries. In Sheppard, E. and McMaster, B. (eds.) Scale and geographic inquiry. Malden: Blackwell.

Sheppard, E. (2002). The spaces and times of globalization: place, scale, networks, and positionality. Economic geography. 78, 307-330.

Shortridge, J. 1976. Patterns of religion in the United States. Geographical Review. 66. 420-434.

Skole, D. (2004). Geography as a great intellectual melting pot and the preeminent interdisciplinary environmental discipline. Annals of the Association of American Geographers. 94:4. 
Smith, N. (1997). Classics in human geography revisited: Commentary 2. Progress in human geography. 21, 557-59.

(1992). Geography, difference, and the politics of scale. In Doherty, J. Graham, E. and Mallekm M., editors, Postmodernism and the social sciences. London: Macmillian, 57-79.

(1990). Uneven development: Nature, capital, and the production of space. $\left(2^{\text {nd }}\right.$ ed.). Oxford: Blackwell.

Sopher, D. E. (1974). Historical atlas of the religions of the world. Macmillian: New York.

. (1967). Geography of Religion. Englewood Cliffs: Prentice-Hall.

Stark, R. (1987). Correcting church membership rates: 1971 and 1980. Review of Religious research. 29: 69-77.

Stoddard, R. H. and C. V. Prorok. (2003). “Geography of religion and belief systems,” in G. L. Gaile and C. J. Willmott (eds.), Geography in America at the dawn of the 21 ${ }^{\text {st }}$ Century. Oxford: Oxford University Press, 769-767.

Steensland, B., J. Park, M. D. Regnerus, L. D. Robinson, W. B. Wilcox, and R. D. Woodberry. (2000). The measure of American religion: Towards improving the state of the art. Social forces 79: 291-318.

Stump, R. (2008). The Geography of Religion: Faith, Place and Space. New York: Rowman and Littlefield.

. (1998). The effects of geographical variability on Protestant church membership trends, 1980-1990. Journal for the Scientific Study of Religion. 37:4 636-651.

Taylor, P. (1987). The paradox of geographical scale in Marx’s politics. Antipode. 19, 287-306.

. (1984). Introduction: geographical scale and political geography. In Taylor, P. and House, J. editors, Political geography: Recent advances and future directions, London and Sydney: Croom Helm, 1-7.

. (1982). A materialist framework for political geography. Transactions, Institute of British geographers. 7, 15-34.

Tuan, Y. (2004). Cultural geography: Glances backward and forward. Annals of the association of American geographers. 94:4. 
Tweed, T. (2006). Crossings and dwellings: A theory of religion. Harvard University Press: Cambridge.

Uitermark, J. (2002). Rescaling, 'scale fragmentation' and the regulation of antagonistic relationships. Progress in human geography. 26,6 743-7.

United Methodist Church. (2004). United Methodist Book of Discipline. Nashville: United Methodist Publishing House.

Van der Leeuw, G. (1963). Religion in essence and manifestation: A study in phenomenology, translated by J. E. Turner. 2 volumes. New York: Harper \& Row.

Vodde, R. and Galiant, J. (2002). Bridging the gap between micro and macro practice: Large scale change and a unified model of narrative-deconstructive practice. Journal of social work education. 38:3, 439-458.

Wuthnow, R. (1988). The restructuring of American religion: Society and faith since World War II. Princeton, NJ: Princeton University Press.

Zelinsky, W. (2001). "Critique of new historical atlas of religion in America.” Annals of the Association of American Geographers 91:4, 754-61. . (1961). An approach to the religious geography of the United States: patterns in church membership in 1952. Annals of the American Association of Geographers. 51:2, 139-93. 


\section{Appendix A: Research Questions}

1) Survey of Congregational Members:

How frequently do you attend your weekly church service?

Once a week

Twice a month

Once a month

Once a quarter

Do you participate in a weekly small group such as a Sunday School or Bible Study?

Yes

If so, how often do you attend?

Once a week

Twice a month

Once a month

Once a quarter

On average, how many times a week do you attend other functions related to your church?

Less than once a week

Once a week

Two or three times a week

Four or five times a week

More than five times a week

Put the following in order of its impact to your daily spiritual life $(1=$ most impact and 3

= least impact):

my small group

my congregation

my denomination

What percentage of the activities and practices that occur in your weekly worship service do you understand (you know why the activities or practice are being done)? $100 \%$

$80 \%$

$60 \%$

$40 \%$

$20 \%$

$0 \%$

Do you believe the number of people attending your church has grown, declined or remained about the same over the past year? 
Rate the following $(1=$ most, $7=$ least $)$ in regard to the reasons you attend your particular congregation: small groups distance from home to church building worship style

_ pastor family ministries size of the congregation denomination

How frequently do congregational responsibilities negatively impede your other life roles?

once per year once per month once per week multiple times per week

How frequently do congregational responsibilities positively affect or enhance your other life roles? once per year once per month once per week multiple times per week

With 1 being very much and 5 being very little, how much do you feel a sense of belonging to each of the following: your small group (Sunday School or Bible Study) your church your denomination

Why did you initially choose to attend this congregation?

Why do you remain in this congregation?

2) Semi-structured interviews with congregational leaders:

Do you lead a small group (Sunday School or Bible Study)?

If so, how did it form and what is its history? 
What is the significance of small groups in your congregation?

How frequently do you personally attend weekly worship services?

How does attending congregational worship impact your life and the lives of your family members?

To what degree are you involved in congregational worship, leadership, and outreach?

To what degree are you involved in denominational worship, leadership, and outreach?

How important do you think denominational issues and debates are to the daily lives of members of your congregation?

How frequently do you disagree with church and / or denominational polity, policy or practice?

What kinds of guidelines do members of your congregation have in regard to gender roles?

How do you see yourself as a bridge between individual adherents and the broader congregation?

How about between adherents and the denomination?

3) Semi-structured interviews with pastors:

How was your church formed and what is its history?

How many people belong to your congregation?

What does the term "fidelity" mean to you? 
How might you measure fidelity of members in your congregation?

Would you be willing to share your weekly 2007 attendance figures?

What commentary can you provide to help interpret last year's attendance figures?

How do beliefs in the congregation impact the broader community?

In what ways does your church support your association / denomination?

How does your church impact your community?

How does your church impact the world (globally)?

What effect does your church's community and global impact have on weekly congregational life?

What kinds of restrictions or freedoms does your church have in regard to gender roles?

How do you use preaching to enhance congregational loyalty? Do you have any examples?

How do you use preaching to enhance denominational loyalty? Do you have any examples?

What percentage of your congregation is involved in leadership within the congregation and within the larger community?

How do you see yourself as a bridge between individual adherents in your congregation and the denomination? 
4) Semi-structured interviews with denominational leaders:

How was your parish / conference / diocese formed? What is its history?

What does the term "fidelity" mean to you?

How might you measure the fidelity of adherents in your denomination?

How is doctrine and polity passed down to congregations and adherents?

How do individual adherents and congregational leaders impact denominational doctrine and polity?

How does the denomination resource and empower local lay leaders and clergy?

How many churches do you oversee?

Would you be willing to share a map and annual attendance figures?

Can you offer any commentary on the maps and figures?

How is your denomination organized?

How many staff work for you and what do they do? Do you have a central office?

What kinds of restrictions or freedoms does your denomination have in regard to gender roles?

What major issues does your denomination advocate for?

At what scales does this advocacy occur? 
How do you serve as a bridge between your congregations and the larger denomination? 


\section{WestVirginiaUniversity}

Eberly College of Arts and Sciences

\section{Appendix B: Human Subjects}

\section{(PROVIDED TO SURVEY PARTICIPANTS):}

\section{Dear Participant,}

This letter is a request for you to take part in a research project assessing the relationships between individuals, churches and denominations in order to better understand scale in the geography of religion. This project is being conducted by Michael P. Ferber, M.Div, MA in the Department of Geology and Geography at West Virginia University with supervision of Dr. Trevor Harris, Professor of Geography and Chair of the Department of Geology and Geography for a Doctorate Degree in Geography. Your participation in this project is greatly appreciated and will involve a questionnaire that will take approximately 10 minutes to fill out.

Your involvement in this project will be kept as confidential as legally possible. All data will be reported in the aggregate. You must be 18 years of age or older to participate. No information will be asked that should lead back to your identity as a participant. Your participation is completely voluntary. You may skip any question that you do not wish to answer and you may discontinue at any time. West Virginia University's Institutional Review Board acknowledgement of this project is on file.

I hope that you will participate in this research project, as it could be beneficial in understanding the relationships between individuals, churches and denominations. Thank you very much for your time. Should you have any questions about this letter or the research project, please feel free to contact Michael Ferber at mike.ferber@mail.wvu.edu.

Sincerely,

Michael P. Ferber 


\section{WestVirginiaUniversity}

Eberly College of Arts and Sciences

\section{(PRINTED IN CHURCH BULLETINS WHEN SURVEYS WERE PROVIDED):}

"Inserted in this bulletin you will find an invitation to take part in a research project assessing the relationships between individuals, churches and denominations in order to better understand scale in the geography of religion. This project is being conducted by Michael P. Ferber, M.Div, MA in the Department of Geology and Geography at West Virginia University with supervision of Dr. Trevor Harris, Professor of Geography and Chair of the Department of Geology and Geography for a Doctorate Degree in Geography. Your participation in this project is greatly appreciated and is entirely voluntary. You must be eighteen years of age or older to participate in the survey.”

\section{(VERBAL ANNOUNCEMENT SHARED WHEN SURVEYS WERE PROVIDED):}

"This morning in your bulletin you will find an invitation to take part in a research project assessing the relationships between individuals, churches and denominations in order to better understand scale in the geography of religion. This project is being conducted by Michael P. Ferber, M.Div, MA in the Department of Geology and Geography at West Virginia University with supervision of Dr. Trevor Harris, Professor of Geography and Chair of the Department of Geology and Geography for a Doctorate Degree in Geography. Your participation in this project is greatly appreciated and is entirely voluntary. You must be eighteen years of age or older to participate in the survey." 


\section{WestVirginiaUniversity}

Eberly College of Arts and Sciences

\section{(PROVIDED TO INTERVIEW PARTICIPANTS):}

Dear Participant,

This letter is a request for you to take part in a research project assessing the relationships between individuals, churches and denominations in order to better understand scale in the geography of religion. This project is being conducted by Michael P. Ferber, M.Div, MA in the Department of Geology and Geography at West Virginia University with supervision of Dr. Trevor Harris, Professor of Geography and Chair of the Department of Geology and Geography for a Doctorate Degree in Geography. Your participation in this project is greatly appreciated and will involve an interview that will take approximately 1 hour.

Your involvement in this project will be kept as confidential as legally possible. You must be 18 years of age or older to participate. Your participation is completely voluntary. You may skip any question that you do not wish to answer and you may discontinue at any time. West Virginia University’s Institutional Review Board acknowledgement of this project is on file.

I hope that you will participate in this research project, as it could be beneficial in understanding the relationships between individuals, churches and denominations. Thank you very much for your time. Should you have any questions about this letter or the research project, please feel free to contact Michael Ferber at mike.ferber@mail.wvu.edu.

Sincerely,

Michael P. Ferber 


\section{WestVirginiaUniversity}

Eberly College of Arts and Sciences

\section{(Provided to Focus Group Participants):}

\section{Dear Participant,}

This letter is a request for you to take part in a research project assessing the relationships between individuals, churches and denominations in order to better understand scale in the geography of religion. This project is being conducted by Michael P. Ferber, M.Div, MA in the Department of Geology and Geography at West Virginia University with supervision of Dr. Trevor Harris, Professor of Geography and Chair of the Department of Geology and Geography for a Doctorate Degree in Geography. Your participation in this project is greatly appreciated and will involve a focus group interview that will take approximately 1 hour.

Your involvement in this project will be kept as confidential as legally possible. All data will be reported in the aggregate. You must be 18 years of age or older to participate. No information will be asked that should lead back to your identity as a participant. However, while I will keep your responses confidential other focus groups members may not. Your participation is completely voluntary. You may skip any question that you do not wish to answer and you may discontinue at any time. West Virginia University's Institutional Review Board acknowledgement of this project is on file.

I hope that you will participate in this research project, as it could be beneficial in understanding the relationships between individuals, churches and denominations. Thank you very much for your time. Should you have any questions about this letter or the research project, please feel free to contact Michael Ferber at mike.ferber@mail.wvu.edu.

Sincerely,

Michael P. Ferber 


\section{Michael Philip Ferber $912550^{\text {th }}$ St.. \\ Edmonton, AB Canada \\ (780) 465-3500 ext. 8130 \\ michael.ferber@kingsu.ca}

\section{Academic Preparation:}

PhD in Geography West Virginia University, 2010

Concentrations: cultural geography, geography of religion, American

religious history, geographic information systems, qualitative methods.

Master of Arts in Science Education West Virginia University, 2004 Concentrations: Geography Education

Master of Divinity Asbury Theological Seminary, Lexington, KY, 2001 Concentrations: homiletics, exegesis, hermeneutics

B.A. in Liberal Arts and Geography West Virginia University, 1994. Concentrations: history; human, urban, world region, and physical geography.

\section{Relevant Professional Experience:}

Assistant Professor of Geography and Director of Environmental Studies. The King's University College. July 2008 - present. *Responsible for all aspects of the Environmental Studies Program and all physical and human geography courses.

Adjunct Faculty Regent University. January 2006 - present.

${ }^{*}$ Course Designer and Instructor for the World Regional Geography course; Instructor for the General Education 101 course.

Lecturer West Virginia University. January 2006 - May 2008.

* Responsible for all aspects of the urban geography and urban and regional planning courses.

Computational Graduate Teaching Assistant West Virginia University Department of Geology and Geography, August 2003 - 2004. ${ }^{*}$ Responsible for assisting in the technological support of computers for departmental faculty and staff. *Responsible for assisting in daily maintenance of the departmental computer lab. *Oversight of departmental website. 
NSF GK-12 Graduate Teaching Fellow West Virginia University TIGERS Program, May 2001 - August, 2003. *Responsible for co-planning and co-teaching earth science curriculum with middle school science teachers throughout the state of West Virginia. ${ }^{*}$ Creation and implementation of a web-based Community Atlas project in three Middle Schools. *Creation and implementation of a web-based flood atlas in a community ravaged by two simultaneous floods.

\section{Publications:}

"Religion, Geography and." Encyclopedia of Geography. Sage. Barney Warf (ed.). To be released 2010.

"Strengthening the Rural Community" chapter of Ending Poverty in America: How to Restore the American Dream. Co-authored with Ruston Seaman. Ed. By Sen. John Edwards. The New Press. 2007.

"Geography of Religion." In the Dictionary of Critical Realism. Edited by Mervin Hartwig. Routledge. 2007.

"History and Basic Beliefs of Islam" chapter of Geographic Education of the Islamic Culture Region. Commission on Geographic Education. 2006.

"Critical Realism and religion: objectivity and the insider / outsider problem." Annals of the Association of American Geographers. 96(1) 176-181. March, 2006.

"Denominational Mountain Religion: A History of the Free Methodist Movement in West Virginia." American Religious Experience. http://are.as.wvu.edu/ Posted July, 2003

"Introducing middle school students to the spatial sciences through a community atlas project" Co-authored with Timothy Warner, Eric Pyle, and Tina Knight. Geocarto International 18:1 March, 2003

"PPGIS in Middle School: A Web-Based Community Atlas Project." Conference Proceedings of the 1st Annual Public Participation GIS Conference. URISA July, 2002.

\section{Conference Presentations:}

"Blogging to Change the World: Sustainability and The King's Green Pad." Coauthored with Gordon Preston. 2009 Stewardship and Sustainability Conference. July 9, 2009. Calgary, AB. 
"Emerging Solutions to the Problem of Scale in Geography of Religion." Coauthored with Trevor Harris. The Association of American Geographers 2009 Annual Meeting. March 24, 2009. Las Vegas, NV.

"Cartographic representation and scale in the geography of religion." Coauthored with Trevor Harris. The Association of American Geographers 2006 Annual Meeting. March 8, 2006. Chicago, IL.

"A leap of faith: Scale in the geography of religions and belief systems" Coauthored with Trevor Harris. The Association of American Geographers 2005 Annual Meeting. April 6, 2005. Denver, CO.

"A leap of faith: critical GIS perspectives on the Geography of Religion" Coauthored with Trevor Harris. Conference of the International Study of Religion. December 11, 2004. Szeged, Hungary.

"The McDowell County Flood Atlas: A pragmatic approach for GIS and Remote Sensing education at the middle school level." WV GIS Conference. May 10, 2004. Morgantown, WV

"A Flood of Learning: The McDowell County flood atlas project." Conference on Appalachian Geography and Geography Education. March 6, 2004. Shepherdstown, WV

"Critical Realism Revisited: Potential Applications in the Geography of Religions and Belief Systems" The Association of American Geographer's 100th Annual Meeting. March 19, 2004. Philadelphia, PA

"Horizons in the Mapping of Religion in North America" Co-authored with Trevor Harris. Eberly College of Arts and Sciences Research Horizons Poster Session. April 22, 2003. Morgantown, WV

"Introducing Middle School Students to Flood Hazards through an Internet-Based Flood Atlas Project" The Association of American Geographers 99th Annual Meeting. March 6, 2003 New Orleans, LA

"A Critique of Cartographic Approaches to Mapping Religion in North America" Co-authored with Trevor Harris and Jesse Rouse. The Association of American Geographers 99th Annual Meeting. March 5, 2003 New Orleans, LA

"What a Disaster! Teaching Science through Earthquakes, Floods, and Emergency Preparedness" West Virginia Science Teacher's Association Conference. October 19, 2002.Charleston, WV 
"Where am I? Teaching Technology to Middle-School students using a Community Atlas" West Virginia Science Teacher's Association Conference. October 18, 2002. Charleston, WV

"PPGIS in Middle School: A Web-Based Community Atlas Project." 1st Annual Public Participation GIS Conference. URISA. July 21, 2002 Rutgers University

\section{Book Reviews:}

Gautier, Catherine. Oil, Water and Climate. New York: Cambridge University Press, 2008. For Environmental Politics. Upcoming, 2010.

Simon Goldhill. The Temple of Jerusalem. Cambridge, MA: Harvard University Press, 2005. For The Journal of Material Culture. July, 2007.

Tweed, Thomas. Crossings and Dwellings: A Theory of Religion. For The American Religious Experience 2006.

Gold, Lorna. The Sharing Economy: Solidarity networks transforming globalization. For The Professional Geographer. 57:4 2006.

John Sparks, The Roots of Appalachian Christianity: The Life and Legacy of Elder Shubal Stearns. For the Journal of Southern Religion Volume 6, 2003.

\section{Academic Service:}

Managing Editor, Geography of Religions and Belief Systems. 2005 - present

Chair, Young Environmental Professionals. 2010 - present.

Executive Committee Member, Young Environmental Professionals. 2009 2010.

Board Member, Geography of Religions and Belief Systems Specialty Group of the Association of American Geographers, 2005 - 2009

Chairperson, Geography of Religions and Belief Systems Specialty Group of the Association of American Geographers, 2003 - 2005

Board Member, Graduate Student Affinity Group of the Association of American Geographers, $2002-2004$ 